\title{
Efeitos da especificação incorreta da função de ligação no modelo de regressão beta
}

\author{
Augusto César Giovanetti de Andrade
}

\author{
DISSERTAÇÃO APRESENTADA \\ $\mathrm{AO}$ \\ INSTITUTO DE MATEMÁTICA E ESTATÍSTICA \\ DA \\ UNIVERSIDADE DE SÃO PAULO \\ PARA \\ OBTENÇÃO DO TÍTULO DE MESTRE \\ EM \\ CIÊNCIAS
}

\section{Área de Concentração: Estatística \\ Orientadora: Profa. Dra. Silvia Lopes de Paula Ferrari}

Durante a elaboração deste trabalho o autor recebeu apoio financeiro do CNPq

São Paulo, agosto de 2007. 


\title{
Efeitos da especificação incorreta da função de ligação no modelo de regressão beta
}

\author{
Este exemplar corresponde à redação final da \\ dissertação devidamente corrigida e defendida \\ por Augusto César Giovanetti de Andrade \\ e aprovada pela Comissão Julgadora.
}

São Paulo, agosto de 2007.

Banca examinadora:

Profa. Dra. Silvia Lopes de Paula Ferrari (orientadora) - IME-USP

Profa. Dra. Denise Aparecida Botter - IME-USP

Profa. Dra. Linda Lee Ho - POLI-USP 
Na vida, nada acontece por acaso. (Autor desconhecido) 


\section{Agradecimentos}

As forças divinas que iluminaram os meus caminhos e fizeram as oportunidades surgirem em momentos oportunos.

À professora Silvia Ferrari, pela orientação e confiança depositada em mim desde a nossa primeira conversa.

Aos professores da UNICAMP e da USP, pela sólida formação acadêmica e recepção. Em especial aos professores Ademir Petenate e Filidor Vilca-Labra, pelo aprendizado transmitido e incentivo que foram essenciais para que iniciasse o mestrado.

Aos meus familiares e amigos de infância, que de perto ou de longe sempre me deram forças para seguir o meu caminho.

A Jacqueline David, que desde o começo se mostrou além de chefe, orientadora e uma grande amiga. Essa dissertação com certeza não seria a mesma sem ela no meu caminho.

Aos amigos que foram também meus orientadores durante o mestrado, Raydonal, Patricia, Marcos, Gisela, Kelly, Lourdes, Betsabe, Edijane, Frederico e todos os demais que me acompanharam no dia-a-dia no instituto. 
Aos amigos que fiz desde que cheguei a São Paulo e que cultivarei pra sempre, Mariana, Karina, Grazielle, Lauren, Fernando, Nubia, Josivon, Pedro, Cecília, Bárbara, Luis Henrique, Juliana, Ivan, Joan e todos os que estiveram comigo nos momentos difíceis de estudo e nas comemorações de cada etapa que concluímos no mestrado, juntos.

Aos companheiros do handebol, vôlei e capoeira que me receberam muito bem e me suportaram nos treinos que utilizei para acabar com o estresse. Em especial ao Telmo, que apesar de não estar mais entre nós, deixou ensinamentos para toda a vida.

Aos colegas e amigos do trabalho que me apoiaram dia-a-dia.

Ao CNPQ, pelo apoio financeiro. 


\section{Resumo}

O ajuste de modelos de regressão beta requer a especificação de uma função de ligação. Algumas funções de ligação úteis são: logito, probito, complemento log-log e log-log. Usualmente, a ligação logito é utilizada pois permite interpretação simples para os parâmetros de regressão.

O principal objetivo deste trabalho é avaliar o impacto da especificação incorreta da função de ligação em regressão beta. Estudos de simulação serão usados com esse propósito. Amostras da variável resposta serão geradas assumindo uma função de ligação conhecida (verdadeira) e o modelo de regressão beta será ajustado usando a função de ligação verdadeira (correta) e algumas funções de ligação incorretas. Resultados numéricos serão comparados para avaliar o efeito da especificação incorreta da função de ligação sobre as inferências em regressão beta. Adicionalmente, será introduzido um modelo de regressão beta com função de ligação de Aranda-Ordaz, a qual depende de um parâmetro que pode ser estimado através dos dados. 


\section{Abstract}

Fitting beta regression models requires the specification of the link function. Some useful link functions for beta regression are: logit, probit, complementary log-log and log-log. Usually, the logit link is used since it allows easy interpretation for the regression parameters.

The main objective of this work is to evaluate the impact of misspecification of the link function in beta regression. Simulation studies will be used for this purpose. Samples of the response variable will be generated assuming a known (true) link function, and the beta regression will be fitted using the true (correct) link and some incorrect link

functions. Numerical results will be compared to evaluate the effect of misspecification of the link function on inference in beta regression. Also, we will introduce a beta regression model with Aranda-Ordaz link function, which depends on an unknown parameter that can be estimated through the data. 


\section{Índice}

1 Modelo de Regressão Beta 1

1.1 Introdução . . . . . . . . . . . . . . . . . . . . . 1

1.2 Distribuição Beta . . . . . . . . . . . . . . . . . . . . . . . 1

1.3 Especificação do Modelo de Regressão Beta . . . . . . . . . . . . . . . . . 2

1.3.1 Estimadores de Máxima Verossimilhança . . . . . . . . . . . . 6

1.3.2 Intervalos de Confiança . . . . . . . . . . . . . . . . . . . . . . 8

1.3 .3 Funções de Ligação . . . . . . . . . . . . . . . . . . . . . . . . . . 9

2 Especificação Incorreta da Função de Ligação 14

2.1 Introdução . . . . . . . . . . . . . . . . . . . . . . . . . . . . . . 14

2.2 Resultados das Simulações . . . . . . . . . . . . . . . . . 17

2.2.1 Casos 1 e 2: Função de Ligação Logito e Probito . . . . . . . . . . . 17

2.2.2 Caso 3: Função de Ligação Logito e Complemento Log-log . . . . 19

2.2.3 Caso 4: Função de Ligação Correta Log-log e Incorreta Logito . 22

2.2.4 Discussão dos Resultados das Simulações . . . . . . . . . . . . 25

2.3 Avaliação da Adequação da Função de Ligação . . . . . . . . . . . . . . . 25

2.3.1 Viés Relativo dos Estimadores das Médias . . . . . . . . . . . 30

2.4 Conclusões . . . . . . . . . . . . . . . . . . . . . 32

3 Função de Ligação de Aranda-Ordaz 34

3.1 Introdução . . . . . . . . . . . . . . . . . . . . . . 34

3.2 Função Escore e Matriz de Informação . . . . . . . . . . . . . . . . . . . 35

3.3 Avaliação dos Estimadores dos Parâmetros . . . . . . . . . . . . . . . 38 
3.4 Avaliação dos Estimadores para as Médias . . . . . . . . . . . . . . . . . 42

3.4.1 Função de Ligação de Aranda-Ordaz e Logito . . . . . . . . . . . 45

3.5 Conclusões . . . . . . . . . . . . . . . . . . . . . . 48

4 Aplicação $\quad 49$

5 Considerações finais $\quad 53$

A Programa de simulação no Ox

B Resultados das simulações $\quad 65$

B.1 Função de Ligação Correta Logito e Incorreta Probito . . . . . . . . . . . 65

B.2 Função de Ligação Correta Probito e Incorreta Logito . . . . . . . . . . . . 69

B.3 Função de Ligação Correta Complemento Log-Log e Incorreta Logito 73

B.4 Função de Ligação Correta Log-log e Incorreta Logito . . . . . . . . . . . 79

$\begin{array}{ll}\text { Referências bibliográficas } & 86\end{array}$ 
Capítulo 1

\section{Modelo de Regressão Beta}

\subsection{Introdução}

Quando o interesse é estudar a relação de uma variável resposta observada no intervalo $(0,1)$ com variáveis explicativas, um modelo que tem sido estudado é o modelo de regressão beta. Como foi tratado por Ferrari \& Cribari-Neto (2004) este modelo tem algumas características semelhantes às dos modelos lineares generalizados (MLGs; detalhes em McCullagh \& Nelder, 1989). Um dos componentes de extrema importância na especificação dos MLGs é a escolha da função de ligação, pois uma escolha imprópria da função de ligação pode causar resultados significativamente problemáticos segundo Myers, Montgomery \& Vining (Seção 7.3, 2002).

Neste capítulo é apresentado o modelo de regressão beta definido por Ferrari \& Cribari-Neto (2004). Este modelo será utilizado para estudar o comportamento de uma variável resposta contínua definida no intervalo $(0,1)$ como função de um conjunto de variáveis explicativas.

\subsection{Distribuição Beta}

O interesse no estudo da distribuição beta é ter a possibilidade de obter um modelo de regressão adequado à situação em que a variável dependente é contínua e assume valores apenas no intervalo $(0,1)$. Kieschnick \& McCullough (2003) recomendam a utilização de um modelo de regressão paramétrico baseado na distribuição beta ou um modelo de regressão de quasi-verossimilhança desenvolvido por Papke \& Wooldridge (1996) para 
essa situação.

A distribuição beta é muito flexível para o estudo de taxas e proporções, dado que sua função de densidade pode tomar diferentes formas dependendo dos valores definidos pelos dois parâmetros que a compõem. A função densidade da distribuição beta é definida por

$$
\pi(y ; p, q)=\frac{\Gamma(p+q)}{\Gamma(p) \Gamma(q)} y^{p-1}(1-y)^{q-1}, 0<y<1,
$$

onde $p>0, q>0$ e $\Gamma(\cdot)$ é a função gama. A média e a variância de $y$ são dadas por

$$
\mathrm{E}(y)=\frac{p}{p+q}
$$

e

$$
\operatorname{var}(y)=\frac{p q}{(p+q)^{2}(p+q+1)} .
$$

A moda da distribuição existe quando $p>1$ e $q>1$ e é dada por moda $(y)=$ $(p-1) /(p+q-2)$. A distribuição uniforme é um caso particular da distribuição beta quando $p=q=1$. Muitas aplicações da distribuição beta são discutidas por Bury (1999) e por Johnson, Kotz \& Balakrishnan (1995).

\subsection{Especificação do Modelo de Regressão Beta}

Para definição do modelo de regressão beta Ferrari \& Cribari-Neto (2004) sugerem uma parametrização da distribuição beta em termos de sua média e um parâmetro de dispersão. Mais especificamente, sejam $\mu$ e $\phi$ os parâmetros definidos por $\mu=p /(p+q)$ e $\phi=p+q$, ou seja, $p=\mu \phi$ e $q=(1-\mu) \phi$. Com essa parametrização a função densidade da distribuição beta pode ser reescrita como

$$
f(y ; \mu, \phi)=\frac{\Gamma(\phi)}{\Gamma(\mu \phi) \Gamma((1-\mu) \phi)} y^{\mu \phi-1}(1-y)^{(1-\mu) \phi-1}, 0<y<1
$$

onde $0<\mu<1$ e $\phi>0$. A esperança e a variância são, então, dadas por

$$
\mathrm{E}(y)=\mu
$$

$\mathrm{e}$

$$
\operatorname{var}(y)=\frac{\mathrm{V}(\mu)}{1+\phi}
$$

onde $\mathrm{V}(\mu)=\mu(1-\mu)$ é chamada de função de variância. Portanto, $\mu$ é a média de $y$ e $\phi$ pode ser interpretado como parâmetro de precisão no sentido que, para um valor 
fixo de $\mu$, quanto maior o valor de $\phi$, menor a variância de $y$. Diferentes formas para a densidade beta podem ser obtidas de acordo com a escolha dos valores para $\mu$ e $\phi$ como, por exemplo, J, J invertido e U; estas podem ser vistas na Figura 1.1 extraída de Ferrari \& Cribari-Neto (2004). A distribuição uniforme é obtida fazendo $\mu=0.5$ e $\phi=2$.

No modelo a ser estudado assume-se que a variável resposta $y$ tem distribuição contínua definida no intervalo $(0,1)$. Este modelo poderá ser útil também para respostas restritas a um intervalo $(a, b)$, onde $a$ e $b$ são escalares conhecidos e $a<b$. Para tanto bastará modelar $(y-a) /(b-a)$ ao invés de modelar $y$ diretamente.

Para definição do modelo de regressão beta assume-se que $y_{1}, \ldots, y_{n}$ são variáveis aleatórias independentes e que cada $y_{t}, t=1, \ldots, n$, segue distribuição beta com densidade (1.1) com média $\mu_{t}$ e parâmetro de precisão $\phi$, constante para todo $t$, desconhecido. Como componente sistemático assume-se que uma função da média $\mu_{t}$ pode ser igualada ao preditor linear $\eta_{t}$ :

$$
g\left(\mu_{t}\right)=\sum_{i=0}^{k} x_{t i} \beta_{i}=x_{t}^{\top} \beta=\eta_{t}
$$

e, consequentemente,

$$
\mu_{t}=g^{-1}\left(\eta_{t}\right)
$$

onde $\beta=\left(\beta_{0}, \ldots, \beta_{k}\right)^{\top}$ é o vetor de parâmetros de regressão desconhecidos $\left(\beta \in \Re^{k+1}\right)$, sendo $\beta_{0}$ o intercepto e $\left(\beta_{1}, \ldots, \beta_{k}\right)$ os parâmetros referentes às variáveis explicativas; e $x_{t}^{\top}=\left(1, x_{t 1}, \ldots, x_{t k}\right)$, sendo $x_{t 1}, \ldots, x_{t k}$ os $k$ valores das variáveis explicativas correspondentes à t-ésima observação $(k<n)$, que são fixos e conhecidos. A função $g(\cdot)$, estritamente monótona e duplamente diferenciável, transforma valores do intervalo $(0,1)$ em $\Re$. Essa função é chamada de função de ligação e será estudada com mais detalhes na Seção 1.3.3. A sua escolha no modelo de regressão beta é objeto deste estudo, no qual será verificado o efeito da especificação inadequada desta função de ligação.

No modelo definido pela distribuição beta e com a parte sistemática estabelecida (1.3), respostas com variância não constantes são naturalmente acomodadas, pois a variância de $y_{t}$ depende de $\mu_{t}$ e, como conseqüência, das variáveis explicativas $x_{t}^{\top}$.

A função de log-verossimilhança baseada numa amostra de $n$ observações independentes é

$$
\ell(\beta, \phi)=\sum_{t=1}^{n} \ell_{t}\left(\mu_{t}, \phi\right),
$$



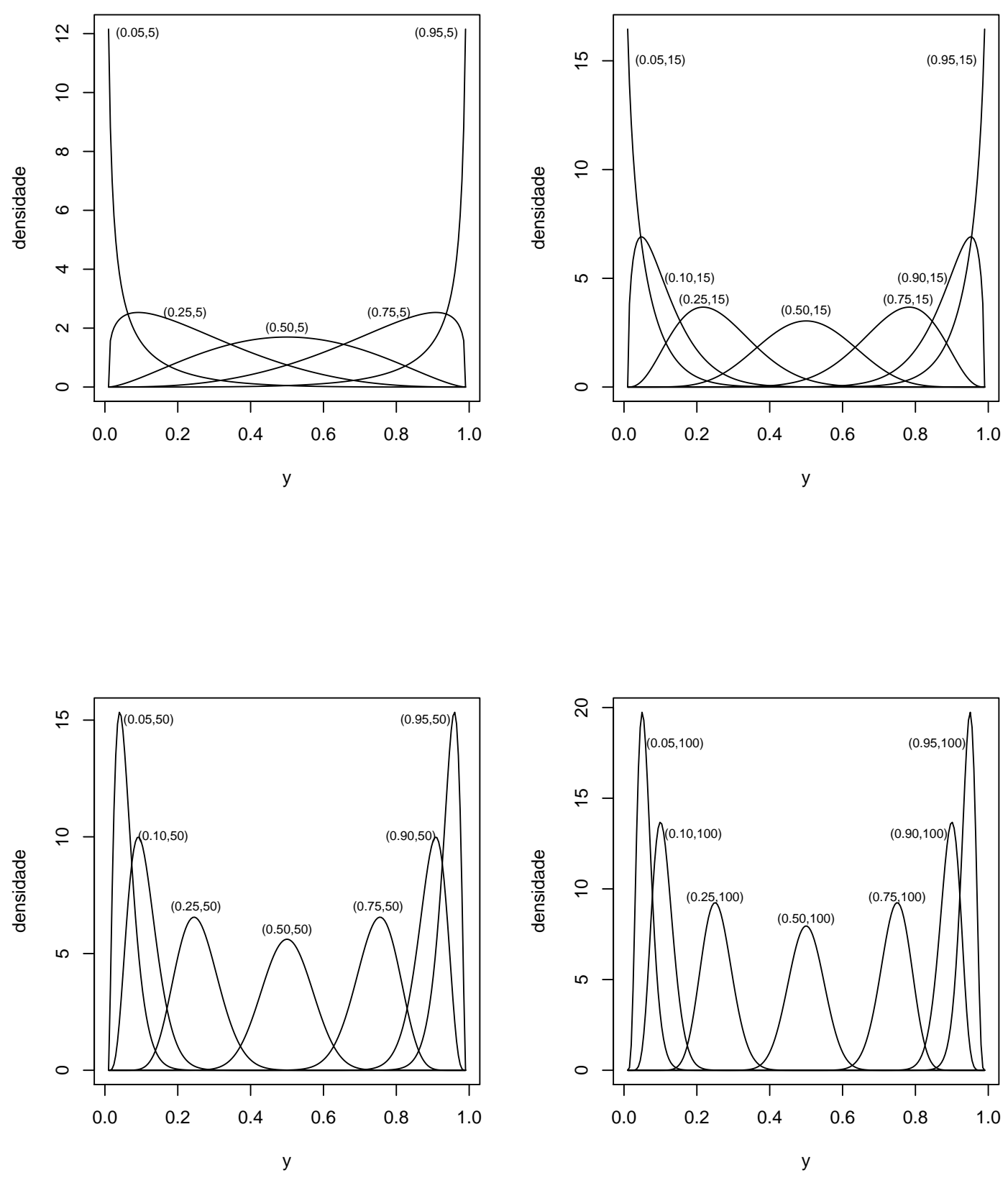

Figura 1.1: Densidades beta para diferentes combinações de $(\mu, \phi)$.

onde

$$
\begin{aligned}
\ell_{t}\left(\mu_{t}, \phi\right)=\log \Gamma(\phi) & -\log \Gamma\left(\mu_{t} \phi\right)-\log \Gamma\left(\left(1-\mu_{t}\right) \phi\right)+\left(\mu_{t} \phi-1\right) \log y_{t} \\
& +\left\{\left(1-\mu_{t}\right) \phi-1\right\} \log \left(1-y_{t}\right)
\end{aligned}
$$

com $\mu_{t}$ definido em (1.3). Definem-se $y_{t}^{*}=\log \left\{y_{t} /\left(1-y_{t}\right)\right\}$ e $\mu_{t}^{*}=\psi\left(\mu_{t} \phi\right)-\psi\left(\left(1-\mu_{t}\right) \phi\right)$, onde $\psi(\cdot)$ é a função digama (pode-se mostrar que $\mathrm{E}\left(y_{t}^{*}\right)=\mu_{t}^{*}$ ). A função escore, obtida pela diferenciação da função de log-verossimilhança com respeito aos parâmetros 
desconhecidos $(\beta, \phi)$, é dada por $\left(U_{\beta}(\beta, \phi), U_{\phi}(\beta, \phi)\right)^{\top}$, onde

$$
U_{\beta}(\beta, \phi)=\phi X^{\top} T\left(y^{*}-\mu^{*}\right)
$$

no qual $X$ é uma matriz $n \times k$, sendo $x_{t}^{\top}$ a $t$-ésima linha dessa matriz, $y^{*}=\left(y_{1}^{*}, \ldots, y_{n}^{*}\right)^{\top}$, $T=\operatorname{diag}\left\{1 / g^{\prime}\left(\mu_{1}\right), \ldots, 1 / g^{\prime}\left(\mu_{n}\right)\right\}$ e $\mu^{*}=\left(\mu_{1}^{*}, \ldots, \mu_{n}^{*}\right)^{\top} ; \mathrm{e}$

$$
U_{\phi}(\beta, \phi)=\sum_{t=1}^{n}\left\{\mu_{t}\left(y_{t}^{*}-\mu_{t}^{*}\right)+\log \left(1-y_{t}\right)-\psi\left(\left(1-\mu_{t}\right) \phi\right)+\psi(\phi)\right\} .
$$

Pelas segundas derivadas da função de log-verossimilhança, obtém-se a matriz de informação de Fisher. Para isso, definem-se

$$
\begin{aligned}
& -W=\operatorname{diag}\left\{w_{1}, \ldots, w_{n}\right\}, \operatorname{com} w_{t}=\phi\left\{\psi^{\prime}\left(\mu_{t} \phi\right)+\psi^{\prime}\left(\left(1-\mu_{t}\right) \phi\right)\right\} \frac{1}{\left\{g^{\prime}\left(\mu_{t}\right)\right\}} ; \\
& \text { - } c=\left(c_{1}, \ldots, c_{n}\right)^{\top}, \operatorname{com} c_{t}=\phi\left\{\psi^{\prime}\left(\mu_{t} \phi\right) \mu_{t}-\psi^{\prime}\left(\left(1-\mu_{t}\right) \phi\right)\left(1-\mu_{t}\right)\right\} \\
& \text { - } D=\operatorname{diag}\left\{d_{1}, \ldots, d_{n}\right\}, \operatorname{com} d_{t}=\psi^{\prime}\left(\mu_{t} \phi\right) \mu_{t}^{2}+\psi^{\prime}\left(\left(1-\mu_{t}\right) \phi\right)\left(1-\mu_{t}\right)^{2}-\psi^{\prime}(\phi),
\end{aligned}
$$

onde $\psi^{\prime}(\cdot)$ é a função trigama. A matriz de informação de Fisher é dada por

$$
K=K(\beta, \phi)=\left(\begin{array}{cc}
K_{\beta \beta} & K_{\beta \phi} \\
K_{\phi \beta} & K_{\phi \phi}
\end{array}\right)
$$

onde $K_{\beta \beta}=\phi X^{\top} W X, K_{\beta \phi}=K_{\phi \beta}^{\top}=X^{\top} T c$ e $K_{\phi \phi}=\operatorname{tr}(\mathrm{D})$. Ao contrário do que se verifica na classe dos modelos lineares generalizados (McCullagh \& Nelder, 1989), os parâmetros $\beta$ e $\phi$ não são ortogonais para o modelo de regressão beta, ou seja, a matriz $K_{\beta \phi}$ não é nula para todo par $(\beta, \phi)$.

Sob condições gerais de regularidade (descritas em Sen \& Singer, 1993), quando o tamanho da amostra é grande, os estimadores de máxima verossimilhança dos parâmetros têm distribuição aproximada dada por

$$
\left(\begin{array}{l}
\widehat{\beta} \\
\widehat{\phi}
\end{array}\right) \sim N_{k+2}\left(\left(\begin{array}{l}
\beta \\
\phi
\end{array}\right), K^{-1}\right)
$$

no qual $\widehat{\beta}$ e $\widehat{\phi}$ são os estimadores de máxima verossimilhança de $\beta$ e $\phi$, respectivamente. Para se obter os erros padrão assintóticos dos estimadores de máxima verossimilhança é interessante escrever $K^{-1}$ de forma explícita. Utilizando a fórmula para inversa 
de matrizes subdivididas dada por Rao (1973, p. 33), obtém-se

$$
K^{-1}=K^{-1}(\beta, \phi)=\left(\begin{array}{cc}
K^{\beta \beta} & K^{\beta \phi} \\
K^{\phi \beta} & K^{\phi \phi}
\end{array}\right)
$$

onde

$$
K^{\beta \beta}=\frac{1}{\phi}\left(X^{\top} W X\right)^{-1}\left\{I_{k}+\frac{X^{\top} T c c^{\top} T^{\top} X\left(X^{\top} W X\right)^{-1}}{\gamma \phi}\right\},
$$

sendo $I_{k}$ uma matriz identidade $k \times k$ e $\gamma=\operatorname{tr}(D)-\phi^{-1} c^{\top} T^{\top} X\left(X^{\top} W X\right)^{-1} X^{\top} T c$;

$$
K^{\beta \phi}=\left(K^{\phi \beta}\right)^{\top}=-\frac{1}{\gamma \phi}\left(X^{\top} W X\right)^{-1} X^{\top} T c
$$

e

$$
K^{\phi \phi}=\gamma^{-1}
$$

Nas próximas seções será mostrado como obter os estimadores de máxima verossimilhança e intervalos de confiança para os parâmetros $\beta$ e $\phi$ do modelo de regressão beta e para média $\mu_{t}$. Alguns detalhes sobre as funções de ligação que podem ser utilizadas para o ajuste do modelo de regressão beta também serão abordados.

\subsubsection{Estimadores de Máxima Verossimilhança}

Os estimadores de máxima verossimilhança de $\beta$ e $\phi$ são obtidos das equações $U_{\beta}(\beta, \phi)$ $=0$ e $U_{\phi}(\beta, \phi)=0$ dados em (1.5) e (1.6) respectivamente. Entretanto, não há uma forma fechada em que se possa escrever os estimadores de forma explícita a partir das equações anteriores. Portanto, um algoritmo de otimização não linear como, por exemplo, os algoritmos de Newton ou Quasi-Newton, é necessário para obter a maximização numérica da função de log-verossimilhança (1.4). Para detalhes sobre os algoritmos de Newton ou Quasi-Newton ver Nocedal \& Wright (1999).

Nos algoritmos de maximização numérica é exigido um valor inicial para os parâmetros de interesse. Ferrari \& Cribari-Neto (2004) sugerem utilizar para $\beta$ a estimativa de mínimos quadrados ordinários obtida da regressão linear das respostas transformadas $\left(g\left(y_{1}\right), \ldots, g\left(y_{n}\right)\right)$ com relação a $X$, ou seja, $\left(X^{\top} X\right)^{-1} X^{\top} z$, onde $z=\left(g\left(y_{1}\right), \ldots, g\left(y_{n}\right)\right)^{\top}$. Para obter uma estimativa inicial para $\phi$, Ferrari \& Cribari-Neto (2004) observam que

$$
\operatorname{var}\left(y_{t}\right)=\frac{\mu_{t}\left(1-\mu_{t}\right)}{1+\phi}
$$


e, portanto,

$$
\phi=\frac{\mu_{t}\left(1-\mu_{t}\right)}{\operatorname{var}\left(y_{t}\right)}-1
$$

Como

$$
\operatorname{var}\left(g\left(y_{t}\right)\right) \approx \operatorname{var}\left\{g\left(\mu_{t}\right)+\left(y_{t}-\mu_{t}\right) g^{\prime}\left(\mu_{t}\right)\right\}=\operatorname{var}\left(y_{t}\right)\left\{g^{\prime}\left(\mu_{t}\right)\right\}^{2},
$$

tem-se $\operatorname{var}\left(y_{t}\right) \approx \operatorname{var}\left\{g\left(y_{t}\right)\right\}\left\{g^{\prime}\left(\mu_{t}\right)\right\}^{-2}$. Assim eles sugerem a seguinte expressão como estimativa inicial para $\phi$ :

$$
\phi^{(0)}=\frac{1}{n} \sum_{t=1}^{n} \frac{\breve{\mu}_{t}\left(1-\breve{\mu}_{t}\right)}{\breve{\sigma}_{t}^{2}}-1,
$$

onde $\breve{\mu_{t}}$ é obtido aplicando $g^{-1}(\cdot)$ ao $t$-ésimo valor ajustado para a regressão linear, mais especificamente,

$$
\breve{\mu_{t}}=g^{-1}\left(x_{t}^{\top}\left(X^{\top} X\right)^{-1} X^{\top} z\right)
$$

e

$$
\breve{\sigma_{t}^{2}}=\frac{\breve{e}^{\top} \breve{e}}{(n-k)\left\{g^{\prime}\left(\breve{\mu}_{t}\right)\right\}^{2}},
$$

no qual $\breve{e}=z-X\left(X^{\top} X\right)^{-1} X^{\top} z$, que é o vetor de resíduos de mínimos quadrados ordinários da regressão linear com os dados transformados.

Smithson \& Verkuilen (2006) trabalham com o ajuste do modelo de regressão beta através dos softwares R/SPlus, SPSS e SAS. Instruções, discussões e exemplos sobre as estimações envolvidas nestes softwares são apresentadas e podem ser acessados na internet através da página http://www.anu.edu.au/psychology/people/smithson/details/betareg /betareg.html. Recentemente, um código em R (pacote "betareg") foi desenvolvido por Simas (2006) para ajuste do modelo de regressão beta. As estimativas dos parâmetros são obtidas de diferentes formas em cada pacote e em todos eles são requeridos ao usuário valores iniciais para estimativas dos parâmetros. É interessante entender o que está envolvido na estimação dos parâmetros em cada software que se escolha utilizar e verificar como se comporta a convergência para diferentes valores iniciais dos parâmetros. De acordo com Smithson \& Verkuilen (2005), nos vários ajustes realizados, os resultados geralmente convergiram para o valor ótimo assumindo bons valores iniciais dos parâmetros.

Neste trabalho optou-se pelo desenvolvimento de um programa na linguagem de programação matricial Ox (Doornik, 2001) para os ajustes dos modelos de regressão beta com a escolha de valores iniciais sugeridas por Ferrari \& Cribari-Neto (2004). 


\subsubsection{Intervalos de Confiança}

Para obter intervalos de confiança para os parâmetros de interesse pode-se considerar a distribuição assintótica dos estimadores de máxima verossimilhança $\hat{\beta}$ e $\hat{\phi}(\operatorname{ver}(1.7)$ ), substituindo $K$ por $\hat{K}$, o estimador de máxima verossimilhança.

Um intervalo de confiança com coeficiente de confiança aproximado de $(1-\alpha) \times 100 \%$ para $\beta_{i}, i=1, \ldots, k$ e $0<\alpha<1$, tem limites dado por

$$
\hat{\beta}_{i} \pm \Phi^{-1}(1-\alpha / 2) \operatorname{se}\left(\hat{\beta}_{i}\right)
$$

onde $\Phi^{-1}($.$) é a função de distribuição acumulada de uma variável aleatória normal$ padrão e se $\left(\hat{\beta}_{i}\right)$ é o erro padrão para $\hat{\beta}_{i}$ obtido pela raiz quadrada do $i$-ésimo elemento da diagonal da matriz $\hat{K}^{-1}$. Para $\phi$ um intervalo de confiança com coeficiente de confiança aproximado de $(1-\alpha) \times 100 \%$ tem limites

$$
\hat{\phi} \pm \Phi^{-1}(1-\alpha / 2) \operatorname{se}(\hat{\phi})
$$

onde $\operatorname{se}(\hat{\phi})=\hat{\gamma}^{-1 / 2}$ é o erro padrão para $\hat{\phi}$ obtido pelo $(k+2)$-ésimo elemento da diagonal da matriz $\hat{K}^{-1}$. Finalmente, um intervalo de confiança com coeficiente de confiança aproximado de $(1-\alpha) \times 100 \%$ para $\mu_{t}$, a média da variável resposta para um dado vetor de covariáveis $x_{t}^{\top}$, pode ser obtido por

$$
\left[g^{-1}\left(\hat{\eta}_{t}-\Phi^{-1}(1-\alpha / 2) \operatorname{se}\left(\hat{\eta}_{t}\right)\right), g^{-1}\left(\hat{\eta}_{t}+\Phi^{-1}(1-\alpha / 2) \operatorname{se}\left(\hat{\eta}_{t}\right)\right)\right]
$$

onde $\eta_{t}=x_{t}^{\top} \hat{\beta}$ e o erro padrão de $\hat{\eta}_{t}$ é dado por se $\left(\hat{\eta}_{t}\right)=\left(x_{t}^{\top} \widehat{\operatorname{cov}}(\hat{\beta}) x_{t}\right)^{1 / 2}$, sendo $\widehat{\operatorname{cov}}(\hat{\beta})$ a matriz obtida da inversa da matriz de informação de Fisher avaliada nas estimativas de máxima verossimilhança, excluindo a linha e a coluna correspondente ao parâmetro de dispersão $\phi$.

Avaliações da qualidade das aproximações utilizadas para este modelo podem ser vistas em Ospina, Cribari-Neto \& Vasconcellos (2006) (ver também Oliveira, 2004). Através de estudos de simulações eles observaram bons resultados quanto ao viés, comportamento assintótico, taxa de cobertura e assimetria para os estimadores dos parâmetros de regressão e resultados não tão satisfatórios para o parâmetro de dispersão. Vale destacar que o parâmetro de dispersão exerce alguma influência nas estimativas intervalares dos parâmetros de regressão e pouca influência nas estimativas pontuais. 


\subsubsection{Funções de Ligação}

A função $g(\cdot)$ é conhecida como função de ligação e existem muitas possibilidades para sua escolha. Como $g\left(\mu_{t}\right)=\eta_{t}$, então a média $\mu_{t}$ pode ser facilmente obtida pela inversa de $g\left(\mu_{t}\right)$ (ver (1.3)). Nos modelos de regressão beta a variável resposta tem distribuição definida no intervalo $(0,1)$ e, portanto, a sua média também estará neste mesmo intervalo. Sendo assim, as funções de ligação aqui apresentadas levam o intervalo $(0,1)$ a $\Re$. São elas:

- Logito: $g\left(\mu_{t}\right)=\log \left(\frac{\mu_{t}}{1-\mu_{t}}\right) ; \mu_{t}=\frac{e^{\eta_{t}}}{1+e^{\eta_{t}}}$.

- Probito: $g\left(\mu_{t}\right)=\Phi^{-1}\left(\mu_{t}\right)$, onde $\Phi^{-1}($.$) é a função de distribuição acumulada de$ uma variável aleatória normal padrão; $\mu_{t}=\Phi\left(\eta_{t}\right)$.

- Complemento log-log: $g\left(\mu_{t}\right)=\log \left\{-\log \left(1-\mu_{t}\right)\right\} ; \mu_{t}=1-\exp \left\{-\exp \left(\eta_{t}\right)\right\}$.

- Log-log: $g\left(\mu_{t}\right)=-\log \left\{-\log \left(\mu_{t}\right)\right\} ; \mu_{t}=\exp \left\{-\exp \left(-\eta_{t}\right)\right\}$.

- Aranda-Ordaz (assimétrica) (Aranda-Ordaz, 1981):

$$
g\left(\mu_{t}, \lambda\right)=\log \left\{\frac{\left(1-\mu_{t}\right)^{-\lambda}-1}{\lambda}\right\} ; \mu_{t}=1-\left(1+\lambda \exp \left(\eta_{t}\right)\right)^{-1 / \lambda}
$$

onde $\lambda>0$ é um parâmetro adicional que deverá ser especificado ou estimado. ArandaOrdaz (1981) define a função $g\left(\mu_{t}, \lambda\right)$ para todo $\lambda \in \Re$. No entanto, $\lambda<0$ implica em restrição no espaço paramétrico para $\eta_{t}$. De fato, se $\lambda<0$, seja $\delta=-\lambda>0$, então

$$
\eta_{t}=\log \left\{-\frac{\left(1-\mu_{t}\right)^{\delta}-1}{\delta}\right\}=\log \left\{\frac{1-\left(1-\mu_{t}\right)^{\delta}}{\delta}\right\} .
$$

Como $\mu_{t} \in(0,1)$ pode-se escrever:

$$
\begin{aligned}
& 0<1-\mu_{t}<1 \Leftrightarrow 0<\left(1-\mu_{t}\right)^{\delta}<1 \Leftrightarrow 0<1-\left(1-\mu_{t}\right)^{\delta}<1 \\
& \Leftrightarrow 0<\frac{1-\left(1-\mu_{t}\right)^{\delta}}{\delta}<\frac{1}{\delta} \Leftrightarrow \log \left\{\frac{1-\left(1-\mu_{t}\right)^{\delta}}{\delta}\right\}<\log \left\{\frac{1}{\delta}\right\}
\end{aligned}
$$

portanto, $\eta_{t} \leq-\log (\delta)$. Note que quando $\lambda \rightarrow 0, g\left(\mu_{t}, \lambda\right) \rightarrow \log \left\{-\log \left(1-\mu_{t}\right)\right\}$, que é a função de ligação complemento log-log. Desta forma, neste trabalho considerou-se apenas $\lambda>0$ na definição da função de ligação Aranda-Ordaz. 
Atkinson (1985) considera algumas funções ("folded-power", Guerrero-Johnson e Aranda-Ordaz) em que um parâmetro adicional $\lambda$ é incluído para transformação de porcentagens e proporções. Este trabalho incluirá o estudo da função de ligação de ArandaOrdaz definida acima. Maiores detalhes sobre a utilização desta função de ligação serão vistos no Capítulo 3. A função de ligação logito é um caso particular da ligação de Aranda-Ordaz quando $\lambda=1$.

A primeira derivada de $g\left(\mu_{t}\right)$, necessária para ajustar um modelo de regressão beta, é dada a seguir para cada função de ligação.

- Logito: $g^{\prime}\left(\mu_{t}\right)=\frac{\{1+\exp (\eta)\}^{2}}{\exp (\eta)}$.

- Probito: $g^{\prime}\left(\mu_{t}\right)=\sqrt{2 \pi} \exp \left\{\eta^{2} / 2\right\}$.

- Complemento log-log: $g^{\prime}\left(\mu_{t}\right)=\exp \{\exp (\eta)-\eta\}$.

- Log-log: $g^{\prime}\left(\mu_{t}\right)=\exp \{\exp (-\eta)+\eta\}$.

- Aranda-Ordaz: $g^{\prime}\left(\mu_{t}\right)=\frac{\lambda\left(1-\mu_{t}\right)^{-(\lambda+1)}}{\left(1-\mu_{t}\right)^{-\lambda}-1}$.

Dentre as funções de ligação, a mais utilizada é a logito, pois possibilita interpretação simples para os parâmetros de regressão. Para função de ligação logito pode-se escrever

$$
\frac{\mu_{t}}{1-\mu_{t}}=\exp \left(\eta_{t}\right)=\exp \left(x_{t}^{\top} \beta\right)
$$

Definindo $\mu_{t}^{\dagger}$ como a média de $y_{t}$ com a $i$-ésima variável regressora acrescida de $c$ unidades e as demais variáveis regressoras constantes tem-se

$$
\frac{\mu_{t}^{\dagger}}{1-\mu_{t}^{\dagger}}=\exp \left\{x_{t 1} \beta_{1}+\ldots+\left(x_{t i}+c\right) \beta_{i}+\ldots+x_{t k} \beta_{k}\right\}
$$

e assim, é fácil verificar que

$$
\exp \left(c \beta_{i}\right)=\frac{\mu_{t}^{\dagger} /\left(1-\mu_{t}^{\dagger}\right)}{\mu_{t} /\left(1-\mu_{t}\right)}
$$

onde $\exp \left(c \beta_{i}\right)$ representa a razão de chances ("odds ratio").

McCullagh \& Nelder (1989) compararam a função de ligação logito com as funções de ligação probito, complemento log-log e log-log. Note que, se $c \in(0,0.5), g(0.5-c)=$ $-g(0.5+c)$ para as funções de ligação: logito e probito. A função de ligação logito e 
a probito são quase linearmente relacionadas quando $\mu_{t}$ pertence ao intervalo $[0.1 ; 0.9]$ e, por esta razão, fica mais difícil verificar com qual dessas funções se tem um melhor ajuste. Para valores pequenos de $\mu_{t}$ a função de ligação complemento log-log é próxima à logito. Já para valores de $\mu_{t}$ próximos de 1 , é a função de ligação log-log que está próxima da função de ligação logito.

A Figura 1.2 apresenta o comportamento de $\eta$ como função de $\mu$ para as funções de ligação logito, probito, complemento log-log, log-log e Aranda-Ordaz com $\lambda=0.5$. É possível verificar que as funções de ligação logito e probito são próximas. A função de ligação complemento log-log tem comportamento similar à logito para valores de $\mu$ próximos de 0 e a função de ligação log-log tem comportamento similar à logito para valores de $\mu$ próximos de 1 .

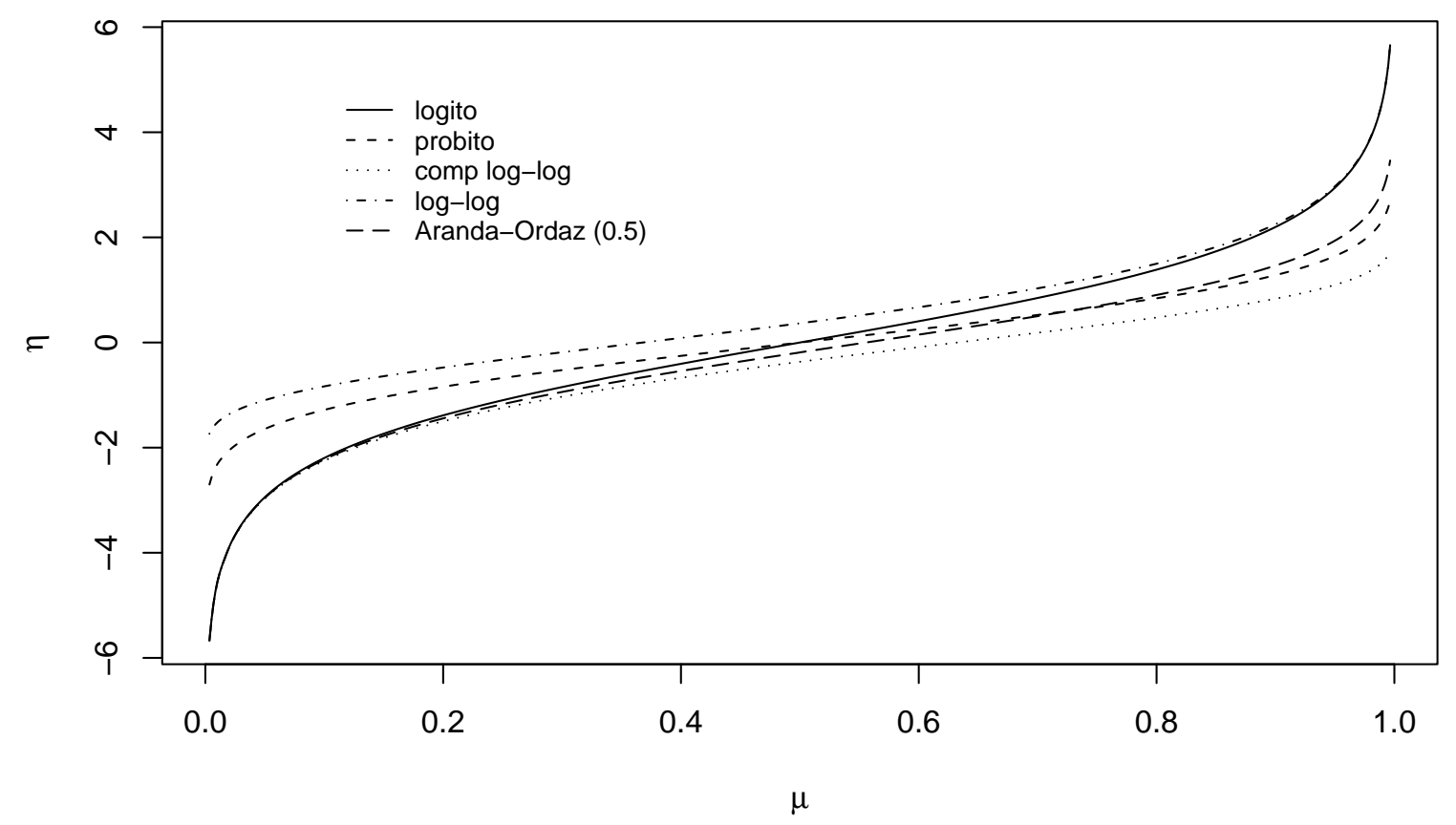

Figura 1.2: Gráfico de funções de ligação.

Para valores de $\mu$ próximos de 0 , as funções de ligação logito e de Aranda-Ordaz $(\lambda=0.5)$ estão próximas, como se pode ver na Figura 1.2. Na Figura 1.3 são apresentados o comportamento de $\eta$ como função de $\mu$ para a função de ligação de Aranda-Ordaz para diferentes valores de $\lambda$. Novamente se observa que para valores de $\mu$ próximos de 0 as funções de ligação de Aranda-Ordaz para qualquer valor de $\lambda$ tem comportamento próximo ao da função de ligação logito (Aranda-Ordaz, $\lambda=1$ ). Nota-se que quando $\lambda<1$ na função de ligação de Aranda-Ordaz $\mu$ se aproxima mais rapidamente de 1 com 
o aumento de $\eta$ do que na função de ligação logito, já para $\lambda>1, \mu$ se aproxima mais lentamente de um do que na função de ligação logito.

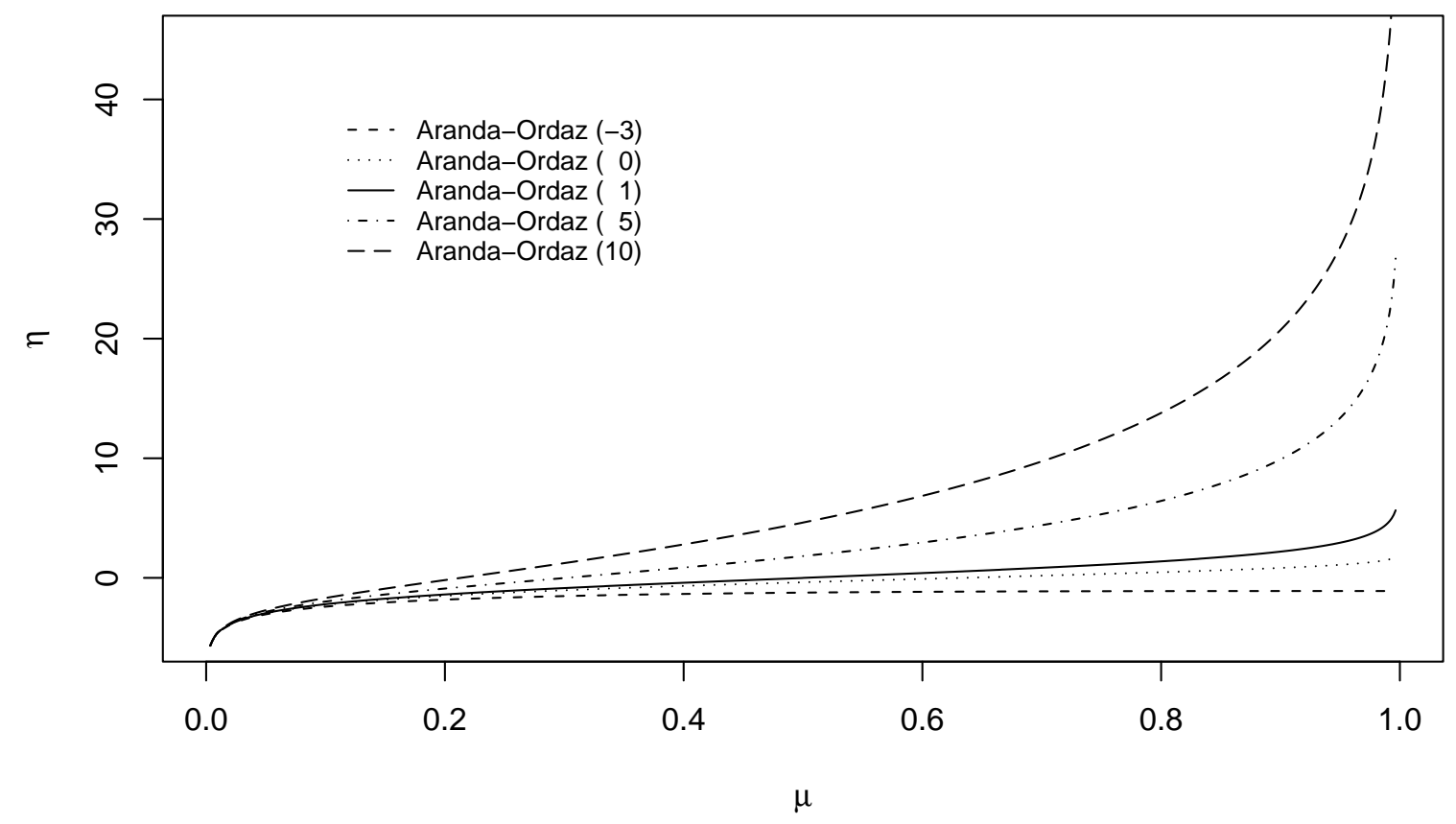

Figura 1.3: Gráfico de função de ligação de Aranda-Ordaz $(\lambda)$.

Como mencionado anteriormente, existem muitas opções para escolha da função de ligação no ajuste do modelo de regressão beta. O foco deste trabalho é avaliar através de estudos de simulação o efeito da especificação inadequada da função de ligação nas inferências acerca das médias $\mu_{t}$. Para isso serão comparados os ajustes obtidos com a função de ligação correta, a ser utilizada para geração dos dados, com uma função de ligação incorreta.

Myers, Montgomery \& Vining (Seção 7.3, 2002) desenvolveram estudo semelhante para verificar o efeito da especificação inadequada da função de ligação em modelos lineares generalizados para as distribuições binomial, Poisson e gama. Foram comparados os ajustes com a função de ligação canônica e uma não canônica para cada distribuição; detalhes sobre as funções de ligação canônica para cada uma das distribuições podem ser vistas em McCullagh \& Nelder (1989). Nos resultados apresentados por Myers, Montgomery \& Vining (Seção 7.3, 2002) a função de ligação verdadeira foi a canônica e o ajuste com a função de ligação incorreta (uma que não fosse a canônica) causou impacto maior nas inferências dos resultados paras as médias geradas a partir das distribuições binomial e Poisson, nos quais as taxas de cobertura de intervalos de confiança para as 
médias diminuíram com o aumento do tamanho da amostra. Esta taxa de cobertura representa a proporção de vezes em que a média verdadeira pertence aos intervalos de confiança de $95 \%$ estimados para cada réplica de Monte Carlo, e o esperado é que com o aumento do tamanho da amostra esta medida se aproxime do valor nominal de $95 \%$. Para a distribuição gama não foram verificados grandes problemas.

No Capítulo 2 serão verificados os efeitos da especificação inadequada no modelo de regressão beta para as funções de ligação logito, probito, complemento log-log e log-log. A utilização da função de ligação de Aranda-Ordaz no ajuste do modelo de regressão beta será discutida no Capítulo 3.

Os estudos serão realizados a partir de dados simulados utilizando o programa $\mathrm{Ox}$ (Doornik, 2001). 
Capítulo 2

\section{Especificação Incorreta da Função}

\section{de Ligação}

\subsection{Introdução}

Neste capítulo serão verificados os efeitos da especificação incorreta da função de ligação (logito, probito, complemento log-log e log-log) nos modelos de regressão beta. Para isso serão realizados estudos de simulação. Serão ajustados dois modelos de regressão beta utilizando duas funções de ligação diferentes para um mesmo vetor resposta $y=\left(y_{1}, \ldots, y_{n}\right)^{\top}$. Para obtenção do vetor resposta $y$ a função de ligação será conhecida e esta será utilizada para o ajuste de um dos modelos de regressão beta.

As simulações dos ajustes dos modelos de regressão beta serão obtidas em réplicas de Monte Carlo. Em cada réplica serão geradas amostras aleatórias para o vetor da variável resposta $y=\left(y_{1}, \ldots, y_{n}\right)^{\top}$, com $y_{t} \sim \operatorname{Beta}\left(\mu_{t}, \phi\right), \mathrm{t}=1, \ldots, n$. O parâmetro de dispersão $\phi$ será o mesmo para as $n$ observações e a média será obtida por $\mu_{t}=g^{-1}\left(x_{t}^{\top} \beta\right)$, onde $g($.) é a função de ligação, o vetor $x_{t}^{\top}$ é a $t$-ésima linha da matriz regressora $X$, e $\beta=\left(\beta_{0}, \ldots, \beta_{k}\right)$ é o vetor de parâmetros do modelo de regressão beta. O tamanho amostral $n$ será escolhido de acordo com o interesse em avaliar os ajustes para amostras pequenas e grandes.

A simulação dos dados e os ajustes dos modelos de regressão beta em cada réplica de Monte Carlo serão realizados na linguagem de programação Ox e os números aleatórios envolvidos no processo serão obtidos através do gerador "GM - George Marsaglia" (ver detalhes em Doornik, 2001). O programa utilizado nas simulações é apresentado no Apêndice A. 
O número de réplicas de Monte Carlo foi fixado em 10000. Em cada réplica de Monte Carlo serão obtidos intervalos de confiança com coeficiente de confiança nominal de $95 \%$ para as médias $\mu_{t}(t=1, \ldots, n)$ e para o parâmetro de dispersão $\phi$. A partir dos 10000 intervalos de confiança serão obtidas as taxas de cobertura e a medida de balanceamento para os parâmetros mencionados acima. A taxa de cobertura representa a proporção de vezes em que o verdadeiro parâmetro pertence ao intervalo de confiança, sendo esperada uma taxa de cobertura em torno de 95\%. A medida de balanceamento é o resultado da subtração entre a proporção de vezes em que o verdadeiro valor do parâmetro é maior que o limite superior do intervalo de confiança estimado e a proporção de vezes em que o verdadeiro parâmetro é menor que o limite inferior deste intervalo. O ideal é que esta medida esteja em torno de zero. Se ela for positiva indica que os intervalos de confiança estão mais freqüentemente à esquerda do verdadeiro valor do parâmetro. Valores negativos desta medida indicam que os intervalos de confiança estão mais freqüentemente à direita do verdadeiro valor do parâmetro.

Para comparar os resultados inferenciais obtidos usando a função de ligação correta, ou verdadeira, com os obtidos sob má especificação da função de ligação foram utilizados 48 cenários que representam situações diversas. Os 48 cenários variam de acordo com a combinação das seguintes opções:

- tamanhos amostrais $n$ "pequenos" (20 e 50) e "grandes" (250 e 500): espera-se que quanto maior seja o tamanho amostral melhores deverão ser os resultados de taxa de cobertura e medida de balanceamento para bons ajustes;

- dispersão $\phi$ igual a 20 e 120: com o aumento da dispersão, a variância de y passa a ser menor e por isso os intervalos de confiança para as médias terão menores amplitudes. Portanto, em ajustes ruins espera-se que uma proporção considerável dos intervalos de confiança não contenham o verdadeiro valor do parâmetro;

- com e sem réplicas nas observações da matriz $X$ : a matriz regressora $X$ sem réplicas será composta por uma coluna de uns (representando o intercepto) e duas colunas representando duas variáveis regressoras, obtidas como observações independentes da distribuição uniforme em $(0,1)$. Quando se utilizam réplicas na matriz $X$ as primeiras dez observações dessa matriz serão obtidas de forma aleatória e as demais observações serão réplicas das anteriores. Mais especificamente, para as primeiras dez observações a primeira coluna é de uns, as duas outras colunas são obtidas 
como observações independentes de distribuição uniforme em $(0,1)$ e para atingir o tamanho amostral escolhido replica-se esta matriz;

- as médias próximas de 0 , em torno de 0.5 ou próximas de 1: o vetor $\beta$ será escolhido adequadamente para tal. Os intervalos para as médias foram escolhidos a partir dos comportamentos observados para relação entre $\mu_{t}$ e $\eta_{t}$ com as diferentes funções de ligação apresentados na Figura 1.2. Foi observado, por exemplo, que para os valores das médias próximos de 0 as curvas da relação entre $\mu_{t}$ e $\eta_{t}$ para as funções de ligação complemento log-log e logito estão próximas, entretanto, para valores próximos de 1 as curvas se afastam. Portanto, o interesse é verificar se essa separação na relação pode trazer diferenças inferenciais nos resultados.

Para cada cenário de simulação descrito acima ajustou-se um modelo com a função de ligação correta e outro com uma função de ligação incorreta. A Tabela 2.1 traz as combinações das funções de ligação utilizadas nos ajustes. No caso 1 está sendo utilizada a função de ligação logito como a verdadeira e optou-se por utilizar a função de ligação probito como função de ligação incorreta. Nos casos 2, 3 e 4 as funções de ligação correta utilizadas para simulação dos dados foram respectivamente probito, complemento log$\log$ e $\log -\log$ e a função de ligação incorreta para todos esses casos foi a função de ligação logito, pois na prática é a mais utilizada pela facilidade de interpretação dos seus parâmetros.

\begin{tabular}{ccc}
\hline Tabela 2.1: & Funções de Ligação Comparadas. \\
\hline \hline Caso & Correta & Incorreta \\
\hline 1 & Logito & Probito \\
2 & Probito & Logito \\
3 & Complemento log-log & Logito \\
4 & Log-log & Logito \\
\hline \hline
\end{tabular}

Na seção seguinte serão discutidos os resultados obtidos para a taxa de cobertura e medida de balanceamento para as médias $\mu_{t}$ nas 10000 réplicas de Monte Carlo. Foram comparados os ajustes obtidos com as funções de ligação dadas na Tabela 2.1 nos 48 cenários propostos acima. No entanto, não seria conveniente apresentar aqui os detalhes 
dos resultados obtidos para todas as simulações, portanto, os resultados serão comentados de forma global. Também serão avaliados a taxa de cobertura e balanceamento para $\phi$.

\subsection{Resultados das Simulações}

\subsubsection{Casos 1 e 2: Função de Ligação Logito e Probito}

Os resultados obtidos tendo como função de ligação verdadeira a logito ou a probito e ajustando-se os modelos com essas duas funções de ligação, como descrito nos casos 1 e 2 da Tabela 2.1, foram semelhantes e por isso serão discutidos nesta mesma seção. Na Seção B.1 do Apêndice B são apresentadas tabelas com os resultados das simulações para os ajustes em que a função de ligação logito é a verdadeira (Tabelas B.1 a B.8) e na Seção B.2 os resultados quando a função de ligação verdadeira é a probito (Tabelas B.9 a B.16), todos considerando réplicas na matriz $X$.

Para as simulações das médias $\mu_{t}$ próximas de 0 , em torno de 0.5 e próximas de 1 utilizaram-se os seguintes conjuntos de valores (vetores) para $\beta$, quando se assume como função de ligação verdadeira a logito: $(-0.7 ;-1.1 ;-2.3),(0.7 ; 1.0 ;-1.0)$ e $(0.7 ; 1.1 ; 2.3)$. Esses vetores produziram médias $\mu_{t}$ nos intervalos [0.021;0.054], [0.385; 0.614] e [0.946; 0.979] respectivamente. Já para função de ligação probito sendo a verdadeira os vetores escolhidos para $\beta$ foram $(-0.5 ;-0.3 ;-1.3),(-0.2 ;-0.7 ; 0.5)$ e $(0.5 ; 0.3 ; 1.3)$ que geraram médias $\mu_{t}$ nos intervalos [0.023;0.056], [0.386; 0.611] e [0.944; 0.977] respectivamente.

Foram verificados resultados semelhantes nos ajustes com a função de ligação logito para as médias no intervalo próximas de zero e próximas de 1, pelo fato das duas funções de ligação (logito e probito) serem simétricas em torno de 0.5, e por isso na Seção B.1 são mostrados os resultados apenas para as médias $\mu_{t}$ próximas de 0 . O mesmo se verifica quando se assume como função de ligação verdadeira a probito. Portanto, na Seção B.2 são apresentados os resultados para as médias $\mu_{t}$ próximas de 1 .

Na Tabela B.1 ( $n=20, \phi=20$ e médias $\mu_{t}$ próximas de 0$)$ observa-se que as taxas de cobertura obtidas no ajuste com a função de ligação logito (correta) e no ajuste com a probito (incorreta) são próximas. Por exemplo, para $\mu_{t}=0.054$ as taxas de cobertura são de $91.2 \%$ e $90.6 \%$ respectivamente. As medidas de balanceamento estão próximas para os dois ajustes e não estão afastadas de zero. Com o aumento do tamanho amostral os resultados obtidos nos dois ajustes continuam próximos e as taxas de cobertura se 
aproximam de $95 \%$, como pode ser visto na Tabela B.3. Resultados semelhantes podem ser vistos nas Tabelas B.9 e B.11, com médias próximas de um, nos quais a função de ligação correta é a probito e a incorreta é a logito.

Ainda nas Tabelas B.9 e B.11 pode-se notar que com o aumento do tamanho amostral (digamos, passando de 20 para 500) as medidas de balanceamento se aproximam mais de zero nos dois ajustes. Os valores máximos das medidas de balanceamento para $n=20$ foram, em valor absoluto, de 4.2 e 3.7 nos ajustes com a função de ligação correta e incorreta respectivamente. Já para $n=500$ essas medidas passam a ser 1.1 e 1.7 respectivamente.

As taxas de cobertura obtidas nos ajustes com $\phi=20$ e 120 também são muito próximas, para todos os tamanhos amostrais avaliados, como se pode ver, por exemplo, comparando-se as Tabelas B.1 e B.2, para médias próximas de 0.

Nos resultados obtidos para a situação em que as médias são próximas zero, a medida de balanceamento na maioria das vezes é maior nos ajustes com a função de ligação incorreta que nos ajustes com a função de ligação correta. Entretanto, essas diferenças não se verificam quando as médias estão em torno de 0.5, como se pode ver, por exemplo, nas Tabelas B.13 e B.15, nas quais o máximo dessas medidas em valor absoluto é igual a 0.3 para todos os ajustes.

Observou-se a partir das simulações que as taxas de cobertura e balanceamento para os planejamentos com réplicas ou não na matriz $X$ são semelhantes e por isso foram apresentados nas tabelas do Apêndice B apenas os resultados das simulações referentes ao planejamento com réplicas.

As estimativas para $\phi$ geraram taxas de coberturas sempre em torno de $95 \%$ e medidas de balanceamento próximas de zero em todos os ajustes considerados.

De forma geral, verificou-se a partir das simulações que quando a função de ligação verdadeira é a logito ou a probito, os ajustes com uma dessas duas funções trará resultados satisfatórios e semelhantes para as estimativas das médias $\mu_{t}$. Com o aumento do tamanho amostral houve aproximação da taxa de cobertura ao valor nominal de $95 \%$ e o aumento de $\phi$ não causou nenhum impacto no desempenho das estimativas intervalares. 


\subsubsection{Caso 3: Função de Ligação Logito e Complemento Log- $\log$}

Nesta seção serão discutidos os resultados obtidos para os ajustes dos modelos obtidos com a função de ligação logito e complemento log-log, sendo que a função de ligação verdadeira é a complemento log-log. As Tabelas B.17 a B.28 do Apêndice B apresentam os resultados de alguns dos cenários simulados para estes ajustes, todos com réplicas na matriz $X$.

Para $\mu_{t} \in[0.022 ; 0.084]$, obtidos usando $\beta=(-0.5 ;-1.7 ;-1.9)$, foram verificados resultados semelhantes para os ajustes dos modelos de regressão beta com a função de ligação complemento log-log (correta) e com a função de ligação logito (incorreta). Os resultados verificados a partir das Tabelas B.17 a B.20 estão dentro do esperado, pois as taxas de coberturas se aproximam de $95 \%$ com o aumento do tamanho amostral nos dois ajustes e a medida de balanceamento se aproxima de zero. Não são observadas diferenças das conclusões acima para os resultados considerando os cenários em que $\phi=20$ e 120 e $X$ com e sem réplicas.

As Tabelas B.21 a B.24 trazem alguns dos resultados das simulações para a situação em que as médias $\mu_{t}$ estão no intervalo [0.343; 0.657], obtidas usando $\beta=(-0.7 ;-1.0 ; 0.6)$ e considerando réplicas na matriz $X$. Pode-se observar que os ajustes dos modelos de regressão beta com a função de ligação logito incorreta produzem taxas de cobertura menores e medidas de balanceamento mais afastadas de zero quando comparados com os ajustes com a função de ligação correta. Na Tabela 2.2 pode-se observar, por exemplo, que para $\mu_{t}=0.466$ a taxa de cobertura no ajuste do modelo com função de ligação correta é de $94.8 \%$ enquanto que no ajuste com a função de ligação incorreta é de $50.9 \%$. As medidas de balanceamento são respectivamente iguais a $0.2 \%$ e $-49.1 \%$. No cenário desta última tabela foram consideradas réplicas na matriz $X$.

Na Tabela 2.3 comparam-se as simulações do cenário da Tabela 2.2 (planejamento com réplicas na matriz $X)$ com o cenário em que não há réplicas na matriz $X$. Nestas tabelas de comparação dos resultados das simulações com e sem réplicas são mostradas as taxas de cobertura mínima (CobMin) e média (CobMed) e as medidas de balanceamento mínima (BalanMin) e máxima (BalanMax) para as $n$ respostas médias. Na Tabela 2.3 é possível verificar que as médias das taxas de coberturas nos ajustes com a função de ligação correta estão próximas de $95 \%$ enquanto que nos ajustes com a função de ligação incorreta essas médias estão sempre abaixo, chegando ao valor de $54.7 \%$ quando a matriz 
Tabela 2.2: Resultados dos intervalos de confiança para as respostas médias: taxa de cobertura e balanceamento; ligação correta complemento log-log, ligação incorreta logito, planejamento com réplicas, $\mu_{t} \in[0.343 ; 0.657], n=500$ e $\phi=120$.

\begin{tabular}{ccccc}
\hline \hline & \multicolumn{2}{c}{ Cobertura (\%) } & \multicolumn{2}{c}{ Balanceamento (\%) } \\
Médias & Correta & Incorreta & Correta & Incorreta \\
\hline 0.343 & 95.1 & 58.8 & 0.2 & 41.2 \\
0.377 & 94.9 & 94.5 & 0.2 & 2.7 \\
0.411 & 94.8 & 94.1 & -0.1 & -3.0 \\
0.466 & 94.8 & 50.9 & 0.2 & -49.1 \\
0.536 & 94.3 & 85.6 & 0.0 & -13.9 \\
0.540 & 95.0 & 42.6 & 0.4 & -57.4 \\
0.583 & 94.3 & 92.8 & -0.1 & -5.1 \\
0.644 & 94.6 & 87.6 & 0.4 & 11.9 \\
0.652 & 94.5 & 73.3 & 0.3 & 26.6 \\
0.657 & 94.7 & 75.8 & 0.4 & 24.1 \\
\hline \hline
\end{tabular}

Tabela 2.3: Resultados dos intervalos de confiança para as respostas médias: taxas de cobertura mínima e média, balanceamentos mínimo e máximo; ligação correta complemento log-log, ligação incorreta logito, planejamento com réplicas e $\mu_{t} \in[0.343 ; 0.657]$, planejamento sem réplicas e $\mu_{t} \in[0.309 ; 0.819]$ e $n=500$.

\begin{tabular}{cccccc}
\hline \hline & & \multicolumn{2}{c}{ Com Réplicas } & \multicolumn{2}{c}{ Sem Réplicas } \\
& Medidas & Correta & Incorreta & Correta & Incorreta \\
\hline \multirow{2}{*}{$\phi=20$} & CobMin(\%) & 94.4 & 84.9 & 94.3 & 12.3 \\
& CobMed(\%) & 94.9 & 91.5 & 94.8 & 84.1 \\
& BalanMax(\%) & -0.1 & 10.6 & 0.4 & 87.7 \\
& BalanMin(\%) & -0.5 & -14.6 & -0.7 & -29.8 \\
\hline \multirow{2}{*}{$\phi=120$} & CobMin(\%) & 94.3 & 42.6 & 94.2 & 0.0 \\
& CobMed(\%) & 94.7 & 75.6 & 94.7 & 54.7 \\
& BalanMax(\%) & 0.4 & 41.2 & 0.4 & 100.0 \\
& BalanMin(\%) & -0.1 & -57.4 & -0.3 & -91.6 \\
\hline \hline
\end{tabular}

$X$ é sem réplicas e $\phi=120$.

De maneira geral, observou-se que, para os casos em que as médias verdadeiras estão em torno de 0.5 , os ajustes com a função de ligação correta estão dentro do esperado, com taxas de coberturas próximas de $95 \%$ e medidas de balanceamento próximas de zero. Já nos ajustes com a função de ligação incorreta as taxas de cobertura são baixas e mais afastadas de $95 \%$ quando se aumentam o tamanho amostral e a dispersão $\phi$ e considera-se a matriz $X$ sem réplicas. As medidas de balanceamento estão próximas de zero nos ajustes dos modelos que usam a função de ligação correta e afastadas de zero nos ajustes que utilizam a função de ligação incorreta. 
Nas Tabelas B.25 a B.28 são apresentados alguns resultados das simulações para o cenário em que as médias estão intervalo [0.913; 0.974], obtidas usando $\beta=(0.5 ; 0.3 ; 0.6)$. Nota-se que com o aumento do tamanho amostral há maior desbalanceamento para os intervalos de confiança e a taxa de cobertura é um pouco menor nos ajustes com a função de ligação incorreta do que nos ajustes com a função de ligação correta. Na Tabela 2.4 pode-se observar, por exemplo, que para $\mu_{t}=0.946$ a taxa de cobertura obtida utilizando a função de ligação correta é de $95.0 \%$ enquanto que, quando a função de ligação é incorretamente especificada, essa taxa é de 86.6\%; as medidas de balanceamento são, respectivamente, iguais a $0 \%$ e $-12.7 \%$.

Tabela 2.4: Resultados dos intervalos de confiança para as respostas médias: taxa de cobertura e balanceamento; ligação correta complemento log-log, ligação incorreta logito, planejamento com réplicas, $\mu_{t} \in[0.913 ; 0.974], n=500$ e $\phi=120$.

\begin{tabular}{ccccc}
\hline \hline & \multicolumn{2}{c}{ Cobertura (\%) } & \multicolumn{2}{c}{ Balanceamento (\%) } \\
Médias & Correta & Incorreta & Correta & Incorreta \\
\hline 0.913 & 95.1 & 91.1 & 0.1 & 8.2 \\
0.917 & 95.1 & 93.6 & 0.1 & 4.8 \\
0.920 & 95.1 & 94.8 & 0.0 & 2.0 \\
0.933 & 95.1 & 89.9 & -0.2 & -9.2 \\
0.946 & 95.0 & 86.6 & 0.0 & -12.7 \\
0.949 & 95.2 & 91.2 & -0.4 & -7.4 \\
0.957 & 95.1 & 93.8 & -0.4 & -4.0 \\
0.959 & 94.8 & 93.6 & 0.2 & -3.4 \\
0.966 & 94.8 & 93.9 & -0.3 & 3.7 \\
0.974 & 95.1 & 76.0 & -0.2 & 23.8 \\
\hline \hline
\end{tabular}

Na Tabela 2.5 comparam-se os resultados obtidos com e sem réplicas em $X$ e notamse diferenças ainda maiores nos ajustes dos modelos com as funções de ligação correta e incorreta e sem réplicas em $X$. A cobertura mínima quando se consideram réplicas e $\phi=120$ é de $76 \%$ e sem réplicas chega ao valor de $2.4 \%$ para pelo menos umas das médias enquanto que, para o ajuste com a função de ligação correta, as taxas estão sempre em torno de 95\%. Observa-se também que o aumento na dispersão $\phi$ produz taxas de coberturas mais baixas nos ajustes com a função de ligação incorreta.

De forma geral, pode-se notar em todas as simulações realizadas que as estimativas para $\phi$ são sempre próximas nos dois modelos ajustados, com taxas de cobertura próximas de 95\%. Quando se consideraram médias próximas de 0, os ajustes com a função de ligação correta (complemento log-log) e com a função de ligação incorreta (logito) trouxeram resultados semelhantes e próximos do esperado. Já para as médias 
Tabela 2.5: Resultados dos intervalos de confiança para as respostas médias: taxas de cobertura mínima e média, balanceamentos mínimo e máximo; ligação correta complemento log-log, ligação incorreta logito, planejamento com réplicas e $\mu_{t} \in[0.913 ; 0.974]$, planejamento sem réplicas e $\mu_{t} \in[0.850 ; 0.980]$ e $n=500$.

\begin{tabular}{cccccc}
\hline \hline & & \multicolumn{2}{c}{ Com Réplicas } & \multicolumn{2}{c}{ Sem Réplicas } \\
& Medidas & Correta & Incorreta & Correta & Incorreta \\
\hline \multirow{2}{*}{$\phi=20$} & CobMin(\%) & 95.0 & 92.2 & 94.2 & 62.8 \\
& CobMed(\%) & 95.1 & 94.1 & 94.9 & 91.0 \\
& BalanMax(\%) & 0.2 & 6.6 & 0.0 & 37.1 \\
& BalanMin(\%) & -0.7 & -5.5 & -1.1 & -13.5 \\
\hline \multirow{2}{*}{$\phi=120$} & CobMin(\%) & 94.8 & 76.0 & 94.3 & 2.4 \\
& CobMed(\%) & 95.0 & 90.5 & 94.9 & 77.5 \\
& BalanMax(\%) & 0.2 & 23.8 & 0.7 & 97.6 \\
& BalanMin(\%) & -0.4 & -12.7 & -0.5 & -45.1 \\
\hline \hline
\end{tabular}

em torno de 0.5 e próximas de 1 , o ajuste com a função de ligação correta continuou trazendo bons resultados, mas o ajuste com a função de ligação incorreta produziu taxas de cobertura baixas em alguns casos, que pioraram com o aumento do tamanho amostral, o aumento de $\phi$ e quando não há réplicas na matriz $X$.

\subsubsection{Caso 4: Função de Ligação Correta Log-log e Incorreta Logito}

Nesta seção serão abordados os resultados dos ajustes do modelo de regressão beta com as funções de ligação logito e log-log, sendo que a função de ligação verdadeira é a log-log. Alguns dos resultados dessas simulações estão mostrados no Apêndice B nas Tabelas B.29 a B.40, considerando réplicas na matriz $X$.

Nas Tabelas B.29 a B.32 são apresentados os resultados para a situação em que as médias $\mu_{t}$ estão no intervalo [0.026;0.087], obtidas com $\beta=(-0.5 ;-0.3 ;-0.6)$. Quando se ajusta o modelo com a função de ligação correta nota-se que com o aumento do tamanho amostral as taxas de cobertura para as médias estão em torno de 95\% e o desbalanceamento próximo de zero. Já para o ajuste com a função de ligação incorreta se verifica uma queda na taxa de cobertura e maior desbalanceamento de alguns casos. Esse afastamento dos resultados esperados é maior para os cenários em que $\phi=120$, como se pode ver na Tabela 2.6, nos quais réplicas da matriz $X$ foram consideradas. No ajuste do modelo com a função de ligação correta as taxas de cobertura estão sempre 
próximas de $95 \%$ enquanto que no ajuste com a função de ligação incorreta as taxas estão abaixo de $90 \%$. Por exemplo, para $\mu_{t}=0.054$ a taxa de cobertura é $94.9 \%$ no ajuste com a função de ligação correta e $86.3 \%$ no ajuste com a função de ligação incorreta e as medidas de balanceamento são, respectivamente, iguais a $0.5 \%$ e $13.2 \%$.

Tabela 2.6: Resultados dos intervalos de confiança para as respostas médias: taxa de cobertura e balanceamento; ligação correta log-log, ligação incorreta logito, planejamento com réplicas, $\mu_{t} \in[0.026 ; 0.087], n=500$ e $\phi=120$.

\begin{tabular}{ccccc}
\hline \hline & \multicolumn{2}{c}{ Cobertura (\%) } & \multicolumn{2}{c}{ Balanceamento (\%) } \\
Médias & Correta & Incorreta & Correta & Incorreta \\
\hline 0.026 & 94.7 & 76.2 & 0.3 & -23.7 \\
0.034 & 94.7 & 93.7 & 0.5 & -3.9 \\
0.041 & 94.7 & 93.8 & 0.2 & 3.7 \\
0.043 & 95.2 & 93.9 & 0.4 & 3.9 \\
0.051 & 95.1 & 91.2 & 0.3 & 7.4 \\
0.054 & 94.9 & 86.3 & 0.5 & 13.2 \\
0.067 & 94.9 & 90.0 & 0.3 & 9.3 \\
0.080 & 95.0 & 94.7 & 0.2 & -2.1 \\
0.083 & 95.2 & 93.3 & 0.1 & -5.2 \\
0.087 & 95.2 & 90.5 & 0.1 & -8.8 \\
\hline \hline
\end{tabular}

É possível comparar os resultados obtidos para $\phi=20$ e 120 e $X$ com e sem réplicas na Tabela 2.7. Nos ajustes sem réplicas na matriz $X$ notam-se maiores diferenças entre os ajustes dos modelos com a função de ligação correta e incorreta, a média das taxas de cobertura que é de $94.7 \%$ nos ajustes com a função de ligação correta passa a ser de $77.3 \%$ nos ajustes com a função de ligação incorreta, quando $\phi=120$. Pode-se verificar também que com o aumento da dispersão $\phi$ os resultados são mais afastados do esperado nos ajustes com a função de ligação incorreta.

Nas Tabelas B.33 a B.36 são apresentados os resultados para as médias no intervalo [0.430; 0.592], obtidas com $\beta=(0.3 ;-0.4 ; 0.4)$ e réplicas na matriz $X$. Observou-se a partir dessas tabelas que há aproximação maior aos resultados esperados nos ajustes com a função de ligação correta, com taxas de cobertura em torno de $95 \%$ e medidas de balanceamento próximos de zero. Nos ajustes com a função de ligação incorreta as taxas de cobertura ficaram próximas de $95 \%$ e as medidas de balanceamento próximas de zero, porém mais afastadas de zero do que os resultados obtidos nos ajustes com a função de ligação correta. Esse desbalanceamento quando se ajusta o modelo com a função de ligação incorreta gera uma queda um pouco maior nas taxas de cobertura quando se considera $X$ sem réplicas. Por exemplo, a taxa de cobertura mínima obtida nos ajustes 
Tabela 2.7: Resultados dos intervalos de confiança para as respostas médias: taxas de cobertura mínima e média, balanceamentos mínimo e máximo; ligação correta log-log, ligação incorreta logito, planejamento com réplicas e $\mu_{t} \in[0.026 ; 0.087]$, planejamento sem réplicas e $\mu_{t} \in[0.020 ; 0.150]$ e $n=500$.

\begin{tabular}{cccccc}
\hline \hline & & \multicolumn{2}{c}{ Com Réplicas } & \multicolumn{2}{c}{ Sem Réplicas } \\
& Medidas & Correta & Incorreta & Correta & Incorreta \\
\hline \multirow{2}{*}{$\phi=20$} & CobMin(\%) & 94.7 & 91.8 & 94.5 & 61.5 \\
& CobMed(\%) & 94.9 & 94.0 & 94.9 & 90.9 \\
& BalanMax(\%) & 0.8 & 5.8 & 1.3 & 13.4 \\
& BalanMin(\%) & 0.1 & -6.9 & 0.1 & -38.4 \\
\hline \multirow{2}{*}{$\phi=120$} & CobMin(\%) & 94.7 & 76.2 & 94.4 & 2.6 \\
& CobMed(\%) & 95.0 & 90.4 & 94.7 & 77.3 \\
& BalanMax(\%) & 0.5 & 13.2 & 0.9 & 45.9 \\
& BalanMin(\%) & 0.1 & -23.6 & -0.2 & -97.4 \\
\hline \hline
\end{tabular}

com a função de ligação incorreta foi $83.5 \%$ para $n=500, \phi=120$ e sem réplicas na matriz $X$, enquanto que no mesmo ajuste considerando réplicas na matriz $X$ esse valor mínimo foi de $91.3 \%$.

Pelas Tabelas B.37 a B.40 bons resultados são observados nos ajustes com a função de ligação correta e incorreta para o cenário com réplicas na matriz $X$ e médias no intervalo $[0.932 ; 0.974]$, obtidas para $\beta=(0.7 ; 1.1 ; 2.1)$. Mais especificamente, a taxa de cobertura aumenta e a medida de balanceamento se aproxima de zero com o aumento do tamanho amostral, para todo $\phi$. Os resultados verificados sem réplicas na matriz $X$ são semelhantes aos obtidos nos ajustes considerando réplicas nesta matriz.

Pode-se notar em todas simulações realizadas que as estimativas para a dispersão $\phi$ são sempre próximas nos dois modelos ajustados, com cobertura e balanceamento similares em todos os casos.

De forma geral, verificou-se que os ajustes com a função de ligação correta e a incorreta trouxeram bons resultados quando as médias estão em torno de 0.5 e próximas de 1, com um pequeno afastamento do esperado para as médias em torno de 0.5. Considerando as médias próximas de 0 nos ajustes com a função de ligação correta os resultados estiveram dentro do esperado, já nos ajustes com a função de ligação incorreta as taxas de cobertura são baixas para algumas médias, e os resultados tendem a se afastar do esperado com o aumento do tamanho amostral, aumento de $\phi$ e quando não se consideram réplicas na matriz $X$. 


\subsubsection{Discussão dos Resultados das Simulações}

Nos casos 1 e 2, quando se utilizaram as funções de ligação logito e probito, os resultados para taxa de cobertura e balanceamento foram observados como esperado. As taxas de cobertura se aproximaram de $95 \%$ e as medidas de balanceamento se aproximaram de 0 , independente da dispersão $\phi$ ser alta ou baixa e de haver réplicas ou não na matriz $X$.

A má especificação da função de ligação afetou os resultados da taxa de cobertura das médias e do balanceamento quando a função de ligação verdadeira era a complemento log-log ou a log-log e se ajustaram os modelos com função de ligação logito (casos 3 e 4). Quando a função de ligação verdadeira era a complemento log-log os resultados ficaram abaixo do esperado para as médias em torno de 0.5 e próximas de 1 . Já quando a função de ligação verdadeira era a log-log os resultados foram comprometidos para situação em que as médias são próximas de 0. Essas quedas nas taxas de cobertura e aumento das medidas de balanceamento para alguns casos foram observados mais claramente para amostras grandes, valores altos de $\phi$ e para o planejamento sem réplicas na matriz $X$.

\subsection{Avaliação da Adequação da Função de Ligação}

Algumas medidas de adequação dos modelos serão analisadas nesta seção para verificar se são úteis para detectar a especificação incorreta da função de ligação nos modelos de regressão beta. A análise inicial será a dos resíduos. Os resíduos a serem tratados aqui neste trabalho serão: resíduos ordinários padronizados definidos por Ferrari \& CribariNeto (2004) e resíduos ponderados padronizados 1 e 2 definidos por Espinheira, Ferrari \& Cribari-Neto (2007). Esses resíduos podem ser descritos por:

- resíduos ordinários padronizados: $r_{t}=\frac{y_{t}-\hat{\mu}_{t}}{\sqrt{\widehat{\operatorname{var}}\left(y_{t}\right)}} ;$

- resíduos ponderados padronizados $1: r_{t}^{p}=\frac{y_{t}^{*}-\hat{\mu}_{t}^{*}}{\sqrt{\widehat{\operatorname{var}}\left(y_{t}^{*}\right)}}$

- resíduos ponderados padronizados 2: $r_{t}^{p p}=\frac{y_{t}^{*}-\hat{\mu}_{t}^{*}}{\sqrt{\widehat{\operatorname{var}}\left(y_{t}^{*}\right)\left(1-h_{t t}\right)}} ;$ 
onde $\widehat{\operatorname{var}}\left(y_{t}\right)=\hat{\mu}_{t}\left(1-\hat{\mu}_{t}\right) /(1+\hat{\phi}), \quad \widehat{\operatorname{var}}\left(y_{t}^{*}\right)=\hat{v}_{t}=\psi^{\prime}\left(\hat{\mu}_{t} \phi\right)+\psi^{\prime}\left(\left(1-\hat{\mu}_{t}\right) \hat{\phi}\right), h_{t t}$ denota o $t$-ésimo elemento da diagonal de $\left.H=\hat{W}^{1 / 2} X(X\rceil \hat{W} X\right)^{-1} X \top \hat{W}^{1 / 2}$ (W foi definido na Seção 1.3), $y_{t}^{*}$ é o logito de $y_{t}$ e $\hat{\mu}_{t}^{*}$ seu valor esperado. As quantidades são estimadas a partir de $\hat{\mu}_{t}=g^{-1}\left(x_{t}^{\top} \hat{\beta}\right)$, sendo $\hat{\beta}$ e $\hat{\phi}$ os estimadores de máxima verossimilhança de $\beta$ e $\phi$ respectivamente.

Os três resíduos descritos acima foram obtidos para uma amostra em cada caso em que a especificação incorreta da função de ligação afetou as taxas de cobertura e as medidas de balanceamento, conforme visto na seção anterior. Os casos considerados foram: função de ligação verdadeira complemento log-log com as médias próximas de 1 e em torno de 0.5 e função de ligação verdadeira log-log com as médias próximas de 0 . A função de ligação incorreta que produziu taxas de cobertura ruins nestes casos é a logito.

Foram construídos os gráficos de cada um dos três resíduos contra os índices das observações e gráficos quantil-quantil com envelopes simulados, proposto por Atkinson (1985), para todas as amostras. Observou-se na comparação dos gráficos para os três resíduos que o comportamento dos resíduos são próximos, portanto serão apresentados neste trabalho apenas os gráficos obtidos com os resíduos ponderados padronizados 2, que são os resíduos recomendados por Espinheira, Ferrari \& Cribari-Neto (2007).

Além dos gráficos anteriores foi construído o gráfico da variável dependente modificada $z_{\text {mod }}$ contra o preditor linear $\eta$, que segundo Paula (2004) e Demetrio (2001) pode servir para verificar a adequação da função de ligação nos estudos de MLG; esse gráfico deve ser próximo a uma reta se a função de ligação utilizada for satisfatória. A variável dependente modificada pode ser obtida por $z_{\bmod }=\eta+W^{-1} T\left(y^{*}-\mu^{*}\right)$, sendo as quantidades definidas na Seção 1.3 (detalhes em Espinheira, Ferrari \& Cribari-Neto, 2007).

Na Figura 2.1 são mostrados os resultados dos ajustes dos modelos de regressão beta com as funções de ligação logito e complemento log-log para uma amostra de dados simulada a partir da função de ligação verdadeira: complemento $\log -\log \operatorname{com} n=500$, $\phi=120$ e $\mu_{t} \in[0.844 ; 0.982]$. Na Figura 2.2 o cenário considerado é semelhante ao descrito para a Figura $2.1 \mathrm{com}$ a diferença que $\mu_{t} \in[0.291 ; 0.829]$. Na Figura 2.3 são mostrados os resultados dos ajustes dos modelos de regressão beta com as funções de ligação logito e log-log para uma amostra de dados simulada a partir da função de ligação $\log -\log \operatorname{com} n=500, \phi=120$ e $\mu_{t} \in[0.019 ; 0.159]$. Os valores escolhidos para $\beta$ para obtenção das médias $\mu_{t}$ nesses intervalos são os mesmos definidos na Seção 2.2; nesse caso 
foram obtidos novos números aleatórios para matriz de planejamento sem réplicas, e por isso os intervalos para as médias não são exatamente os mesmos obtidos anteriormente.

Resíduo ponderado padronizado 2

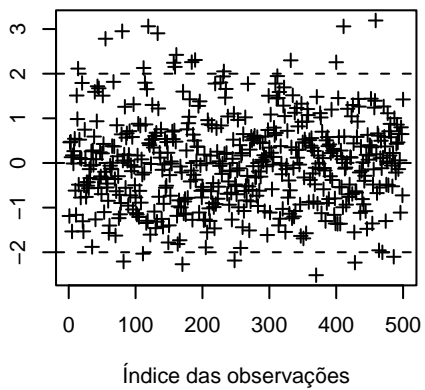

Resíduo ponderado padronizado 2

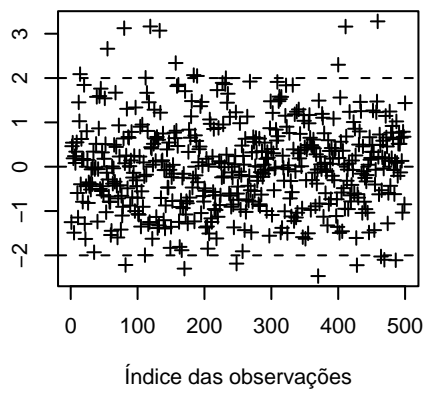

Resíduo ponderado padronizado 2

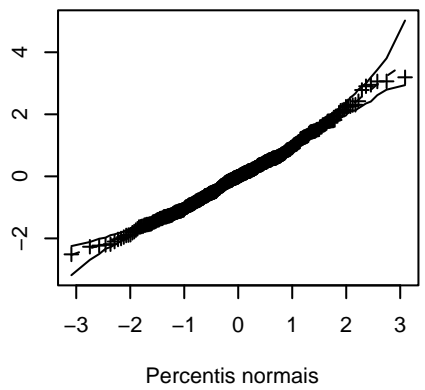

(a)Ajuste com ligação logito (incorreta)

Resíduo ponderado padronizado 2

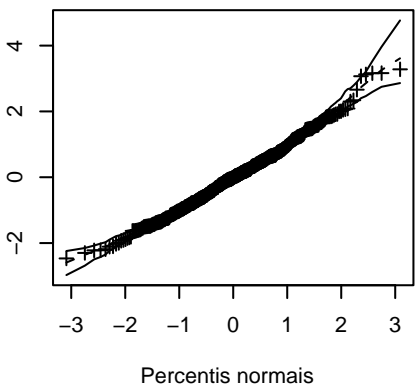

Variável dependente modificada

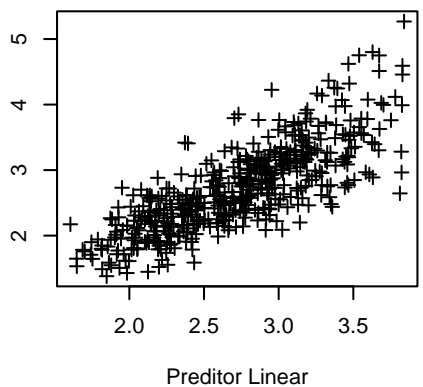

Variável dependente modificada

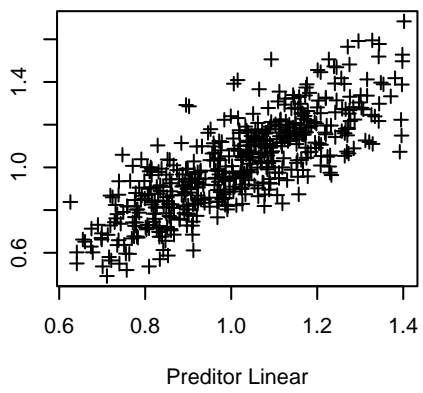

(b)Ajuste com ligação complemento log-log (correta)

Figura 2.1: Gráficos de resíduos e variável dependente modificada - função de ligação verdadeira complemento log-log e $\mu_{t} \in[0.844 ; 0.982]$.

Em todas as figuras apresentadas notam-se que nos gráficos dos resíduos contra os índices das observações há dispersão aparentemente aleatória destes resíduos com alguns pontos acima de 2 e abaixo de -2 , sendo estes resultados semelhantes na comparação dos ajustes (com as funções de ligação correta e incorreta). Nos gráficos quantil-quantil com envelopes simulados não há nenhuma evidência no ajuste com a função de ligação incorreta que o diferencie dos resultados obtidos com a função de ligação correta. Nos gráficos da variável dependente modificada contra o preditor linear se verifica uma tendência linear para todos os ajustes utilizando a função de ligação correta. Já nos ajustes utilizando a função de ligação logito (incorreta) com dados simulados com a função de ligação complemento log-log nota-se relação ligeiramente não linear entre a variável dependente modificada contra o preditor linear. No caso em que os dados foram simulados utilizando a função de ligação log-log e ajustou-se o modelo com a função logito (incorreta) foi ve- 
Resíduo ponderado padronizado 2

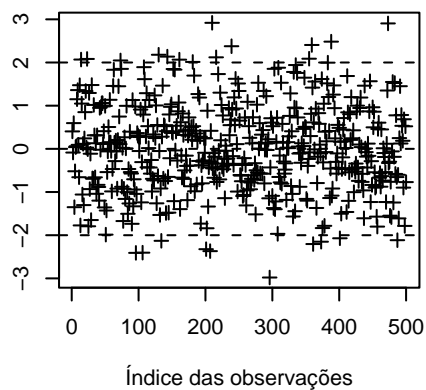

Resíduo ponderado padronizado 2

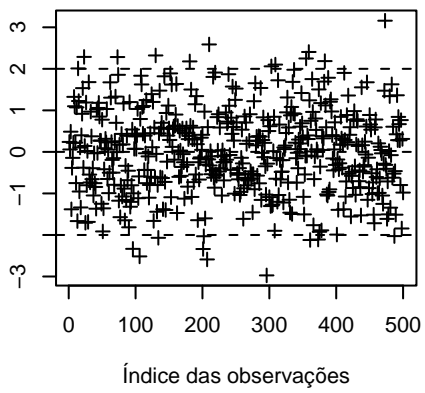

Resíduo ponderado padronizado 2

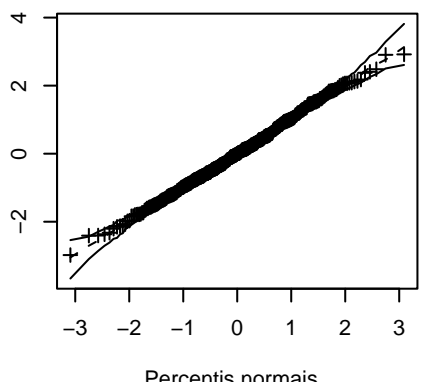

(a)Ajuste com ligação logito (incorreta)

Resíduo ponderado padronizado 2

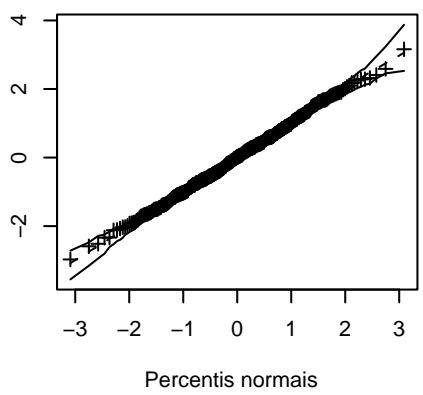

Variável dependente modificada

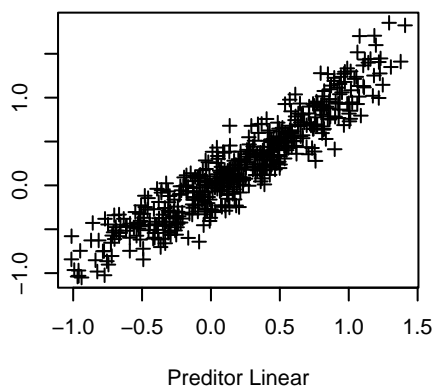

Variável dependente modificada

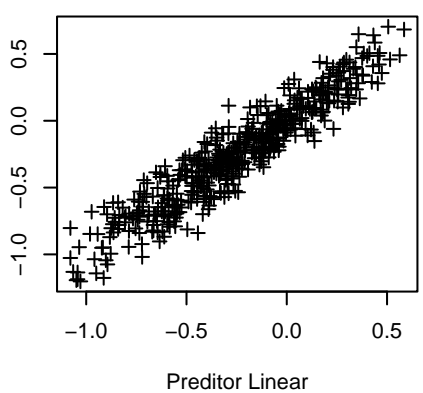

(b)Ajuste com ligação complemento log-log (correta)

Figura 2.2: Gráficos de resíduos e variável dependente modificada - função de ligação verdadeira complemento log-log e $\mu_{t} \in[0.291 ; 0.829]$.

rificada tendência linear na relação da variável dependente modificada com o preditor linear.

Foram avaliadas também algumas medidas de influência, por exemplo, distância de Cook e influência local, desenvolvidas por Espinheira Ospina (2007) no modelo de regressão beta. Essas não detectaram nenhuma evidência da especificação incorreta da função de ligação e por isso não estão aqui apresentadas.

O teste escore baseado no teste RESET (Lima, 2007) foi aplicado para verificar se a especificação incorreta da função de ligação pode ser detectada. O teste escore é aplicado para testar a hipótese nula $\gamma=0$ (o modelo está bem especificado) contra a hipótese alternativa $\gamma \neq 0$ (o modelo está mal especificado) na regressão aumentada $g(\mu)=X \beta+Z \gamma$, onde $Z$ é uma matriz $n \times s$ de variáveis de teste e $\gamma$ é um vetor $s \times 1$ de parâmetros. A estatística do teste utilizada é a estatística escore do teste da exclusão dos termos adicionais neste modelo. A variável de teste utilizada neste estudo é $\hat{\eta}_{t}^{2}$ e os resultados dos testes são apresentados na Tabela 2.8 . 
Resíduo ponderado padronizado 2

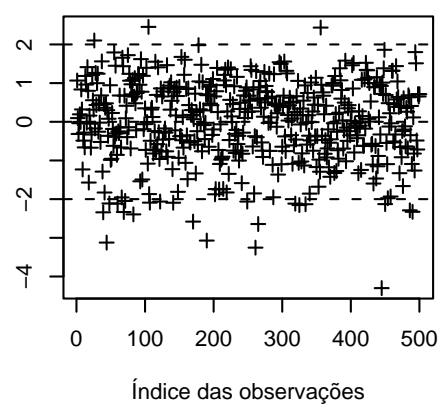

Resíduo ponderado padronizado 2

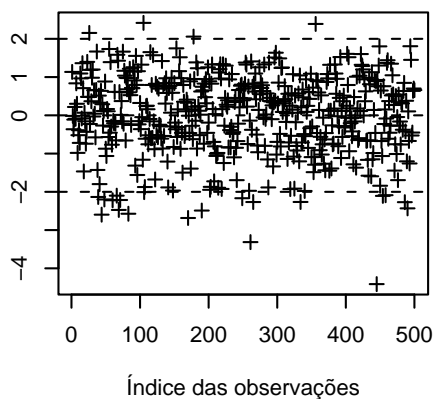

Resíduo ponderado padronizado 2

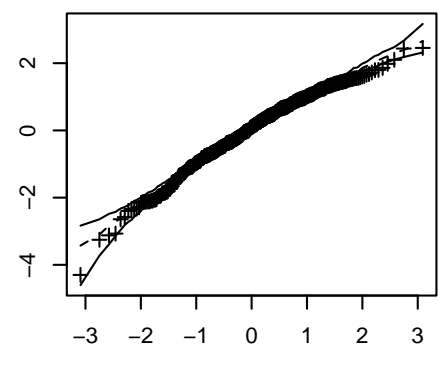

Percentis normais

(a)Ajuste com ligação logito (incorreta)

Resíduo ponderado padronizado 2

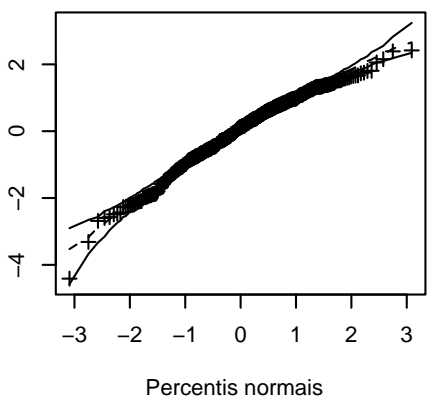

(b)Ajuste com ligação log-log (correta)
Variável dependente modificada

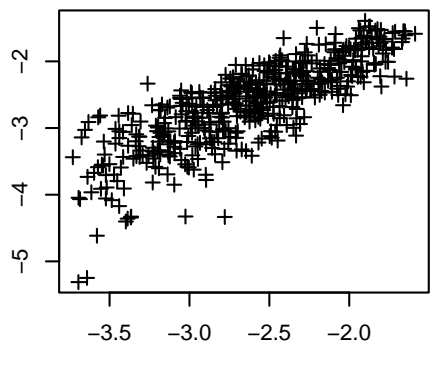

Preditor Linear

Variável dependente modificada

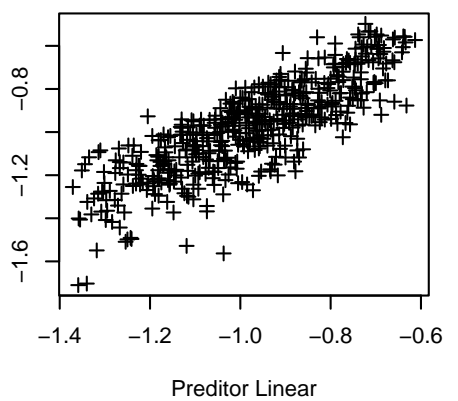

Figura 2.3: Gráficos de resíduos e variável dependente modificada - função de ligação verdadeira $\log -\log$ e $\mu_{t} \in[0.019 ; 0.159]$.

Tabela 2.8: $P$-valor obtido no teste escore para variável adicional $\hat{\eta}_{t}^{2}$.

\begin{tabular}{ccccc}
\hline \hline \multicolumn{2}{c}{ Função de ligação } & Intervalo das & \multicolumn{2}{c}{$\begin{array}{c}\text { Ajuste com função de ligação } \\
\text { Incorreta }\end{array}$} \\
Correta & Incorreta & médias $\mu_{t}$ & Correta & 0.0572 \\
comp log-log & logito & {$[0.844 ; 0.982]$} & 0.6688 & $<0.0001$ \\
comp log-log & logito & {$[0.291 ; 0.829]$} & 0.1295 & 0.148 \\
log-log & logito & {$[0.019 ; 0.159]$} & 0.342 & \multicolumn{2}{l}{} \\
\hline \hline
\end{tabular}

Nota-se na Tabela 2.8 que o teste não rejeita a hipótese nula, ou seja, não há evidências de má especificação do modelo, em todos os ajustes em que a função de ligação correta foi utilizada. Nos testes realizados nos ajustes em que a função de ligação logito (incorreta) foi utilizada rejeita-se a hipótese nula ao nível de $10 \%$ quando a função de ligação complemento log-log é a verdadeira $(p$-valor $<0.10)$, indicando que o modelo não está bem especificado. No caso em que a função de ligação log-log é a correta, a hipótese nula não é rejeitada no teste para o ajuste com a função de ligação logito (incorreta).

A partir desses resultados verificou-se que os resíduos não se mostraram eficientes para detectar a especificação incorreta da função de ligação nos casos estudados. A utilização 
da variável dependente modificada detectou a especificação incorreta da função de ligação em dois dos casos avaliados, assim como o teste que utiliza a variável adicional $\hat{\eta}^{2}$.

\subsubsection{Viés Relativo dos Estimadores das Médias}

Nesta seção será estudado o viés relativo das estimativas para as médias nos ajustes com as funções de ligação correta e incorreta para os casos em que se observaram taxas de cobertura bem abaixo do esperado quando se especificou incorretamente a função de ligação.

Para obtenção do viés relativo médio foram consideradas 1000 réplicas de Monte Carlo, amostras de tamanho 500 e $\phi=120$. Para cada média $\mu_{t}, t=1, \ldots, 500$, calculou-se o viés relativo (VR) da seguinte forma:

$$
\mathrm{VR}=\frac{\left|\hat{\mu}_{\mathrm{t}}-\mu_{\mathrm{t}}\right|}{\mu_{\mathrm{t}}},
$$

onde $\hat{\mu}_{t}$ são as estimativas obtidas para as médias $\mu_{t}, t=1, \ldots, 500$, nos ajustes dos modelos de regressão beta.

As funções de ligações verdadeiras a serem utilizadas para geração dos dados simulados são as mesmas utilizadas para análise de resíduos: função de ligação complemento log-log com as médias próximas de 1 e em torno de 0.5; e função de ligação log-log com as médias próximas de 0 .

Os resultados avaliados foram vieses relativos mínimo, médio e máximo para os estimadores das médias e o gráfico com o viés médio dos estimadores de todas as médias tanto para o ajuste com função de ligação verdadeira como para o ajuste com a função de ligação logito (incorreta).

Para obtenção das médias nos intervalos de interesse foram utilizados os mesmos valores para $\beta$ mencionados na seção anterior com novos valores aleatórios para matriz de planejamento $X$. A função de ligação para geração dos dados e o intervalo obtido para as médias foram:

(i) função de ligação complemento log-log e $\mu_{t} \in[0.842 ; 0.981]$;

(ii) função de ligação complemento log-log e $\mu_{t} \in[0.295 ; 0.828]$;

(iii) função de ligação log-log e $\mu_{t} \in[0.019 ; 0.153]$.

Na Figura 2.4 são apresentados os resultados referentes aos cenários (i) e (ii). Nota-se que os vieses médios obtidos no ajuste do modelo com a função de ligação correta são sempre menores que os obtidos no ajuste com a função de ligação logito. Considerando 
ainda os dados gerados em (i) e (ii), nota-se a partir da Tabela 2.9 que o máximo dos vieses relativos obtidos nos ajustes com a função de ligação logito foram aproximadamente iguais a 0.013 e 0.081 , respectivamente. Portanto, apesar dos vieses relativos no ajuste com a função de ligação logito serem maiores, como visto na figura anterior, as estimativas de $\mu_{t}$ são consideravelmente próximas às verdadeiras médias $\mu_{t}$.

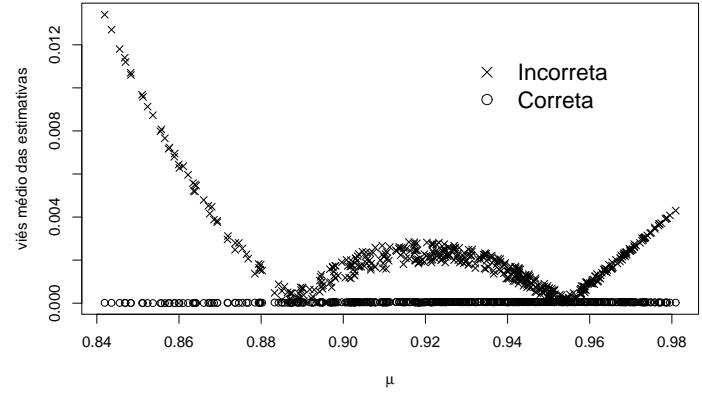

(i) $\mu_{t} \in[0.842 ; 0.981]$

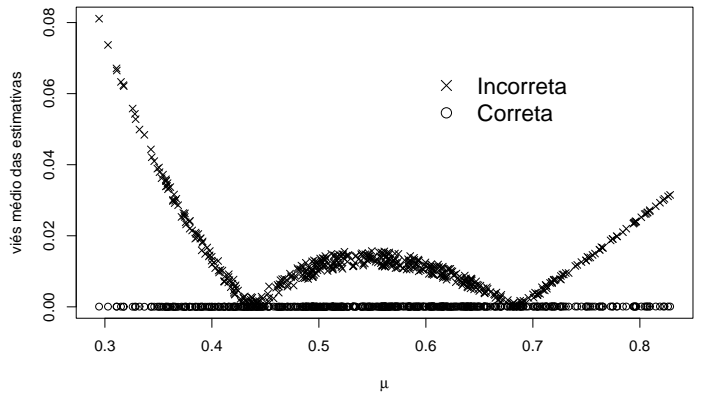

(ii) $\mu_{t} \in[0.295 ; 0.828]$

Figura 2.4: Vieses relativos dos estimadores das médias - função de ligação correta complemento log-log e incorreta logito.

Tabela 2.9: Vieses relativos mínimo, médio e máximo - função de ligação correta complemento log-log e incorreta logito.

\begin{tabular}{clc} 
& (i) $\mu_{t} \in[0.842 ; 0.981]$ \\
\hline \hline Medidas & $\begin{array}{l}\text { Função de Ligação Ajustada } \\
\text { correta }\end{array}$ & logito \\
\hline ViesRelMin & $8.11 \mathrm{E}-08$ & $2.10 \mathrm{E}-05$ \\
ViesRelMed & $4.35 \mathrm{E}-05$ & $2.00 \mathrm{E}-03$ \\
ViesRelMax & $6.14 \mathrm{E}-05$ & $1.34 \mathrm{E}-02$ \\
\hline \hline
\end{tabular}

\begin{tabular}{clc} 
& (ii) $\mu_{t} \in[0.295 ; 0.828]$ \\
\hline \hline & $\begin{array}{l}\text { Função de Ligação Ajustada } \\
\text { correta }\end{array}$ & logito \\
Medidas & . & $3.32 \mathrm{E}-05$ \\
ViesRelMin & $3.52 \mathrm{E}-07$ & $1.29 \mathrm{E}-02$ \\
ViesRelMed & $5.80 \mathrm{E}-05$ & $8.11 \mathrm{E}-02$ \\
ViesRelMax & $1.28 \mathrm{E}-04$ & \\
\hline \hline
\end{tabular}

Na Figura 2.5 são apresentados os resultados para o cenário (iii). Novamente verificase que nos ajustes com a função de ligação logito (incorreta) os vieses relativos são sempre maiores que os obtidos nos ajustes com a função ligação correta. Nota-se a partir da Tabela 2.10, ainda no cenário (iii), que os vieses relativos médios obtidos no ajuste com a função de ligação correta foram próximos de zero (máximo de 0.0001). Já para os ajustes obtidos com a função de ligação logito, verifica-se que a média dos vieses relativos foi aproximadamente igual a 0,03 e o máximo dos vieses relativos médio é aproximadamente igual a 0,21, portanto, essas diferenças podem ser consideradas altas para algumas médias $\mu_{t}$.

Nos três cenários verificou-se que o ajuste com a função de ligação logito (incorreta) apresentou vieses relativos sempre maiores que os obtidos nos ajustes com a função de 


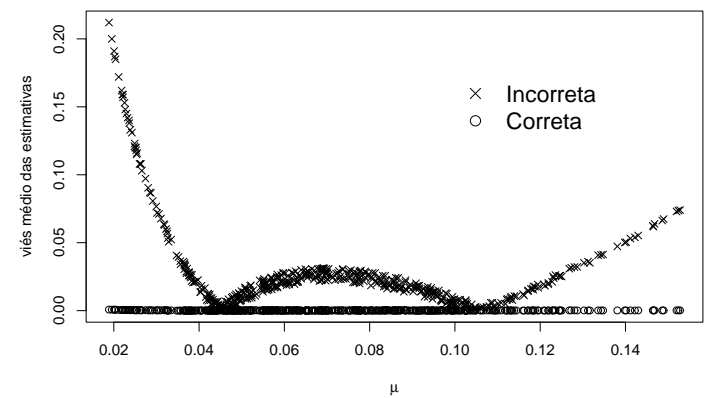

Figura 2.5: Vieses relativos dos estimadores das médias - função de ligação correta log$\log$, incorreta logito e $\mu_{t} \in[0.019 ; 0.153]$.

Tabela 2.10: Vieses relativos mínimo, médio e máximo - função de ligação correta log-log, incorreta logito e $\mu_{t} \in[0.019 ; 0.153]$.

\begin{tabular}{ccc}
\hline \hline & \multicolumn{2}{l}{ Função de Ligação Ajustada } \\
Medidas & correta & logito \\
\hline ViesRelMin & $4.72 \mathrm{E}-07$ & $2.00 \mathrm{E}-06$ \\
ViesRelMed & $1.44 \mathrm{E}-04$ & $2.78 \mathrm{E}-02$ \\
ViesRelMax & $7.96 \mathrm{E}-04$ & $2.12 \mathrm{E}-01$ \\
\hline \hline
\end{tabular}

ligação correta. No entanto, ainda que os vieses relativos sejam maiores quando se ajusta o modelo com a função de ligação logito, em média as estimativas para as médias estão próximas dos seus verdadeiros valores, portanto, os resultados podem ser bons ainda que a função de ligação de logito esteja especificada incorretamente.

\subsection{Conclusões}

Neste capítulo foi dado como foco a utilização da função de ligação logito sendo a incorreta nos ajustes de modelos de regressão beta, pois ela é mais utilizada pela facilidade de interpretação dos parâmetros de regressão. As funções de ligação probito, complemento log-log e log-log foram utilizadas como sendo as funções de ligação corretas. Para avaliação dos resultados nos ajustes foi obtida a proporção de vezes em que os verdadeiros valores para as médias estavam nos intervalos estimados com 95\% de confiança (taxa de cobertura) nas simulações de Monte Carlo. Nos casos em que a função de ligação correta era a complemento log-log e a log-log, o ajuste com a função de ligação logito (incorreta) apresentou resultados com baixas taxas de cobertura em alguns cenários estudados. Nos casos em que a função de ligação verdadeira foi a probito, os ajustes com a função de ligação logito foram considerados satisfatórios em relação às taxas de coberturas para as 
médias.

Nos casos em que a utilização da função de ligação logito (incorreta) não trouxe resultados bons em relação aos intervalos de confiança para as médias, foram feitas análises dos resíduos das observações da variável resposta, estudo da variável dependente modificada e teste RESET com a inclusão da variável $\hat{\eta}_{t}^{2}$. Dentre estas análises, o estudo da variável dependente modificada e o teste RESET foram os que detectaram a especificação incorreta da função de ligação em alguns cenários. Os resíduos não detectaram a especificação incorreta em nenhum cenário. Verificou-se através dos vieses relativos dos estimadores de máxima verossimilhança para as médias que, apesar das taxas de cobertura terem sido baixas para alguns ajustes utilizando a função de ligação logito (incorreta), as estimativas das médias estavam próximas aos seus verdadeiros valores, pois os vieses observados são pequenos. 
Capítulo 3

\section{Função de Ligação de Aranda-Ordaz}

\subsection{Introdução}

Neste capítulo será apresentado o modelo de regressão beta com a função de ligação de Aranda-Ordaz assimétrica. Essa função foi proposta por Aranda-Ordaz (1981) como uma alternativa para transformação de probabilidades, freqüentemente utilizada na análise de dados com resposta binária. Assim, essa também é uma função adequada como escolha para função de ligação no modelo de regressão beta.

A função de ligação de Aranda-Ordaz assimétrica é definida por

$$
g(\mu, \lambda)=\log \left\{\frac{(1-\mu)^{-\lambda}-1}{\lambda}\right\},
$$

onde $\mu \in(0,1)$ e $\lambda>0$. Dessa forma, escrevendo $g(\mu, \lambda)=\eta$, tem-se

$$
\mu=1-(1+\lambda \exp (\eta))^{-1 / \lambda} .
$$

As funções de ligação logito e complemento log-log são casos particulares da função de ligação de Aranda-Ordaz quando $\lambda=1$ e $\lambda \rightarrow 0$ respectivamente.

Para utilização da função de ligação de Aranda-Ordaz é necessário fixar um valor para $\lambda$ ou estimá-lo a partir dos dados. Aqui este parâmetro será estimado por máxima verossimilhança e seu estimador será avaliado a partir de simulações de Monte Carlo.

Para $\lambda$ conhecido, o processo para o ajuste do modelo de regressão beta é o mesmo descrito no Capítulo $1 \mathrm{em}$ que se estimam apenas os parâmetros $\beta$ e $\phi$. Quando $\lambda$ for desconhecido será necessário estimá-lo. Para estimar este parâmetro por máxima verossimilhança é preciso levar em consideração que $\mu_{t}$ depende de $\lambda$, como visto em 
3.1, e, portanto, deve-se obter as funções escore e a matriz de informação de Fisher para os parâmetros $\beta, \phi$ e $\lambda$, dado que a função de verossimilhança depende também do parâmetro $\lambda$ desconhecido. Os cálculos para obtenção dessas funções são apresentados na seção seguinte.

\subsection{Função Escore e Matriz de Informação}

A função de log-verossimilhança baseada em uma amostra de $n$ observações independentes com distribuição beta de média $\mu_{t}, t=1, \ldots, n$, parâmetro de dispersão $\phi$ e considerando a função de ligação de Aranda-Ordaz, que depende do parâmetro adicional $\lambda$, é dada por

$$
\ell(\beta, \phi, \lambda)=\sum_{t=1}^{n} \ell_{t}\left(\mu_{t}, \phi\right)
$$

onde

$$
\begin{aligned}
\ell_{t}\left(\mu_{t}, \phi\right)=\log \Gamma(\phi) & -\log \Gamma\left(\mu_{t} \phi\right)-\log \Gamma\left(\left(1-\mu_{t}\right) \phi\right)+\left(\mu_{t} \phi-1\right) \log y_{t} \\
& +\left\{\left(1-\mu_{t}\right) \phi-1\right\} \log \left(1-y_{t}\right)
\end{aligned}
$$

Esta função de log-verossimilhança difere da apresentada na equação (1.4) por $\mu_{t}$ depender do parâmetro adicional $\lambda$ quando a função de ligação de Aranda-Ordaz assimétrica é utilizada.

As funções escore $\left(U_{\beta}(\beta, \phi), U_{\phi}(\beta, \phi)\right)^{\top}$ obtidas pela diferenciação da função de logverossimilhança com respeito aos parâmetros $(\beta, \phi)$ dadas, respectivamente, em (1.5) e (1.6), não se alteram com a inclusão do novo parâmetro $\lambda$. Portanto, as funções escore com respeito a $\beta$ e $\phi$ podem ser escritas, respectivamente, como $U_{\beta}(\beta, \phi, \lambda)=U_{\beta}(\beta, \phi)$ e $U_{\phi}(\beta, \phi, \lambda)=U_{\phi}(\beta, \phi)$. Para obtenção da função escore para $\lambda, U_{\lambda}(\beta, \phi, \lambda)$, devese derivar a função de $\log$-verossimilhança $\ell(\beta, \phi, \lambda)$ em relação a este parâmetro como segue:

$$
\frac{\partial \ell(\beta, \phi, \lambda)}{\partial \lambda}=\sum_{t=1}^{n} \frac{\partial \ell_{t}\left(\mu_{t}, \phi\right)}{\partial \mu_{t}} \frac{\partial \mu_{t}}{\partial \lambda} .
$$

Como demonstrado por Ferrari \& Cribari-Neto (2004), tem-se que

$$
\frac{\partial \ell_{t}\left(\mu_{t}, \phi\right)}{\partial \mu_{t}}=\phi\left(y_{t}^{*}-\mu_{t}^{*}\right),
$$


onde $\left.y_{t}^{*}=\log \left\{y_{t} /\left(1-y_{t}\right)\right\}, \mu_{t}^{*}=\psi\left(\mu_{t} \phi\right)-\psi\left(\left(1-\mu_{t}\right) \phi\right)\right)$ e $\psi(\cdot)$ é a função digama. A derivada de $\mu_{t}$ em relação a $\lambda$ pode ser escrita como

$$
\begin{gathered}
\frac{\partial \mu_{t}}{\partial \lambda}=\frac{\partial\left[1-\left(1+\lambda \exp \left(\eta_{t}\right)\right)^{-1 / \lambda}\right]}{\partial \lambda} \\
=-\frac{\partial\left[\left(1+\lambda \exp \left(\eta_{t}\right)\right)^{-1 / \lambda}\right]}{\partial \lambda}=-\frac{\partial\left(\exp \left[-\frac{1}{\lambda} \log \left(1+\lambda \exp \left(\eta_{t}\right)\right)\right]\right)}{\partial \lambda} \\
=-\frac{\partial\left[-\frac{1}{\lambda} \log \left(1+\lambda \exp \left(\eta_{t}\right)\right)\right]}{\partial \lambda} \exp \left[-\frac{1}{\lambda} \log \left(1+\lambda \exp \left(\eta_{t}\right)\right)\right] \\
=\frac{\partial\left[\frac{\log \left(1+\lambda \exp \left(\eta_{t}\right)\right)}{\lambda}\right]}{\partial \lambda}\left(1+\lambda \exp \left(\eta_{t}\right)\right)^{-1 / \lambda} \\
=\frac{\frac{1}{\left(1+\lambda \exp \left(\eta_{t}\right)\right)} \exp \left(\eta_{t}\right) \lambda-\log \left(1+\lambda \exp \left(\eta_{t}\right)\right)}{\lambda^{2}}\left(1+\lambda \exp \left(\eta_{t}\right)\right)^{-1 / \lambda} \\
\left.=\frac{1}{\lambda}\left[\frac{1}{\left(\log \left(1+\lambda \exp \left(\eta_{t}\right)\right)\right.} \eta_{t}\right)+\lambda\right) \\
\lambda
\end{gathered}
$$

Finalmente, a função escore em relação a $\lambda$ pode ser escrita como

$$
U_{\lambda}(\beta, \phi, \lambda)=\phi \sum_{t=1}^{n}\left(y_{t}^{*}-\mu_{t}^{*}\right) q_{t}
$$

Para obtenção da matriz de informação de Fisher é necessário obter a segunda derivada das funções escore $U_{\lambda}(\beta, \phi, \lambda), U_{\beta}(\beta, \phi, \lambda)$ e $U_{\phi}(\beta, \phi, \lambda)$ em relação a $\lambda$.

A derivada de $U_{\lambda}(\beta, \phi, \lambda)$ em relação a $\lambda$ pode ser escrita como

$$
\frac{\partial^{2} \ell(\beta, \phi, \lambda)}{\partial \lambda^{2}}=\sum_{t=1}^{n} \frac{\partial^{2} \ell_{t}\left(\mu_{t}, \phi\right)}{\partial \mu_{t}^{2}}\left[\frac{\partial \mu_{t}}{\partial \lambda}\right]^{2}+\frac{\partial \ell_{t}\left(\mu_{t}, \phi\right)}{\partial \mu_{t}} \frac{\partial^{2} \mu_{t}}{\partial \lambda^{2}}
$$

Tem-se também que

$$
\frac{\partial^{2} \ell_{t}\left(\mu_{t}, \phi\right)}{\partial \mu_{t}^{2}}=-\phi^{2}\left\{\psi^{\prime}\left(\mu_{t} \phi\right)+\psi^{\prime}\left(\left(1-\mu_{t}\right) \phi\right)\right\} \stackrel{\text { def }}{=}-\phi^{2} v_{t}
$$

onde $v_{t}=\psi^{\prime}\left(\mu_{t} \phi\right)+\psi^{\prime}\left(\left(1-\mu_{t}\right) \phi\right)$ (ver Ferrari \& Cribari-Neto, 2004). Como $\mathrm{E}\left(\partial \ell_{t}\left(\mu_{t}, \phi\right) / \partial \mu_{t}\right)=0$, não é necessário calcular $\partial^{2} \mu_{t} / \partial \lambda^{2}$. Assim,

$$
\begin{gathered}
\mathrm{E}\left(\frac{\partial^{2} \ell(\beta, \phi, \lambda)}{\partial \lambda^{2}}\right)=\mathrm{E}\left(\sum_{t=1}^{n} \frac{\partial^{2} \ell_{t}\left(\mu_{t}, \phi\right)}{\partial \mu_{t}^{2}}\left[\frac{\partial \mu_{t}}{\partial \lambda}\right]^{2}\right) \\
=\sum_{t=1}^{n} \frac{\partial^{2} \ell_{t}\left(\mu_{t}, \phi\right)}{\partial \mu_{t}^{2}}\left[\frac{\partial \mu_{t}}{\partial \lambda}\right]^{2}=-\phi^{2} \sum_{t=1}^{n} v_{t} q_{t}^{2},
\end{gathered}
$$


que pode ser escrita em forma matricial como

$$
\mathrm{E}\left(\frac{\partial^{2} \ell(\beta, \phi, \lambda)}{\partial \lambda^{2}}\right)=-\phi^{2} \operatorname{tr}\left(V Q^{2}\right)
$$

onde $V=\operatorname{diag}\left(v_{1}, \ldots, v_{n}\right), Q=\operatorname{diag}\left(q_{1}, \ldots, q_{n}\right)$ e tr denota o "traço" da matriz.

Para obter a segunda derivada da função de log-verossimilhança em relação a $\beta_{i}$ e $\lambda$ conjuntamente deve-se considerar a primeira derivada com respeito a $\beta_{i}$ obtida por Ferrari \& Cribari-Neto (2004), dada por

$$
\frac{\partial \ell(\beta, \phi, \lambda)}{\partial \beta_{i}}=\sum_{t=1}^{n} \frac{\partial \ell_{t}\left(\mu_{t}, \phi\right)}{\partial \mu_{t}} \frac{\partial \mu_{t}}{\partial \eta_{t}} \frac{\partial \eta_{t}}{\partial \beta_{i}}
$$

Assim, a segunda derivada da função da verossimilhança com respeito a $\beta_{i}$ e $\lambda$ pode ser obtida por

$$
\frac{\partial^{2} \ell(\beta, \phi, \lambda)}{\partial \beta_{i} \partial \lambda}=\sum_{t=1}^{n}\left[\frac{\partial^{2} \ell_{t}\left(\mu_{t}, \phi\right)}{\partial \mu_{t}^{2}} \frac{\partial \mu_{t}}{\partial \lambda} \frac{\partial \mu_{t}}{\partial \eta_{t}}+\frac{\partial \ell_{t}\left(\mu_{t}, \phi\right)}{\partial \mu_{t}} \frac{\partial}{\partial \lambda}\left(\frac{\partial \mu_{t}}{\partial \eta_{t}}\right)\right] x_{t i}
$$

e como $\mathrm{E}\left(\partial \ell_{t}\left(\mu_{t}, \phi\right) / \partial \mu_{t}\right)=0$ e $\partial \mu_{t} / \partial \eta_{t}=\left[\partial g\left(\mu_{t}, \lambda\right) / \partial \mu_{t}\right]^{-1} \stackrel{\text { def }}{=} s_{t}$, tem-se

$$
\begin{gathered}
\mathrm{E}\left(\frac{\partial^{2} \ell(\beta, \phi, \lambda)}{\partial \beta_{i} \partial \lambda}\right)=\mathrm{E}\left(\sum_{t=1}^{n} \frac{\partial^{2} \ell_{t}\left(\mu_{t}, \phi\right)}{\partial \mu_{t}^{2}} \frac{\partial \mu_{t}}{\partial \lambda} \frac{\partial \mu_{t}}{\partial \eta_{t}} x_{t i}\right) \\
=\sum_{t=1}^{n} \frac{\partial^{2} \ell_{t}\left(\mu_{t}, \phi\right)}{\partial \mu_{t}^{2}} \frac{\partial \mu_{t}}{\partial \lambda} \frac{\partial \mu_{t}}{\partial \eta_{t}} x_{t i}=-\phi^{2} \sum_{t=1}^{n} v_{t} s_{t} q_{t} x_{t i}
\end{gathered}
$$

$i=0,1, \ldots, k$. Assim, em notação matricial, obtém-se

$$
\mathrm{E}\left(\frac{\partial^{2} \ell(\beta, \phi, \lambda)}{\partial \beta \partial \lambda}\right)=-\phi^{2} X^{\top} V T Q \mathbf{1}_{n}
$$

onde $X$ é a matriz $n \times(k+1)$ com as $k$ variáveis regressoras, $V$ e $Q$ foram definidos anteriormente, $T=\operatorname{diag}\left(s_{1}, \ldots, s_{n}\right)$ e $\mathbf{1}_{n}$ é um vetor coluna de uns e dimensão $n$.

A segunda derivada da função log-verossimilhança com respeito a $\lambda$ e $\phi$ pode ser escrita como

$$
\frac{\partial^{2} \ell(\beta, \phi, \lambda)}{\partial \lambda \partial \phi}=\sum_{t=1}^{n} \frac{\partial^{2} \ell_{t}\left(\mu_{t}, \phi\right)}{\partial \mu_{t} \partial \phi} \frac{\partial \mu_{t}}{\partial \lambda} .
$$

Ferrari \& Cribari-Neto (2004) mostram que

$$
\left.\frac{\partial^{2} \ell_{t}\left(\mu_{t}, \phi\right)}{\partial \mu_{t} \partial \phi}=\left\{\left(y_{t}^{*}-\mu_{t}^{*}\right)-\phi\left[\psi^{\prime}\left(\mu_{t} \phi\right) \mu_{t}-\psi^{\prime}\left(\left(1-\mu_{t}\right) \phi\right)\right)\left(1-\mu_{t}\right)\right]\right\}
$$


$\mathrm{e}$, como, $\mathrm{E}\left(y_{t}^{*}\right)=\left(\mu_{t}^{*}\right)$, tem-se

$$
\left.\mathrm{E}\left(\frac{\partial^{2} \ell(\beta, \phi, \lambda)}{\partial \lambda \partial \phi}\right)=\mathrm{E}\left(-\phi\left[\psi^{\prime}\left(\mu_{t} \phi\right) \mu_{t}-\psi^{\prime}\left(\left(1-\mu_{t}\right) \phi\right)\right)\left(1-\mu_{t}\right)\right] q_{t}\right)=-\phi \sum_{t=1}^{n} m_{t} q_{t}
$$

onde $\left.m_{t} \stackrel{\text { def }}{=} \psi^{\prime}\left(\mu_{t} \phi\right) \mu_{t}-\psi^{\prime}\left(\left(1-\mu_{t}\right) \phi\right)\right)\left(1-\mu_{t}\right)$. Em forma matricial, tem-se

$$
\mathrm{E}\left(\frac{\partial^{2} \ell(\beta, \phi, \lambda)}{\partial \lambda \partial \phi}\right)=-\phi \operatorname{tr}(M Q)
$$

onde $Q$ foi definido anteriormente e $M=\operatorname{diag}\left(m_{1}, \ldots, m_{n}\right)$.

Pode-se então reescrever a matriz de informação de Fisher para $(\beta, \phi$ e $\lambda)$ como

$$
K=K(\beta, \phi, \lambda)=\left(\begin{array}{ccc}
K_{\beta \beta} & K_{\beta \phi} & K_{\beta \lambda} \\
K_{\phi \beta} & K_{\phi \phi} & K_{\phi \lambda} \\
K_{\lambda \beta} & K_{\lambda \phi} & K_{\lambda \lambda}
\end{array}\right)
$$

onde $K_{\beta \beta}=\phi X^{\top} W X, K_{\beta \phi}=K_{\phi \beta}^{\top}=X^{\top} T c, K_{\beta \lambda}=K_{\lambda \beta}^{\top}=\phi^{2} X^{\top} V T Q I_{n}, K_{\phi \phi}=\operatorname{tr}(D)$, $K_{\phi \lambda}=K_{\lambda \phi}^{\top}=\phi \operatorname{tr}(M Q)$ e $K_{\lambda \lambda}=\phi^{2} \operatorname{tr}\left(V Q^{2}\right)$.

Para obtenção dos estimadores de máxima verossimilhança dos parâmetros $\beta, \phi$ e $\lambda$ seria suficiente encontrar os valores desses parâmetros que fossem solução das equações $U_{\beta}(\beta, \phi, \lambda)=0, U_{\phi}(\beta, \phi, \lambda)=0$ e $U_{\lambda}(\beta, \phi, \lambda)=0$. Como visto na Seção 1.3.1, não há uma forma fechada para estes estimadores. Portanto, um algoritmo de otimização não linear deverá ser utilizado para maximização da função de verossimilhança. Para isso são necessárias as escolhas dos valores iniciais para os parâmetros a serem maximizados. Adotou-se que o valor inicial para $\lambda$ será 1 (função de ligação logito). Os valores iniciais para $\beta$ e $\phi$ serão os mesmos sugeridos por Ferrari \& Cribari-Neto (2004), já apresentados na Seção 1.3.1.

\subsection{Avaliação dos Estimadores dos Parâmetros}

Nesta seção será estudado o comportamento dos estimadores de máxima verossimilhança do modelo de regressão beta com a função de ligação de Aranda-Ordaz.

Para avaliação dos estimadores foram realizadas 1000 réplicas de Monte Carlo ajustando-se em cada uma das réplicas o modelo de regressão beta para um vetor resposta aleatória $y=\left(y_{1}, y_{2}, \ldots, y_{n}\right)$ obtido da distribuição beta, com $y_{t} \sim \operatorname{Beta}\left(\mu_{t}, \phi\right), t=1, \ldots, n$, 
sendo $\phi$ fixado e $\mu_{t}$ obtido a partir da função de ligação de Aranda-Ordaz para um determinado conjunto de parâmetros $\beta$ e $\lambda$. Assim como foi definido no Capítulo 2, $\beta=\left(\beta_{0}, \beta_{1}, \beta_{2}\right)$ é o vetor dos parâmetros relacionados às colunas da matriz $X$, que é a matriz regressora composta por uma coluna de uns (representando o intercepto) e duas colunas representando variáveis regressoras obtidas a partir da distribuição uniforme $(0,1)$. O parâmetro de dispersão é dado por $\phi$ e $\lambda$ é o parâmetro adicional da função de ligação de Aranda-Ordaz. Em cada réplica de Monte Carlo são obtidas as estimativas e os intervalos de confiança com coeficiente de confiança de $95 \%$ para cada um dos parâmetros $\beta_{0}, \beta_{1}, \beta_{2}, \phi$ e $\lambda$.

Como resultado final das simulações serão apresentadas algumas medidas resumos das 1000 estimativas dos parâmetros $\beta_{0}, \beta_{1}, \beta_{2}, \phi$ e $\lambda$. São elas: média, desvio padrão (DP), viés, erro quadrático médio (EQM), assimetria (Assim.), curtose (Curt.), taxa de cobertura (TCob.), média dos limites inferiores (LI) e média dos limites superiores (LS) dos intervalos de confiança. A taxa de cobertura, que indica a proporção de vezes em que se encontra o verdadeiro parâmetro no intervalo de confiança estimado, é esperada ser em torno de 95\%. Para assimetria e curtose esperam-se valores em torno de zero, pois assintoticamente os estimadores têm distribuição normal.

Foram utilizados diferentes tamanhos amostrais $(n=100,500$ e 2000) e diferentes valores para o parâmetro adicional $(\lambda=0.1,0.5,5.0$ e 10.0). Um ponto a ressaltar é que se a estimativa de $\lambda$ não estiver próxima do valor verdadeiro não se deve esperar estimativas de $\beta$ e $\phi$ próximas aos seus verdadeiros valores, pois diferentes valores de $\lambda$ correspondem a diferentes funções de ligação.

Na Tabela 3.1 são apresentados os resultados das estimativas dos parâmetros quando os verdadeiros parâmetros são $\beta_{0}=-0.5, \beta_{1}=-0.3, \beta_{2}=-1.3, \phi=120$ e $\lambda=0.1$. De forma geral, pode-se verificar que as estimativas para os parâmetros melhoram com o aumento do tamanho da amostra. Por exemplo, a estimativa média para $\lambda$ quando $n=100$ é 1.194 e quando $n=2000$ é 0.11 , sendo a última muito próxima do valor verdadeiro. Com o aumento do tamanho amostral verifica-se que: diminuem o desvio padrão, o víes e o erro quadrático médio das estimativas; a taxa de cobertura se aproxima do valor nominal de 95\%; e a assimetria e a curtose se aproximam de zero.

Na Tabela 3.2 são apresentados os resultados considerando os seguintes valores verdadeiros para os parâmetros $\beta_{0}=0.7, \beta_{1}=1.0, \beta_{2}=-1.0, \phi=120$ e $\lambda=0.5$. Nota-se neste caso que as médias das estimativas para os parâmetros são próximas dos verdadei- 
Tabela 3.1: Medidas amostrais dos estimadores dos parâmetros de regressão e dispersão, $\theta=\left(\beta_{0} ; \beta_{1} ; \beta_{2} ; \phi ; \lambda\right)^{\top}=(-0.5 ;-0.3 ;-1.3 ; 120.0 ; 0.1)^{\top}$, com covariáveis uniformes.

\begin{tabular}{|c|c|c|c|c|c|c|c|c|c|c|}
\hline $\mathbf{n}$ & Est. & Médias & $\overline{\overline{\text { DP }}}$ & $\overline{\overline{V i e ́ s}}$ & $\overline{\overline{\text { EQM }}}$ & $\overline{\text { Assim }}$ & Curt. & $\overline{\text { Tcob. }}$. & $\overline{\overline{\mathbf{L I}}}$ & $\overline{\mathrm{LS}}$ \\
\hline \multirow{5}{*}{100} & $\beta_{0}$ & $\overline{0.002}$ & 5.091 & 0.502 & 5.115 & 14.565 & 219.735 & $\overline{93.0}$ & -166.78 & 166.783 \\
\hline & $\beta_{1}$ & -0.387 & 0.845 & -0.087 & 0.849 & -14.302 & 215.997 & 91.7 & -30.691 & 29.916 \\
\hline & $\beta_{2}$ & -1.679 & 3.752 & -0.379 & 3.771 & -14.644 & 223.71 & 92.6 & -121.315 & 117.957 \\
\hline & $\phi$ & 127.985 & 18.782 & 7.985 & 20.409 & 0.685 & 0.897 & 94.8 & 92.607 & 163.364 \\
\hline & $\lambda$ & 1.194 & 10.514 & 1.094 & 10.571 & 13.755 & 201.687 & 94.1 & -341.216 & 0.604 \\
\hline \multirow{5}{*}{500} & $\beta_{0}$ & -0.485 & 0.229 & 0.015 & 0.229 & 0.562 & 0.752 & 94.1 & -0.925 & -0.045 \\
\hline & $\beta_{1}$ & -0.305 & 0.054 & -0.005 & 0.054 & -0.597 & 0.78 & 95.0 & -0.406 & -0.203 \\
\hline & $\beta_{2}$ & -1.313 & 0.168 & -0.013 & 0.169 & -0.572 & 0.735 & 93.9 & -1.636 & -0.989 \\
\hline & $\phi$ & 121.653 & 7.636 & 1.653 & 7.813 & 0.281 & 0.404 & 94.5 & 106.615 & 136.691 \\
\hline & $\lambda$ & 0.127 & 0.842 & 0.027 & 0.843 & 0.374 & 0.368 & 94.1 & -1.51 & 1.763 \\
\hline \multirow{5}{*}{2000} & $\beta_{0}$ & -0.495 & 0.118 & 0.005 & 0.118 & 0.203 & 0.209 & 94.6 & -0.716 & -0.275 \\
\hline & $\beta_{1}$ & -0.302 & 0.026 & -0.002 & 0.026 & -0.183 & 0.017 & 94.1 & -0.351 & -0.253 \\
\hline & $\beta_{2}$ & -1.304 & 0.087 & -0.004 & 0.087 & -0.225 & 0.24 & 93.7 & -1.465 & -1.142 \\
\hline & $\phi$ & 120.498 & 3.797 & 0.498 & 3.829 & 0.239 & 0.125 & 95.0 & 113.05 & 127.946 \\
\hline & $\lambda$ & 0.11 & 0.442 & 0.01 & 0.443 & 0.105 & 0.091 & 94.1 & -0.719 & 0.94 \\
\hline
\end{tabular}

ros valores quando $n=500$. Pode-se ver, por exemplo, que para este tamanho amostral as estimativas médias para os parâmetros $\beta_{0}, \beta_{1}, \beta_{2}$, e $\lambda$ são de $0.708,1.007,-1.008$, e 0.505 respectivamente.

Tabela 3.2: Medidas amostrais dos estimadores dos parâmetros de regressão e dispersão, $\theta=\left(\beta_{0} ; \beta_{1} ; \beta_{2} ; \phi ; \lambda\right)^{\top}=(0.7 ; 1.0 ;-1.0 ; 120.0 ; 0.5)^{\top}$, com covariáveis uniformes.

\begin{tabular}{ccccccccccc}
\hline \hline $\mathbf{n}$ & Est. & Médias & DP & Viés & EQM & Assim & Curt. & Tcob. & LI & LS \\
\hline \multirow{6}{*}{100} & $\beta_{0}$ & 1.02 & 3.285 & 0.32 & 3.3 & 13.761 & 192.086 & 93.4 & 0.191 & 1.849 \\
& $\beta_{1}$ & 1.23 & 2.215 & 0.23 & 2.227 & 13.679 & 191.518 & 93.5 & 0.581 & 1.879 \\
& $\beta_{2}$ & -1.229 & 2.24 & -0.229 & 2.252 & -13.8 & 195.082 & 93.5 & -1.846 & -0.612 \\
& $\phi$ & 127.36 & 18.046 & 7.36 & 19.489 & 0.525 & 0.678 & 95.6 & 92.151 & 162.57 \\
& $\lambda$ & 0.759 & 2.499 & 0.259 & 2.512 & 13.219 & 181.318 & 94.5 & -0.217 & 1.735 \\
\hline \multirow{4}{*}{500} & $\beta_{0}$ & 0.708 & 0.168 & 0.008 & 0.168 & 0.655 & 0.925 & 94.5 & 0.384 & 1.032 \\
& $\beta_{1}$ & 1.007 & 0.129 & 0.007 & 0.129 & 0.666 & 1.06 & 94.6 & 0.757 & 1.258 \\
& $\beta_{2}$ & -1.008 & 0.128 & -0.008 & 0.128 & -0.68 & 0.912 & 95.1 & -1.254 & -0.762 \\
& $\phi$ & 121.389 & 7.641 & 1.389 & 7.767 & 0.284 & 0.087 & 95.3 & 106.381 & 136.396 \\
& $\lambda$ & 0.505 & 0.205 & 0.005 & 0.205 & 0.493 & 0.64 & 95.0 & 0.105 & 0.905 \\
\hline \multirow{4}{*}{2000} & $\beta_{0}$ & 0.703 & 0.08 & 0.003 & 0.08 & 0.221 & -0.11 & 95.6 & 0.546 & 0.859 \\
& $\beta_{1}$ & 1.001 & 0.06 & 0.001 & 0.06 & 0.263 & 0.096 & 95.8 & 0.881 & 1.122 \\
& $\beta_{2}$ & -1.002 & 0.061 & -0.002 & 0.061 & -0.233 & -0.13 & 95.6 & -1.122 & -0.882 \\
& $\phi$ & 120.571 & 3.915 & 0.571 & 3.957 & 0.111 & -0.194 & 95.0 & 113.118 & 128.025 \\
& $\lambda$ & 0.502 & 0.098 & 0.002 & 0.098 & 0.174 & -0.028 & 95.5 & 0.309 & 0.695 \\
\hline \hline
\end{tabular}

No cenário apresentado na Tabela 3.2 verifica-se que, com o aumento do tamanho amostral: há queda do desvio padrão, viés e erro quadrático médio; aproximação da taxa de cobertura ao valor nominal de 95\%; e a assimetria e a curtose se aproximam de zero, como esperado pela teoria assintótica dos estimadores.

Nas Tabelas 3.3 e 3.4 os verdadeiros parâmetros considerados foram, respectivamente, $\beta_{0}=0.7, \beta_{1}=1.0, \beta_{2}=-1.0, \phi=120$ e $\lambda=5 ;$ e $\beta_{0}=-0.5, \beta_{1}=-0.3, \beta_{2}=-1.3$, $\phi=120$ e $\lambda=10$. Nesses casos foram considerados maiores valores para $\lambda$ que os 
apresentados nas simulações anteriores.

Tabela 3.3: Medidas amostrais dos estimadores dos parâmetros de regressão e dispersão, $\theta=\left(\beta_{0} ; \beta_{1} ; \beta_{2} ; \phi ; \lambda\right)^{\top}=(0.7 ; 1.0 ;-1.0 ; 120.0 ; 5.0)^{\top}$, com covariáveis uniformes.

\begin{tabular}{ccccccccccc}
\hline \hline $\mathbf{n}$ & Est. & Médias & DP & Viés & EQM & Assim & Curt. & Tcob. & LI & LS \\
\hline \multirow{4}{*}{100} & $\beta_{0}$ & 7.921 & 10.988 & 7.221 & 13.149 & 0.711 & -1.322 & 49.3 & -7306.54 & 7322.38 \\
& $\beta_{1}$ & 3.965 & 4.586 & 2.965 & 5.461 & 0.821 & -0.984 & 47.6 & -2915.05 & 2922.98 \\
& $\beta_{2}$ & -3.939 & 4.54 & -2.939 & 5.408 & -0.819 & -0.988 & 47.1 & -2845.95 & 2838.07 \\
& $\phi$ & 127.498 & 18.368 & 7.498 & 19.839 & 0.5 & 0.258 & 95.4 & 92.29 & 162.71 \\
& $\lambda$ & 20.784 & 25.798 & 15.784 & 30.243 & 0.653 & -1.389 & 53.1 & -16051.11 & 16092.68 \\
\hline \multirow{4}{*}{500} & $\beta_{0}$ & 6.334 & 9.909 & 5.634 & 11.399 & 1.153 & -0.508 & 64.4 & -7853.63 & 7866.29 \\
& $\beta_{1}$ & 3.3 & 4.054 & 2.3 & 4.661 & 1.161 & -0.445 & 62.9 & -3087.08 & 3093.68 \\
& $\beta_{2}$ & -3.308 & 4.057 & -2.308 & 4.667 & -1.16 & -0.446 & 63.8 & -3082.96 & 3076.34 \\
& $\phi$ & 121.271 & 7.501 & 1.271 & 7.608 & 0.236 & 0.363 & 95.5 & 106.296 & 136.245 \\
& $\lambda$ & 17.606 & 22.902 & 12.606 & 26.142 & 1.116 & -0.57 & 67.0 & -17199.9 & 17235.1 \\
\hline \multirow{4}{*}{2000} & $\beta_{0}$ & 3.561 & 7.391 & 2.861 & 7.925 & 2.25 & 3.296 & 77.7 & -1651.3 & 1658.419 \\
& $\beta_{1}$ & 2.172 & 3.017 & 1.172 & 3.236 & 2.24 & 3.292 & 77.3 & -645.396 & 649.739 \\
& $\beta_{2}$ & -2.173 & 3.018 & -1.173 & 3.238 & -2.236 & 3.262 & 77.0 & -657.599 & 653.253 \\
& $\phi$ & 120.642 & 3.669 & 0.642 & 3.725 & 0.192 & 0.139 & 95.4 & 113.194 & 128.09 \\
& $\lambda$ & 11.477 & 17.011 & 6.477 & 18.202 & 2.208 & 3.159 & 79.7 & -3596.85 & 3619.808 \\
\hline \hline
\end{tabular}

Como se pode verificar nesses casos apresentados nas Tabelas 3.3 e 3.4 os estimadores para $\lambda, \beta_{0}, \beta_{1}$ e $\beta_{2}$ não são satisfatórios nem mesmo para $n=2000$, e as estimativas têm vieses e desvios padrão altos. Verifica-se que com o aumento do tamanho da amostra: diminuem o desvio padrão, viés e erro quadrático médio das estimativas; a taxa de cobertura aumenta e se aproxima mais do valor nominal de 95\%; e a assimetria e a curtose diminuem, mas ainda assim não estão próximas do esperado. E de acordo com esses resultados em relação ao aumento do tamanho amostral, suspeita-se que seriam necessárias amostras extremamente grandes para chegar aos resultados esperados.

Tabela 3.4: Medidas amostrais dos estimadores dos parâmetros de regressão e dispersão, $\theta=\left(\beta_{0} ; \beta_{1} ; \beta_{2} ; \phi ; \lambda\right)^{\top}=(-0.5 ;-0.3 ;-1.3 ; 120.0 ; 10.0)^{\top}$, com covariáveis uniformes.

\begin{tabular}{ccccccccccc}
\hline \hline $\mathbf{n}$ & Est. & Médias & DP & Viés & EQM & Assim & Curt. & Tcob. & LI & LS \\
\hline \multirow{4}{*}{100} & $\beta_{0}$ & 9.036 & 15.825 & 9.536 & 18.476 & 1.003 & -0.734 & 53.4 & -2857.23 & 2875.3 \\
& $\beta_{1}$ & -1.415 & 2.21 & -1.115 & 2.475 & -1.73 & 2.24 & 65.8 & -358.26 & 355.43 \\
& $\beta_{2}$ & -6.421 & 8.543 & -5.121 & 9.961 & -1.13 & -0.24 & 50.4 & -1466.55 & 1453.71 \\
& $\phi$ & 126.111 & 18.927 & 6.111 & 19.889 & 0.821 & 1.633 & 95.3 & 91.16 & 161.06 \\
& $\lambda$ & 61 & 92 & 51 & 105 & 1 & -1 & 59.0 & -16032.22 & 16154.2 \\
\hline \multirow{4}{*}{500} & $\beta_{0}$ & 4.865 & 12.751 & 5.365 & 13.834 & 2.025 & 2.395 & 75.7 & -2770.88 & 2780.61 \\
& $\beta_{1}$ & -0.97 & 1.632 & -0.67 & 1.765 & -2.28 & 4.06 & 74.2 & -395.103 & 393.162 \\
& $\beta_{2}$ & -4.114 & 6.66 & -2.814 & 7.23 & -2.042 & 2.524 & 74.1 & -1407.98 & 1399.76 \\
& $\phi$ & 121.359 & 7.752 & 1.359 & 7.87 & 0.344 & 0.47 & 94.4 & 106.317 & 136.401 \\
& $\lambda$ & 39.584 & 72.999 & 29.584 & 78.765 & 1.961 & 2.174 & 78.6 & -14915.1 & 14994.3 \\
\hline \multirow{4}{*}{2000} & $\beta_{0}$ & 0.863 & 6.446 & 1.363 & 6.589 & 5.092 & 25.361 & 88.0 & -436.459 & 438.184 \\
& $\beta_{1}$ & -0.464 & 0.773 & -0.164 & 0.791 & -5.219 & 27.64 & 87.2 & -54.227 & 53.298 \\
& $\beta_{2}$ & -2.021 & 3.346 & -0.721 & 3.423 & -5.046 & 24.981 & 87.5 & -226.307 & 222.265 \\
& $\phi$ & 120.597 & 3.786 & 0.597 & 3.833 & 0.077 & -0.161 & 94.5 & 113.123 & 128.071 \\
& $\lambda$ & 17.619 & 37.143 & 7.619 & 37.917 & 4.906 & 23.902 & 89.9 & -2368.65 & 2403.891 \\
\hline \hline
\end{tabular}

Verificou-se a partir dos resultados apresentados nessas simulações que para $\lambda=0.1 \mathrm{e}$ 
0.5 as estimativas para os parâmetros estavam próximas aos esperado para $n=2000$. Já para $\lambda=5.0$ e 10.0 as estimativas dos parâmetros não estão próximas ao esperado nem mesmo para o maior tamanho amostral avaliado, que foi $n=2000$, mas há tendência de melhoria dessas estimativas com o aumento do tamanho amostral, como verificado na comparação dos resultados para $n=100$ e $n=2000$.

Nesta seção verificou-se o comportamento das estimativas dos parâmetros $\lambda, \beta_{0}, \beta_{1}$, $\beta_{2}$ e $\phi$. Apesar delas não estarem próximas ao esperado para todos os cenários, na seção seguinte será verificado o comportamento das estimativas das médias $\mu_{t}$ nestes mesmos cenários, para os quais ajustaram-se modelos de regressão beta com função de ligação de Aranda-Ordaz, sendo esta a verdadeira função de ligação.

\subsection{Avaliação dos Estimadores para as Médias}

Nesta seção será avaliada a qualidade das inferências realizadas para as médias $\mu_{t}$ quando a função de ligação de Aranda-Ordaz é utilizada. O modelo de regressão beta com a função de ligação logito também foi utilizado nos ajustes para comparação dos resultados com essas duas funções de ligação, quando a verdadeira função de ligação é a de Aranda-Ordaz.

Nas simulações foram realizadas 1000 réplicas de Monte Carlo. Em cada uma dessas réplicas foi obtido um vetor resposta aletória $y$ com distribuição beta com médias $\mu_{t}, t=$ $1,2, \ldots, n$ e dispersão $\phi$. As médias foram obtidas por $\mu_{t}=g^{-1}\left(x_{t}^{\top} \beta\right)$ e a função de ligação considerada é a de Aranda-Ordaz com os seguintes valores para $\theta=\left(\beta_{0} ; \beta_{1} ; \beta_{2} ; \phi ; \lambda\right)^{\top}$ : $(-0.5 ;-0.3 ;-1.3 ; 120.0 ; 0.1)^{\top}, \quad(0.7 ; 1.0 ;-1.0 ; 120.0 ; 0.5)^{\top}, \quad(0.7 ; 1.0 ;-1.0 ; 120.0 ; 5.0)^{\top} \mathrm{e}$ $(-0.5 ;-0.3 ;-1.3 ; 120.0 ; 10.0)^{\top}$. A matriz regressora $X$ é composta por uns na primeira coluna, representando o intercepto, e duas colunas obtidas a partir da distribução uniforme $(0,1)$, sem réplicas. Foram utilizadas 500 observações e as médias obtidas pelos verdadeiros valores dos parâmetros do vetor $\theta$ estão respectivamente nos intervalos: [0.117;0.427], [0.476;0.922], [0.270;0.482], [0.078;0.173] e [0.412;0.884]. A partir de cada

y obtido em réplicas de Monte Carlo foram ajustados os modelos de regressão com a função de ligação de Aranda-Ordaz e logito. No ajuste com a função de ligação de Aranda-Ordaz estimaram-se todos os parâmetros do vetor $\theta$. Já para a função de ligação logito não é necessário estimar $\lambda$, pois $\lambda$ é conhecido e igual a um.

Para avaliação dos ajustes foram consideradas as taxas de cobertura mínima e média 
para as médias $\mu_{t}$, os balanceamentos mínimo e máximo e os vieses relativos mínimo, médio e máximo. Nas tabelas estas medidas serão descritas por CobMin, CobMed, BalanMax, BalanMin, ViesRelMin, ViesRelMed e ViesRelMax, respectivamente. As medidas de taxa de cobertura e balanceamento foram descritas na Seção 2.1 e o viés relativo para as médias foi descrito na Seção 2.3.1.

Como pode ser visto na Tabela 3.5 os resultados para os ajustes com a função de ligação de Aranda-Ordaz, que é a verdadeira, têm taxa de cobertura mínima em torno de $70 \%$ e média em torno de $90 \%$ para todos os cenários simulados, sendo que a taxa de cobertura esperada era de 95\%. O balanceamento que era esperado estar em torno de zero apresentou como máximo valor absoluto igual a 8.1; o víés relativo no pior dos casos é de 0.00291 .

Os resultados mostrados na Tabela 3.5 indicam que apesar das taxas de cobertura e medidas de balanceamento não estarem todas em torno do esperado, o viés relativo médio das estimativas é pequeno, mais especificamente, as estimativas para as médias são próximas dos valores verdadeiros.

Ainda na Tabela 3.5 são mostrados os ajustes obtidos com a função de ligação logito. Para esta função de ligação verificam-se alguns casos muito ruins para taxa de cobertura mínima, que chega, por exemplo, a $0.2 \%$ no cenário em que $\lambda=0.5$. Os resultados obtidos nos ajustes com a função de ligação de Aranda-Ordaz são sempre melhores que os ajustes obtidos com a função de ligação logito. No ajuste com a função de ligação logito as taxas de cobertura estão sempre mais afastadas de $95 \%$, o balanceamento com valores mais afastados de zero e os vieses são mais altos que os observados nos ajustes com a função de ligação de Aranda-Ordaz.

A partir desses resultados pode-se concluir que apesar das estimativas dos parâmetros do modelo de regressão com função de ligação de Aranda-Ordaz não serem satisfatórias para todos os cenários, como foi discutido na Seção 3.3, as estimativas obtidas para as médias $\mu_{t}$ são boas em relação aos vieses relativos, embora também as taxas de cobertura não estarem sempre próximas de $95 \%$. Pode-se verificar também que em todos os casos apresentados os resultados foram melhores sempre no ajuste com a função de ligação de Aranda-Ordaz do que no ajuste com a função de ligação logito.

Para comparar os resultados obtidos com o ajuste do modelo com as funções de ligação de Aranda-Ordaz e logito foram considerados também os cenários em que as funçõe de ligação utilizadas para simulação dos dados originais são a complemento log- 
Tabela 3.5: Resultados dos intervalos de confiança para as respostas médias: taxas de cobertura mínima e média, balanceamentos mínimo e máximo, viés relativo mínimo, médio e máximo; ligação correta de Aranda-Ordaz $(\lambda)$, ligação incorreta logito, planejamento sem réplicas, $\phi=120$ e $n=500$.

\begin{tabular}{|c|c|c|c|c|}
\hline \multicolumn{3}{|c|}{ Intervalo para } & \multicolumn{2}{|c|}{ Função de Ligação Ajustada } \\
\hline$\lambda$ & Média Verdadeira & Medidas & Aranda-Ordaz & logito \\
\hline \multirow{7}{*}{0.1} & \multirow{7}{*}[0.117;0.427]{} & CobMin(\%) & 75.1 & 57.8 \\
\hline & & CobMed $(\%)$ & 90.5 & 88.4 \\
\hline & & BalanMax $(\%)$ & 2.8 & 42.2 \\
\hline & & BalanMin(\%) & -1.6 & -25.5 \\
\hline & & ViesRelMin & $1.97 \mathrm{E}-07$ & $9.68 \mathrm{E}-06$ \\
\hline & & ViesRelMed & $3.05 \mathrm{E}-04$ & $5.89 \mathrm{E}-03$ \\
\hline & & ViesRelMax & $1.01 \mathrm{E}-03$ & $2.44 \mathrm{E}-02$ \\
\hline \multirow{7}{*}{0.5} & \multirow{7}{*}[0.476;0.922]{} & CobMin(\%) & 70.2 & 0.2 \\
\hline & & $\operatorname{CobMed}(\%)$ & 91.9 & 73.7 \\
\hline & & BalanMax $(\%)$ & 2.0 & 99.8 \\
\hline & & BalanMin(\%) & -1.3 & -55.6 \\
\hline & & ViesRelMin & $3.98 \mathrm{E}-08$ & $3.27 \mathrm{E}-05$ \\
\hline & & ViesRelMed & $9.10 \mathrm{E}-05$ & 3.90E-03 \\
\hline & & ViesRelMax & $9.34 \mathrm{E}-04$ & $3.48 \mathrm{E}-02$ \\
\hline \multirow{7}{*}{5.0} & \multirow{7}{*}[0.270;0482]{} & CobMin(\%) & 76.8 & 33.6 \\
\hline & & CobMed $(\%)$ & 92.6 & 87.9 \\
\hline & & BalanMax(\%) & 4.5 & 21.4 \\
\hline & & BalanMin(\%) & -6.3 & -66.4 \\
\hline & & ViesRelMin & $3.84 \mathrm{E}-07$ & $2.40 \mathrm{E}-05$ \\
\hline & & ViesRelMed & $3.58 \mathrm{E}-04$ & $4.53 \mathrm{E}-03$ \\
\hline & & ViesRelMax & 2.32E-03 & 3.11E-02 \\
\hline \multirow{7}{*}{10.0} & \multirow{7}{*}[0.078;0.173]{} & CobMin(\%) & 78.6 & 69.7 \\
\hline & & CobMed (\%) & 91.0 & 90.3 \\
\hline & & BalanMax(\%) & 6.2 & 21.1 \\
\hline & & BalanMin(\%) & -8.1 & -30.3 \\
\hline & & ViesRelMin & $7.04 \mathrm{E}-06$ & $4.15 \mathrm{E}-05$ \\
\hline & & ViesRelMed & 8.82E-04 & $7.62 \mathrm{E}-03$ \\
\hline & & ViesRelMax & $2.91 \mathrm{E}-03$ & $3.51 \mathrm{E}-02$ \\
\hline
\end{tabular}

log e a log-log, que são as que apresentaram problemas quanto à taxa de cobertura no ajuste com a função de ligação logito (ver Capítulo 2). Os resultados destas comparações serão explorados na seção seguinte. 


\subsubsection{Função de Ligação de Aranda-Ordaz e Logito}

No Capítulo 2 foram apresentados alguns cenários em que o ajuste com a função de ligação logito resultava em taxas de coberturas baixas para as médias. Esses casos foram utilizados aqui ajustando-se o modelo de regressão beta com a função de ligação de Aranda-Ordaz para avaliar se estes ajustes produzem melhores resultados que os obtidos pelo ajuste com a função de ligação logito. As funções de ligação verdadeiras em que se obtiveram taxas de cobertura baixas nos ajustes com a função de ligação logito foram: função de ligação complemento log-log com as médias próximas 1 e em torno de 0.5; e função de ligação log-log com as médias próximas de 0 .

Para essas comparações foram realizadas 1000 réplicas de Monte Carlo. A matriz regressora $X$ é composta por uns na primeira coluna e duas colunas obtidas a partir da distribuição uniforme $(0,1)$. As funções de ligação utilizadas para obtenção das médias $\mu_{t}=g^{-1}\left(x_{t}^{\top} \beta\right)$ e as médias consideradas para comparação dos ajustes são:

1. função de ligação verdadeira complemento log-log e $\mu_{t} \in[0.842 ; 0.981]$;

2. função de ligação verdadeira complemento log-log e $\mu_{t} \in[0.295 ; 0.828]$;

3. função de ligação verdadeira $\log -\log$ e $\mu_{t} \in[0.019 ; 0.153]$.

Os verdadeiros valores para os parâmetros $\beta_{0}, \beta_{1}$ e $\beta_{2}$ são os mesmos utilizados na Seção 2.2 para amostras de tamanho $n=500$ e $\phi=120$.

Na Tabela 3.6 são apresentadas os seguintes resultados em relação as médias $\mu_{t}$ estimadas nas 1000 réplicas de Monte Carlo: taxas de cobertura (mínima e média) e a medida de balanceamento (mínima e máxima) descritas na Seção 2.1; e o viés relativo médio (mínimo, médio e máximo) apresentado na Seção 2.3.1. Esses resultados serão apresentados para os ajustes do modelo de regressão beta obtidos com as funções de ligação de Aranda-Ordaz, logito e a função de ligação correta, que é a verdadeira função de ligação utilizada para obtenção das médias $\mu_{t}$.

Comparando-se os resultados dos ajustes obtidos com a função de ligação correta e de Aranda-Ordaz nos três casos descritos acima, verificam-se melhores ajustes considerando a função de ligação correta. No entanto, nos casos reais nunca se sabe qual é a função de ligação verdadeira e pode-se notar ainda pelos resultados apresentados na Tabela 3.6, que os ajustes com a função de ligação de Aranda-Ordaz são melhores que os obtidos com a função de ligação logito. Nos ajustes com a função de ligação de Aranda-Ordaz as taxas 
Tabela 3.6: Resultados dos intervalos de confiança para as respostas médias: taxas de cobertura mínima e média, balanceamentos mínimo e máximo, viés relativo mínimo, médio e máximo; planejamento sem réplicas, $\phi=120$ e $n=500$.

\begin{tabular}{ccccc}
\hline \hline \multirow{2}{*}{ Casos } & & \multicolumn{2}{c}{ Função de Ligação Ajustada } \\
& Medidas & correta & logito & Aranda-Ordaz \\
\hline & CobMin(\%) & 93.6 & 1.1 & 69.0 \\
& CobMed(\%) & 94.9 & 79.1 & 91.1 \\
& BalanMax(\%) & 1.0 & 42.0 & 8.2 \\
(ligação correta: & BalanMin(\%) & -1.0 & -98.9 & -16.8 \\
complemento log-log) & ViesRelMin & $4.72 \mathrm{E}-07$ & $2.00 \mathrm{E}-06$ & $5.30 \mathrm{E}-06$ \\
& ViesRelMed & $1.44 \mathrm{E}-04$ & $2.78 \mathrm{E}-02$ & $3.11 \mathrm{E}-03$ \\
& ViesRelMax & $7.96 \mathrm{E}-04$ & $2.12 \mathrm{E}-01$ & $3.61 \mathrm{E}-02$ \\
\hline & CobMin(\%) & 92.0 & 0.1 & 70.6 \\
& CobMed(\%) & 94.7 & 76.2 & 91.2 \\
& BalanMax(\%) & 0.7 & 99.9 & 1.4 \\
& BalanMin(\%) & -1.9 & -52.4 & -3.4 \\
(ligação correta: & ViesRelMin & $8.11 \mathrm{E}-08$ & $2.10 \mathrm{E}-05$ & $4.61 \mathrm{E}-07$ \\
complemento log-log) & ViesRelMed & $4.35 \mathrm{E}-05$ & $2.00 \mathrm{E}-03$ & $6.04 \mathrm{E}-05$ \\
& ViesRelMax & $6.14 \mathrm{E}-05$ & $1.34 \mathrm{E}-02$ & $3.45 \mathrm{E}-04$ \\
\hline \multirow{3}{*}{3} & CobMin(\%) & 93.9 & 0.0 & 71.1 \\
& CobMed(\%) & 95.3 & 52.4 & 91.6 \\
& BalanMax(\%) & 1.6 & 100.0 & 3.6 \\
& BalanMin(\%) & -1.1 & -95.4 & -1.9 \\
ViesRelMin & $3.52 \mathrm{E}-07$ & $3.32 \mathrm{E}-05$ & $1.90 \mathrm{E}-07$ \\
(ligação correta: & ViesRelMed & $5.80 \mathrm{E}-05$ & $1.29 \mathrm{E}-02$ & $1.25 \mathrm{E}-04$ \\
log-log) & ViesRelMax & $1.28 \mathrm{E}-04$ & $8.11 \mathrm{E}-02$ & $8.73 \mathrm{E}-04$ \\
\hline \hline
\end{tabular}

de cobertura são mais próximas ao valor nominal de $95 \%$ e as medidas de balanceamento mais próximas de zero, que é o desejável. No caso 2, por exemplo, a taxa de cobertura média observada no ajuste com a função de ligação de Aranda-Ordaz é igual a 91.2\%, enquanto nos ajustes com a função de ligação logito esta média é igual a 76.2\%. Os vieses nos ajustes com a função de ligação de Aranda-Ordaz são menores que os verificados nos ajustes com a função de ligação logito. Também pode-se verificar no caso 3, por exemplo, que nos ajustes com a função de ligação de Aranda-Ordaz o máximo dos vieses relativo médio observados foi de 0.0009 enquanto nos ajustes com a função de ligação logito esse valor é igual a 0.01 .

Na Figura 3.1 são mostrados os resultados dos vieses relativos médios obtidos para todas as médias $\mu_{t}$ nos quatro casos avaliados. É possível verificar que os vieses das estimativas são sempre maiores quando se ajusta o modelo com a função de ligação 
logito; são menores em todos os casos para o ajuste com a função de ligação correta; e quando se ajusta o modelo com a função de ligação de Aranda-Ordaz os vieses estão mais próximos aos obtidos pelo ajuste com a função de ligação correta e menores que os obtidos pela função de ligação logito.

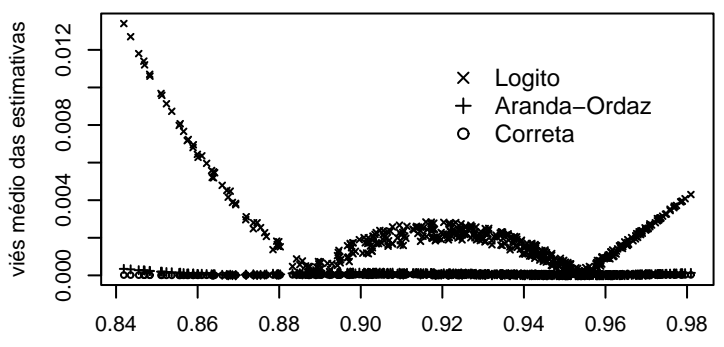

$\mu$

(a) Função de ligação correta comp. log-log

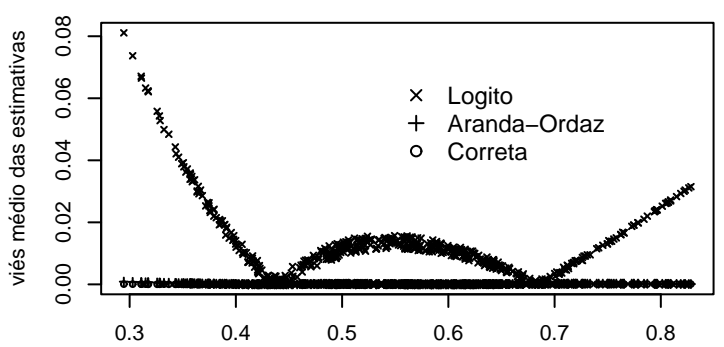

(c) Função de ligação correta comp. log-log

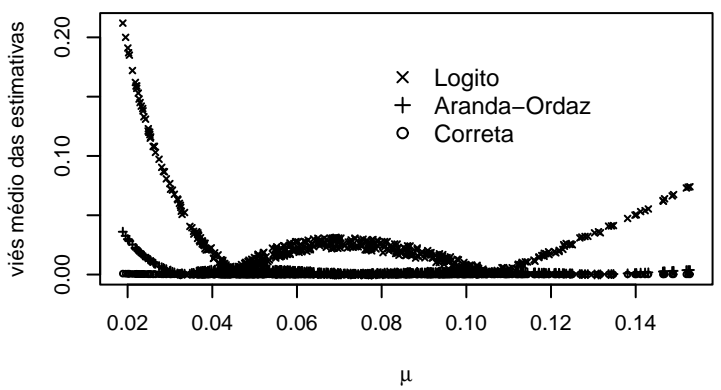

(e) Função de ligação correta log-log

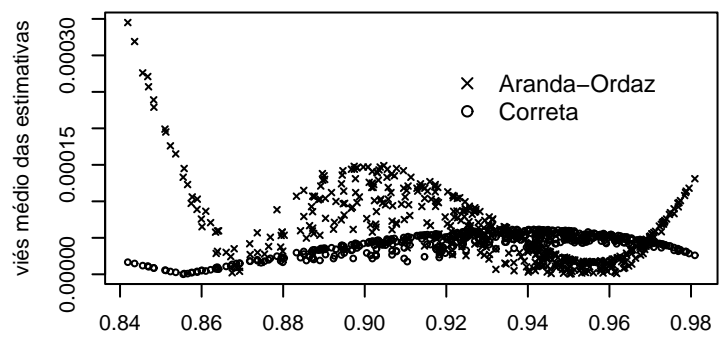

(b) Função de ligação correta comp. log-log

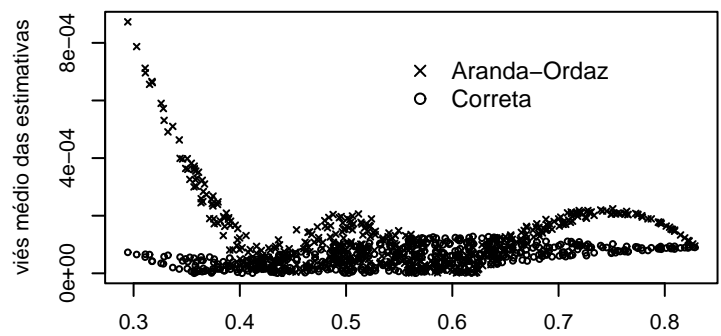

(d) Função de ligação correta comp. log-log

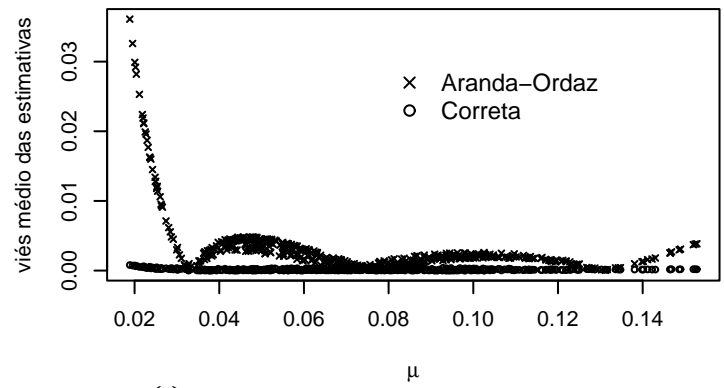

(f) Função de ligação correta log-log

Figura 3.1: Gráfico dos vieses das estimativas para as médias. 


\subsection{Conclusões}

De acordo com os resultados das simulações apresentados neste capítulo verificou-se que as estimativas para os parâmetros da regressão obtidos nos ajustes com a função de ligação de Aranda-Ordaz, quando a verdadeira função de ligação era a de Aranda-Ordaz, nem sempre trouxeram resultados próximos ao esperado em relação às taxas de cobertura e à medida de balanceamento. Pelos resultados obtidos quando se aumenta o tamanho amostral suspeita-se que para obter os resultados esperados pela teoria assintótica seriam necessárias amostras ainda maiores.

Apesar dos resultados não satisfatórios para a estimação dos parâmetros da regressão avaliaram-se as estimativas obtidas para as médias $\mu_{t}$ através das taxas de cobertura e dos vieses relativos médios e verificou-se que os resultados dos ajustes com a função de ligação de Aranda-Ordaz são sempre melhores que os obtidos com a função de ligação logito, tanto nos casos em que a verdadeira função de ligação era a de Aranda-Ordaz como nos casos em que a função de ligação verdadeira era a complemento log-log e a log-log. Portanto, em um caso real em que o interesse seja estimar as médias das observações, quando obviamente não se conhecerá a verdadeira função de ligação, a escolha pela função de ligação de Aranda-Ordaz pode trazer melhores resultados que os ajustes obtidos com a função de ligação logito. Deve-se considerar, no entanto, que se a amostra não for muito grande, o algoritmo de estimação dos parâmetros pode apresentar problemas de convergência. Adicionalmente, a função de ligação de Aranda-Ordaz não possibilita interpretação simples para os parâmetros de regressão como ocorre para a ligação logito. 
CAPÍtulo 4

\section{Aplicação}

Neste capítulo serão comparados os resultados obtidos no ajuste do modelo de regressão beta com as funções de ligação logito, log-log e de Aranda-Ordaz para dados de gasolina de Prater (1956). A variável dependente $(y)$ é a proporção de petróleo que é transformada em gasolina após o processo de destilação e fracionamento. As possíveis variáveis independentes são: gravidade do petróleo (graus API), pressão do vapor do petróleo $\left(\mathrm{Ibf} / \mathrm{in}^{2}\right)$, petróleo a $10 \%$ do ponto ASTM (i.e, a temperatura em que $10 \%$ do petróleo é vaporizado) e temperatura $\left({ }^{\circ} \mathrm{F}\right)$ em que toda a gasolina se evapora. O conjunto de dados é constituído de 32 observações para a variável resposta que foram obtidas para dez conjuntos de valores das três primeiras variáveis independentes, que correspondem aos diferentes tipos de petróleo, submetidos a experimentação sob diferentes condições de destilação. A especificação do modelo para a resposta média usa um intercepto $\left(x_{1}=1\right)$, nove variáveis dummy para os primeiros nove níveis do petróleo cru $\left(x_{2}, \ldots, x_{10}\right)$ e a temperatura em que toda a gasolina é vaporizada $\left(x_{11}\right)$. Especifica-se o modelo para as médias como

$$
g\left(\mu_{t}\right)=\beta_{1}+\beta_{2} x_{t 1}+\ldots+\beta_{11} x_{t 11},
$$

e assume-se que as observações $y_{1}, \ldots, y_{32}$ são independentes e têm distribuição beta de média $\mu_{t}$ e parâmetro de precisão $\phi$ desconhecido.

Os parâmetros deste modelo são estimados através da maximização da função de verossimilhança utilizando o método quasi-Newton BFGS com as primeiras derivadas analíticas. Os valores iniciais para os parâmetros desconhecidos são escolhidos de acordo com a proposta de Ferrari \& Cribari-Neto (2004) para as funções de ligação logito e loglog. Para função de ligação de Aranda-Ordaz é utilizada a sugestão dada no Capítulo 3 . 
Os resultados inferenciais obtidos usando as funções de ligação logito, log-log e de Aranda-Ordaz são apresentadas na Tabela 4.1.

Tabela 4.1: Estimativas dos parâmetros para os dados de gasolina de Prater, utilizando as funções de ligação logito, log-log e de Aranda-Ordaz.

\begin{tabular}{cccccccccc}
\hline \hline & & Logito & & \multicolumn{3}{c}{ Log-log } & \multicolumn{3}{c}{ Aranda-Ordaz } \\
Par. & Est. & EP. & p-valor & Est. & EP. & p-valor & Est. & EP. & p-valor \\
\hline$\beta_{1}$ & -6.160 & 0.182 & 0.000 & -2.794 & 0.058 & 0.000 & -8.800 & 0.696 & 0.000 \\
$\beta_{2}$ & 1.728 & 0.101 & 0.000 & 0.904 & 0.035 & 0.000 & 3.239 & 0.393 & 0.000 \\
$\beta_{3}$ & 1.323 & 0.118 & 0.000 & 0.655 & 0.038 & 0.000 & 2.303 & 0.285 & 0.000 \\
$\beta_{4}$ & 1.572 & 0.116 & 0.000 & 0.768 & 0.038 & 0.000 & 2.698 & 0.320 & 0.000 \\
$\beta_{5}$ & 1.060 & 0.102 & 0.000 & 0.538 & 0.034 & 0.000 & 1.899 & 0.246 & 0.000 \\
$\beta_{6}$ & 1.134 & 0.104 & 0.000 & 0.552 & 0.035 & 0.000 & 1.916 & 0.240 & 0.000 \\
$\beta_{7}$ & 1.040 & 0.106 & 0.000 & 0.520 & 0.035 & 0.000 & 1.829 & 0.239 & 0.000 \\
$\beta_{8}$ & 0.544 & 0.109 & 0.000 & 0.292 & 0.034 & 0.000 & 1.021 & 0.178 & 0.000 \\
$\beta_{9}$ & 0.496 & 0.109 & 0.000 & 0.250 & 0.035 & 0.000 & 0.882 & 0.162 & 0.000 \\
$\beta_{10}$ & 0.386 & 0.119 & 0.001 & 0.187 & 0.038 & 0.000 & 0.648 & 0.145 & 0.000 \\
$\beta_{11}$ & 0.011 & 0.000 & 0.000 & 0.005 & 0.000 & 0.000 & 0.019 & 0.002 & 0.000 \\
$\phi$ & 440.278 & 110.026 & & 906.688 & 226.638 & 0.000 & 942.458 & 235.588 & \\
$\lambda$ & & & & & & & 6.602 & 1.335 & \\
\hline \hline
\end{tabular}

O teste RESET com a variável $\hat{\eta}_{t}^{2}$, sugerido por Lima (2007), foi utilizado para testar se o modelo está corretamente especificado. Como já tinha sido mostrado no seu trabalho, o teste rejeita a hipótese nula de que o modelo esteja corretamente especificado para a função de ligação logito (estatística do teste 16.401, p-valor<0.0001) e não rejeita a hipótese nula para a função de ligação log-log (estatística do teste $1.628, p$-valor $\approx$ 0.202). Para a função de ligação de Aranda-Ordaz o teste não rejeitou a hipótese nula de que o modelo esteja bem especificado (estatística do teste $0.0005, p$-valor $\approx 0.9825$ ).

Na Figura 4.1, em que são mostrados os gráficos quantil-quantil com envelopes simulados do resíduo ponderado padronizado 2, pode-se verificar que em todos os ajustes os resíduos permanecem dentro das bandas de confiança.

A soma de quadrados dos resíduos ordinários das estimativas para as respostas médias obtidas nos ajustes do modelo de regressão beta com as funções de ligação logito, log-log e de Aranda-Ordaz são, respectivamente, iguais a 0.0092, 0.0508 e 0.0048. Dessa forma, nota-se que, apesar da hipótese do modelo estar bem especificado ter sido rejeitada para o ajuste com a função de ligação logito, a soma de quadrados dos erros neste modelo é menor que a obtida no modelo ajustado com a função de ligação log-log. 


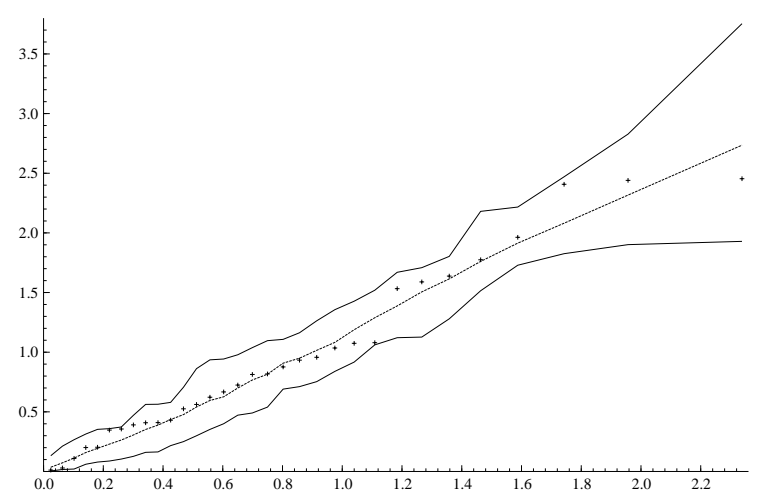

(i) Logito

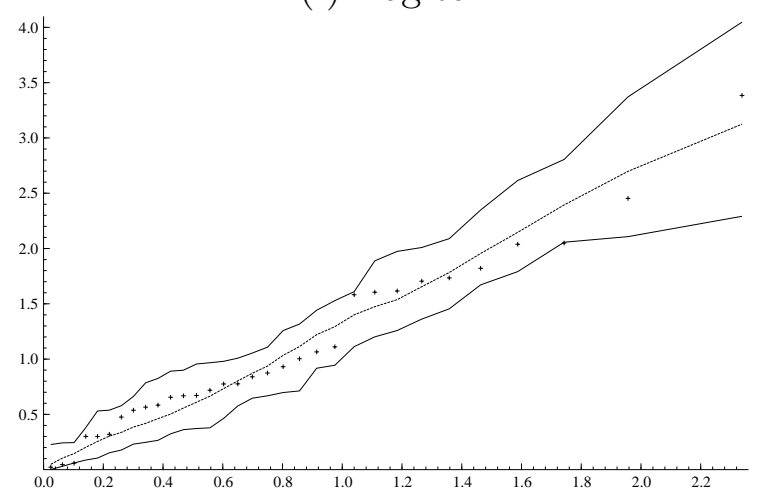

(ii) Aranda-Ordaz

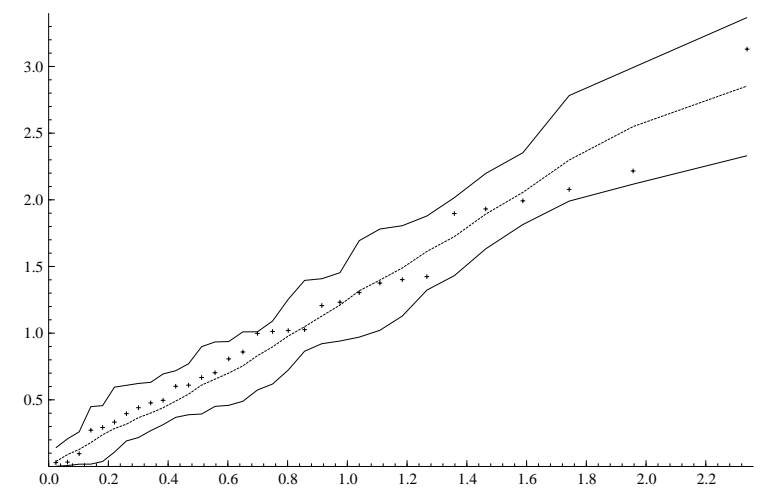

(ii) Log-log

Figura 4.1: Gráficos quantil-quantil com envelopes simulados do resíduo ponderado padronizado 2 para os três ajustes.

Na Tabela 4.2 são mostrados os intervalos de $95 \%$ para as respostas médias nos três ajustes obtidos. Nota-se que as estimativas obtidas nos ajustes com as funções de ligação log-log e de Aranda-Ordaz são as mais próximas, mas apesar disso, as estimativas obtidas com a função de ligação logito também não se afastam dos resultados obtidos com as outras duas funções de ligação.

Como foi visto nas simulações apresentadas neste trabalho a função de ligação logito mesmo quando está especificada incorretamente traz estimativas para as respostas médias com vieses pequenos. Nos três ajustes realizados verificou-se, através dos resíduos e dos intervalos de confiança para as médias, resultados semelhantes e, além disso, a inferência dos parâmetros foi a mesma; portanto, se o interesse é ter interpretação simples para os parâmetros de regressão, a função de ligação logito poderia ser utilizada, apesar da hipótese nula do modelo estar bem especificado com essa função de ligação ter sido 
Tabela 4.2: Intervalos de 95\% de confiança para as respostas médias.

\begin{tabular}{|c|c|c|c|c|c|c|c|c|c|}
\hline \multirow[b]{2}{*}{$y$} & \multicolumn{3}{|c|}{ Logito } & \multicolumn{3}{|c|}{$\overline{\text { Log-log }}$} & \multicolumn{3}{|c|}{ Aranda-Ordaz } \\
\hline & LI & $\hat{\mu}$ & LS & LI & $\hat{\mu}$ & LS & LI & $\hat{\mu}$ & LS \\
\hline 0.122 & 0.088 & 0.101 & 0.116 & 0.099 & 0.110 & 0.123 & 0.101 & 0.114 & 0.127 \\
\hline 0.223 & 0.177 & 0.195 & 0.215 & 0.206 & 0.220 & 0.235 & 0.214 & 0.229 & 0.244 \\
\hline 0.347 & 0.319 & 0.343 & 0.369 & 0.337 & 0.353 & 0.370 & 0.340 & 0.355 & 0.370 \\
\hline 0.457 & 0.477 & 0.508 & 0.539 & 0.456 & 0.474 & 0.492 & 0.441 & 0.457 & 0.472 \\
\hline 0.080 & 0.068 & 0.080 & 0.093 & 0.062 & 0.072 & 0.082 & 0.061 & 0.070 & 0.079 \\
\hline 0.131 & 0.120 & 0.137 & 0.156 & 0.128 & 0.141 & 0.154 & 0.127 & 0.141 & 0.155 \\
\hline 0.266 & 0.234 & 0.263 & 0.294 & 0.249 & 0.267 & 0.286 & 0.253 & 0.270 & 0.287 \\
\hline 0.074 & 0.082 & 0.094 & 0.108 & 0.078 & 0.088 & 0.099 & 0.076 & 0.086 & 0.097 \\
\hline 0.182 & 0.148 & 0.167 & 0.188 & 0.158 & 0.172 & 0.187 & 0.159 & 0.173 & 0.188 \\
\hline 0.304 & 0.268 & 0.298 & 0.329 & 0.276 & 0.294 & 0.313 & 0.278 & 0.295 & 0.312 \\
\hline 0.069 & 0.064 & 0.074 & 0.086 & 0.058 & 0.067 & 0.076 & 0.057 & 0.065 & 0.074 \\
\hline 0.152 & 0.126 & 0.141 & 0.157 & 0.136 & 0.148 & 0.160 & 0.137 & 0.150 & 0.163 \\
\hline 0.260 & 0.228 & 0.250 & 0.274 & 0.245 & 0.260 & 0.275 & 0.249 & 0.264 & 0.278 \\
\hline 0.336 & 0.325 & 0.354 & 0.383 & 0.330 & 0.347 & 0.364 & 0.329 & 0.345 & 0.360 \\
\hline 0.144 & 0.143 & 0.160 & 0.179 & 0.149 & 0.163 & 0.178 & 0.148 & 0.163 & 0.178 \\
\hline 0.268 & 0.245 & 0.269 & 0.294 & 0.252 & 0.269 & 0.286 & 0.253 & 0.269 & 0.285 \\
\hline 0.349 & 0.305 & 0.333 & 0.362 & 0.305 & 0.323 & 0.340 & 0.303 & 0.320 & 0.336 \\
\hline 0.100 & 0.087 & 0.101 & 0.115 & 0.087 & 0.098 & 0.111 & 0.085 & 0.097 & 0.110 \\
\hline 0.248 & 0.213 & 0.237 & 0.261 & 0.228 & 0.244 & 0.261 & 0.231 & 0.248 & 0.264 \\
\hline 0.317 & 0.300 & 0.329 & 0.360 & 0.306 & 0.325 & 0.343 & 0.307 & 0.324 & 0.341 \\
\hline 0.028 & 0.039 & 0.046 & 0.054 & 0.026 & 0.031 & 0.037 & 0.027 & 0.031 & 0.037 \\
\hline 0.064 & 0.060 & 0.069 & 0.080 & 0.054 & 0.061 & 0.070 & 0.052 & 0.059 & 0.067 \\
\hline 0.161 & 0.138 & 0.156 & 0.175 & 0.154 & 0.167 & 0.181 & 0.155 & 0.169 & 0.183 \\
\hline 0.278 & 0.231 & 0.259 & 0.288 & 0.253 & 0.270 & 0.287 & 0.255 & 0.272 & 0.289 \\
\hline 0.050 & 0.063 & 0.073 & 0.086 & 0.055 & 0.063 & 0.073 & 0.053 & 0.062 & 0.071 \\
\hline 0.176 & 0.141 & 0.160 & 0.180 & 0.152 & 0.166 & 0.181 & 0.153 & 0.168 & 0.183 \\
\hline 0.321 & 0.280 & 0.311 & 0.344 & 0.290 & 0.309 & 0.328 & 0.292 & 0.309 & 0.327 \\
\hline 0.140 & 0.109 & 0.127 & 0.148 & 0.112 & 0.127 & 0.143 & 0.111 & 0.126 & 0.142 \\
\hline 0.232 & 0.215 & 0.245 & 0.279 & 0.228 & 0.248 & 0.269 & 0.231 & 0.250 & 0.270 \\
\hline 0.085 & 0.090 & 0.104 & 0.119 & 0.089 & 0.100 & 0.111 & 0.088 & 0.098 & 0.109 \\
\hline 0.147 & 0.103 & 0.119 & 0.136 & 0.106 & 0.118 & 0.130 & 0.106 & 0.117 & 0.129 \\
\hline 0.180 & 0.165 & 0.188 & 0.213 & 0.178 & 0.193 & 0.209 & 0.181 & 0.196 & 0.211 \\
\hline
\end{tabular}

LI: limite inferior; LS: limite superior.

rejeitada. Para o ajuste com a função de ligação de Aranda-Ordaz, a hipótese nula de que o modelo está bem especificado não é rejeitada. Portanto, se não há interesse na interpretação dos parâmetros, o ajuste com esta função de ligação pode ser o mais interessante. 
Capítulo 5

\section{Considerações finais}

Esta dissertação apresenta estudos realizados através de simulações para verificação dos impactos da especificação incorreta da função de ligação nos modelos de regressão beta. As funções de ligação utilizadas nos ajustes foram logito, probito, complemento log-log e log-log. A função de ligação logito permite uma interpretação simples para os parâmetros de regressão. A principal medida utilizada para medir o impacto da especificação incorreta foi a taxa de cobertura, que representa a proporção de amostras em que as médias verdadeiras pertencem aos intervalos estimados com 95\% de confiança nas réplicas de Monte Carlo. A utilização da função de ligação logito apresentou taxas de cobertura baixas nos casos em que as funções de ligação verdadeiras eram a complemento log-log e log-log. O estudo da variável dependente modificada e do teste RESET nestes casos detectaram a especificação incorreta da função de ligação em alguns dos cenários apresentados. Gráficos de resíduos também foram avaliados, mas não detectaram a especificação incorreta da função de ligação. Apesar das baixas taxas de cobertura no ajuste com a função de ligação logito nestes casos, os vieses relativos para as respostas médias mostraram que as estimativas das médias estão próximas aos seus verdadeiros valores.

Adicionalmente foi introduzido o ajuste do modelo de regressão beta com a função de ligação de Aranda-Ordaz, que envolve um parâmetro adicional. Foi verificado que amostras extremamente grandes são necessárias para chegar aos resultados esperados pela teoria assintótica para os estimadores dos parâmetros do modelo. No entanto, mesmo em amostras não muito grandes, as taxas de cobertura dos intervalos de confiança para as respostas médias não são muito distorcidas. Na comparação de alguns cenários obtidos com a função de ligação logito e de Aranda-Ordaz, melhores resultados foram 
obtidos com a função de ligação Aranda-Ordaz em relação à taxa de cobertura dos intervalos de confiança e vieses relativos dos estimadores das respostas médias. Uma aplicação foi realizada comparando os resultados obtidos com algumas das funções de ligação. 


\section{Programa de simulação no $\mathrm{Ox}$}

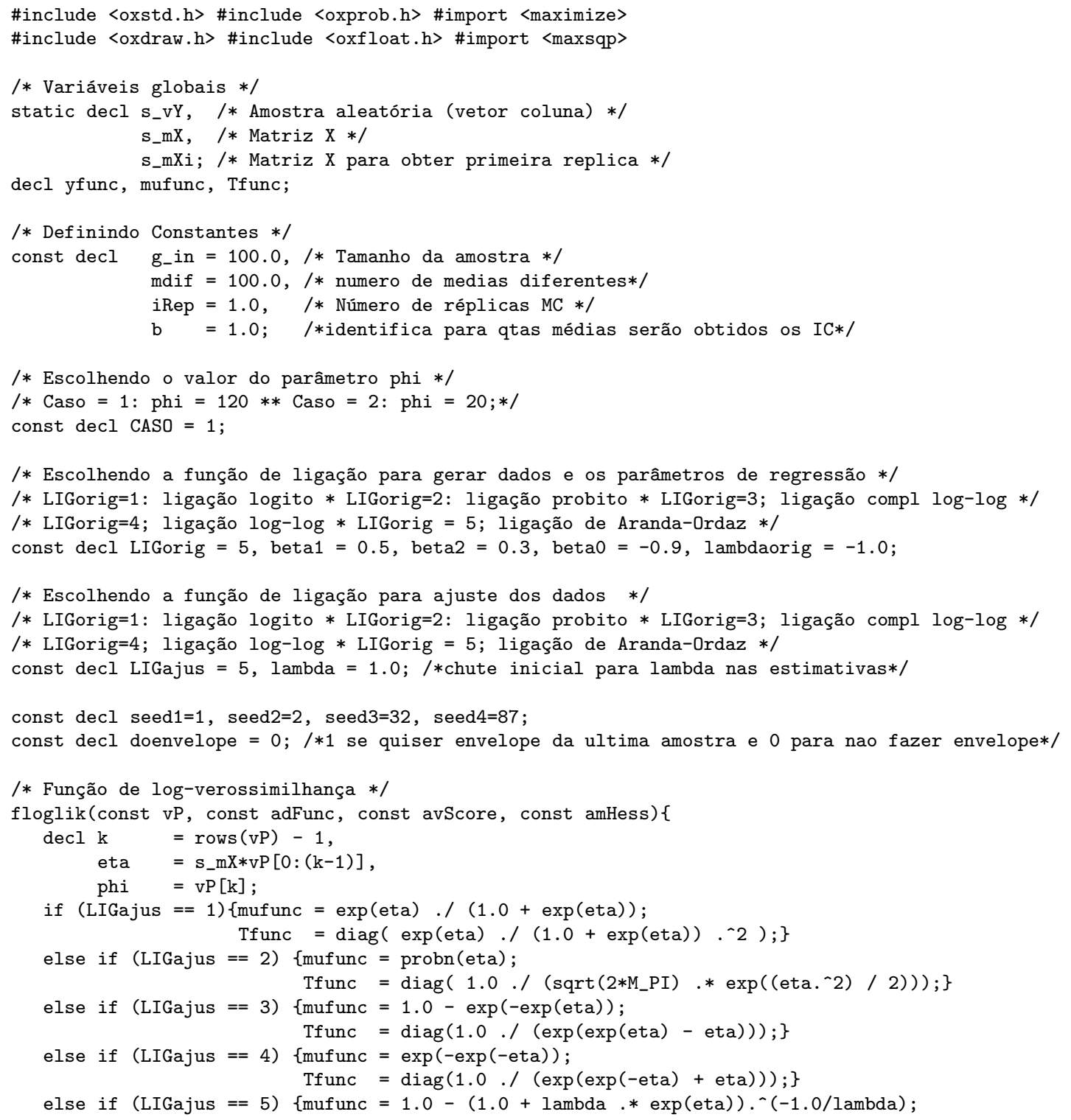




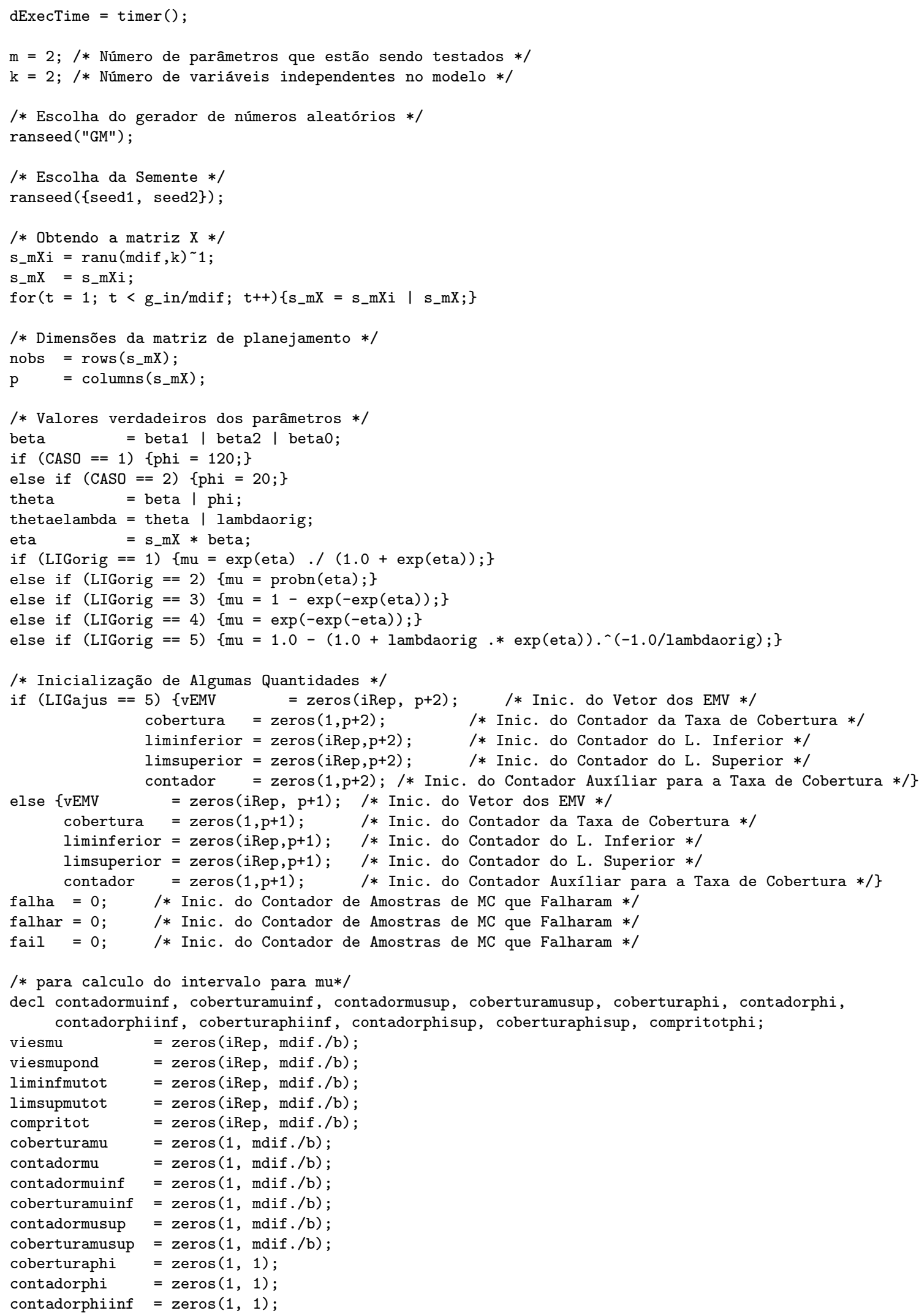




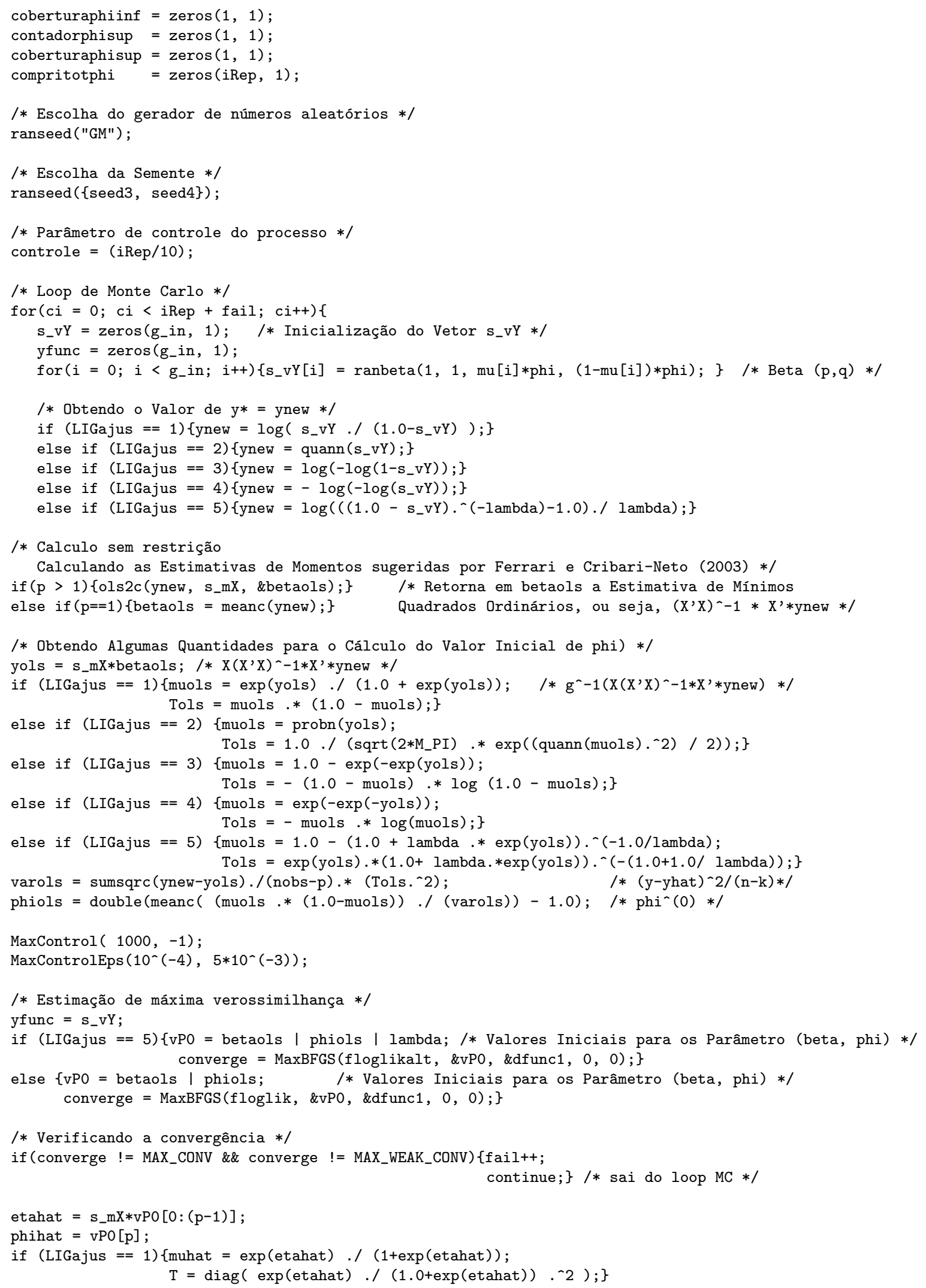




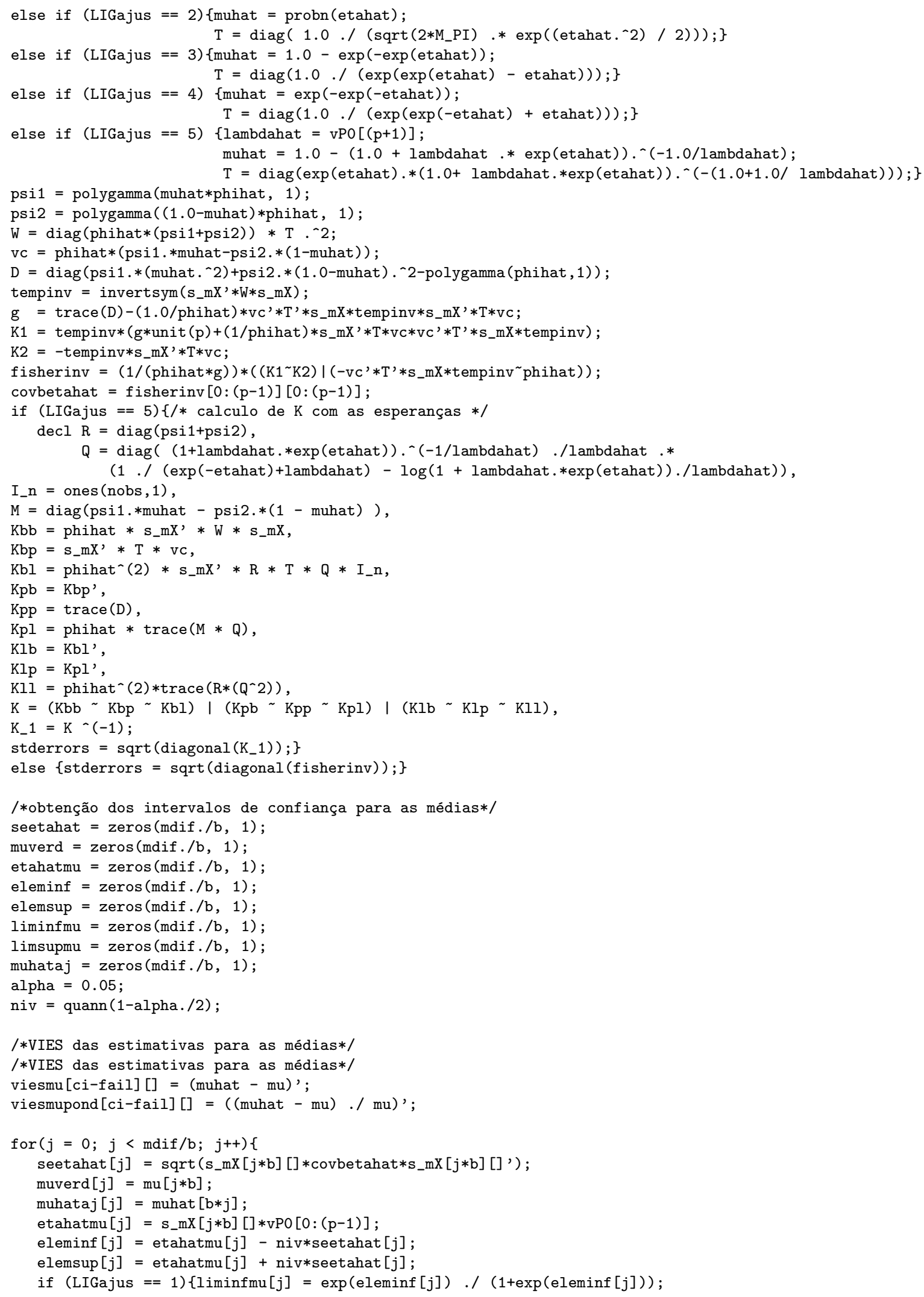




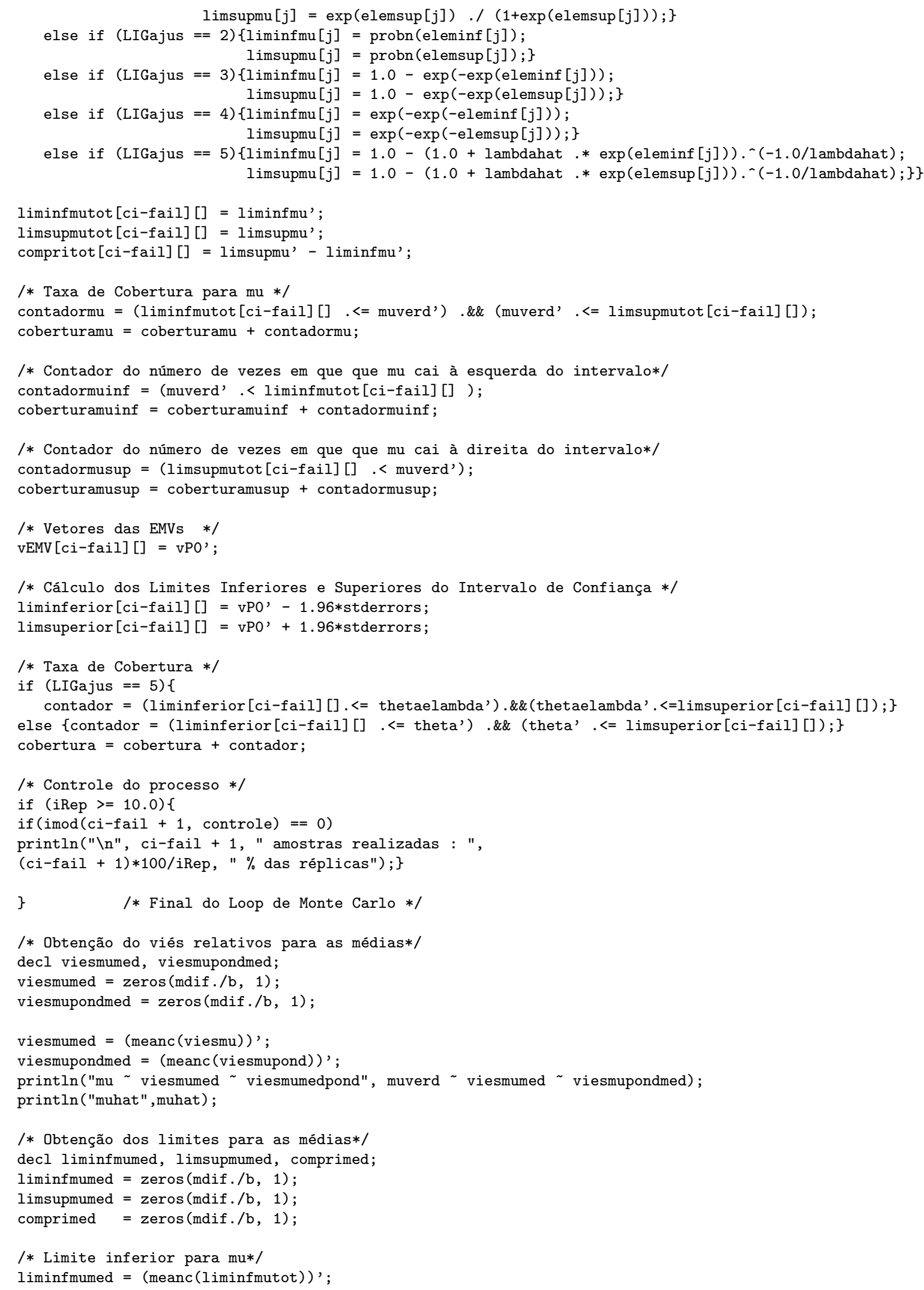




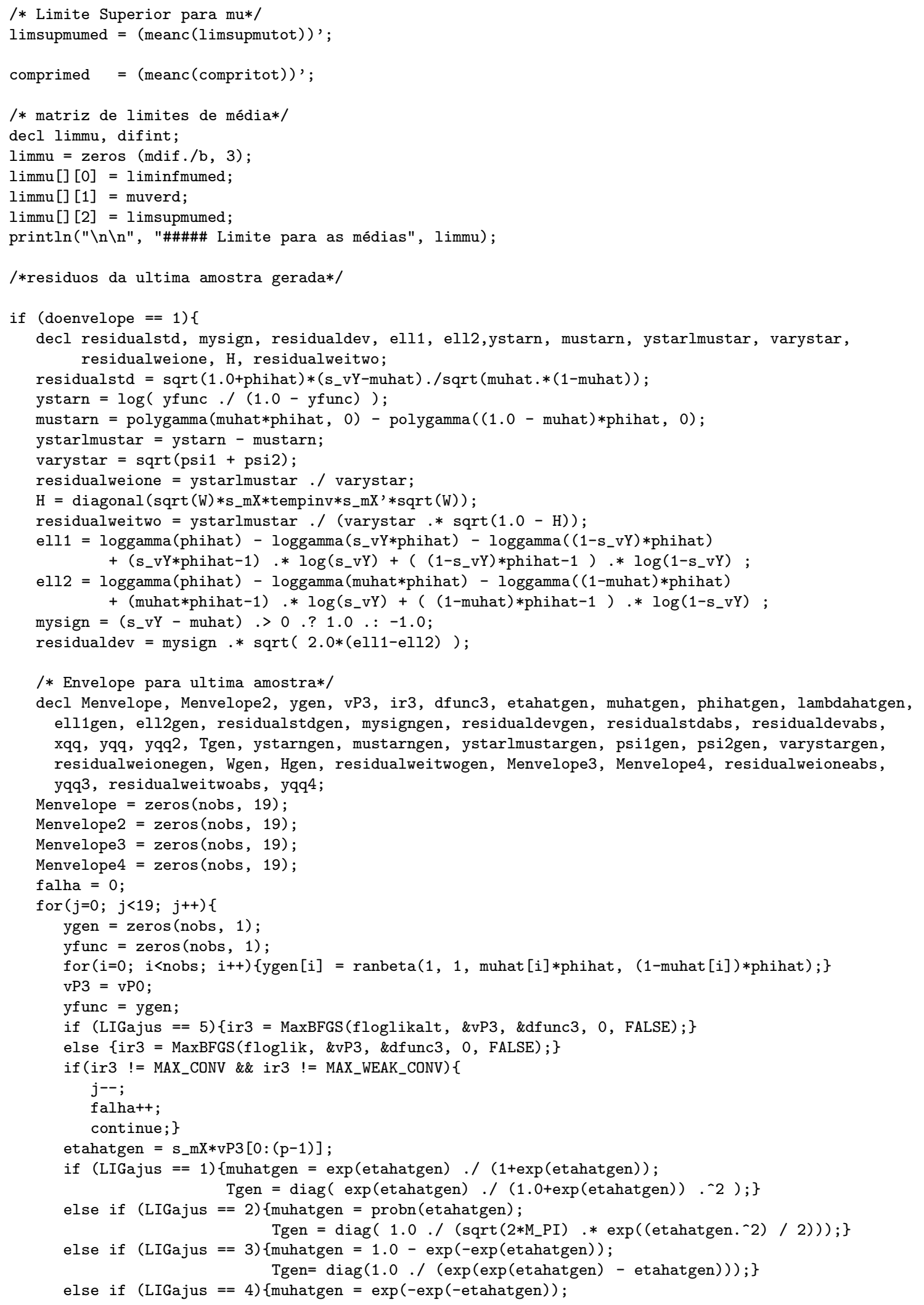


Tgen $=\operatorname{diag}(1.0 . /(\exp (\exp (-$ etahatgen $)+$ etahatgen $))) ;\}$

else if (LIGajus $==5)$ \{lambdahatgen $=\operatorname{vP} 3[(\mathrm{p}+1)]$;

muhatgen $=1.0-(1.0+$ lambdahatgen.$* \exp ($ etahatgen $)) \cdot{ }^{\wedge}(-1.0 /$ lambdahatgen $) ;$

Tgen $=\operatorname{diag}\left(\left((1.0-\right.\right.$ muhatgen $) \cdot{ }^{-}(-$lambdahatgen $\left.)-1.0\right) . /($ lambdahatgen

**(1.0 - muhatgen $).^{\wedge}(-($ lambdahatgen +1.0$\left.\left.\left.))\right)\right) ;\right\}$

phihatgen $=\mathrm{vP} 3[\mathrm{p}]$;

ell1gen = loggamma (phihatgen) - loggamma (ygen*phihatgen $)-\operatorname{loggamma}((1$-ygen $) *$ phihatgen $)$

$+($ ygen*phihatgen -1$) \cdot * \log ($ ygen $)+((1-$ ygen $) *$ phihatgen -1$) \cdot * \log (1-$ ygen $)$

ell2gen $=$ loggamma (phihatgen) - loggamma (muhatgen*phihatgen $)-\operatorname{loggamma}((1$-muhatgen $) *$ phihatgen $)$

$+($ muhatgen*phihatgen -1$) . * \log ($ ygen $)+((1$-muhatgen $) *$ phihatgen -1$) . * \log (1-$ ygen $)$;

residualstdgen $=\operatorname{sqrt}(1.0+$ phihatgen $) *($ ygen-muhatgen $) . /$ sqrt $($ muhatgen.$*(1$-muhatgen $)) ;$

mysigngen $=$ (ygen - muhatgen).$>0 . ? 1.0 .:-1.0$;

residualdevgen $=$ mysigngen $*$ sqrt $(2.0 *($ ell1gen-ell2gen $))$;

Menvelope []$[j]$ = residualstdgen;

Menvelope2[] $[j]$ = residualdevgen;

ystarngen $=\log ($ ygen.$/(1.0-$ ygen $))$;

mustarngen $=$ polygamma $($ muhatgen*phihatgen, 0$)-\operatorname{polygamma}((1.0-$ muhatgen $) *$ phihatgen, 0$) ;$

ystarlmustargen = ystarngen - mustarngen;

psi1gen = polygamma (muhatgen $*$ phihatgen, 1$)$;

psi2gen = polygamma $((1.0$-muhatgen $) *$ phihatgen, 1$) ;$

varystargen $=\operatorname{sqrt}($ psi1gen + psi2gen $) ;$

residualweionegen = ystarlmustargen.$/$ varystargen;

Wgen $=\operatorname{diag}($ phihatgen $*($ psi1gen+psi2gen $)) *$ Tgen $\cdot{ }^{\wedge} 2$;

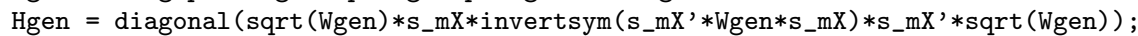

residualweitwogen $=$ ystarlmustargen.$/($ varystargen.$* \operatorname{sqrt}(1.0-$ Hgen $))$;

Menvelope 3[]$[j]$ = residualweionegen;

Menvelope4[] $[j]$ = residualweitwogen; \}

residualstdabs $=$ fabs $($ residualstd $)$;

Menvelope $=\operatorname{sortc}(f \operatorname{abs}($ Menvelope $))$;

$\mathrm{xqq}=$ quann $\left(\left(\right.\right.$ range $(1, \text { nobs })^{\prime}+$ nobs $\left.-1 / 8\right) /(2 *$ nobs +0.5$\left.)\right) ;$

yqq $=\operatorname{zeros}($ nobs , 4);

yqq[] [3] $=\operatorname{sortc}($ residualstdabs $)$;

yqq[] [0] = minc(Menvelope')',

yqq [] [1] = meanr (Menvelope);

yqq [] [2] $=\operatorname{maxc}$ (Menvelope')';

residualdevabs $=$ fabs (residualdev);

Menvelope2 $=\operatorname{sortc}(f \operatorname{abs}($ Menvelope2) $)$;

yqq2 = zeros (nobs, 4);

yqq2 [] [3] = sortc(residualdevabs);

yqq2 [] [0] $=\operatorname{minc}($ Menvelope2' )';

yqq2 [] [1] = meanr (Menvelope2);

yqq2 [] [2] = maxc(Menvelope2' ')';

residualweioneabs = fabs (residualweione);

Menvelope $3=\operatorname{sortc}($ fabs (Menvelope 3$)$ );

yqq3 = zeros (nobs, 4);

yqq3 [] [3] = sortc(residualweioneabs);

yqq3 [] [0] = minc(Menvelope3' )';

yqq3 [] [1] = meanr (Menvelope3);

yqq3 [] [2] $=\operatorname{maxc}($ Menvelope3' )';

residualweitwoabs = fabs (residualweitwo);

Menvelope4 $=\operatorname{sortc}($ fabs (Menvelope 4$)$ );

yqq4 = $\operatorname{zeros}($ nobs, 4$)$;

yqq4 [] [3] = sortc(residualweitwoabs);

yqq4[] [0] $=\operatorname{minc}($ Menvelope4' )';

yqq4 [] [1] = meanr (Menvelope4);

yqq4 [] [2] = maxc(Menvelope4' )';

SetDraw (SET_FONT, 200);

/* Envelope dos residuos padronizados */

DrawXMatrix (0, yqq', 0 , xqq', 0,0 );

DrawAdjust (ADJ_SYMBOLUSE, 1)

DrawAdjust (ADJ_SYMBOL, PL_PLUS);

DrawText (0, "half-normal plot para residuos padronizados", 0, 0, $-1,250$, TRUE);

DrawXMatrix (1, yqq3', 0, xqq', 0, 0);

DrawAdjust (ADJ_SYMBOLUSE, 1); 
DrawAdjust (ADJ_SYMBOL, PL_PLUS);

DrawText (1, "half-normal plot para residuos padron. weigthed 1", 0, 0, -1, 250, TRUE);

DrawXMatrix (2, yqq4', 0 , xqq', 0,0 );

DrawAdjust (ADJ_SYMBOLUSE, 1);

DrawAdjust (ADJ_SYMBOL, PL_PLUS);

DrawText (2, "half-normal plot para residuos padron. weigthed 2", 0, 0, -1, 250, TRUE);

SaveDrawWindow ("envelope.eps");

\}

/* ORGANIZAÇÃO DOS RESULTADOS - PARA AS MEDIAS*/

decl resultfinal, cobertotal;

resultfinal $=\operatorname{zeros}($ rows $($ coberturamu' $)+1,6)$;

cobertotal $=\operatorname{zeros}(1,10)$;

/* Verdadeiras médias*/

resultfinal []$[0]=$ muverd;

/* Cobertura*/

resultfinal [] [1] = coberturamu' ./ iRep*100; //coberturas

resultfinal []$[2]=$ (coberturamusup' - coberturamuinf').$/$ iRep*100; //medida de balanceamento

resultfinal[] [3] = coberturamuinf' ./ iRep*100; //obs a esq do intervalo

resultfinal[] [4] = coberturamusup'./ iRep*100; //obs a dir do intervalo

/* comprimento médio dos intervalos*/

resultfinal [] [5] = comprimed;

resultfinal [rows (coberturamu')] [0] = theta $[\mathrm{p}]$;

resultfinal [rows (coberturamu')] [1] = coberturaphi ./ iRep*100;

resultfinal [rows (coberturamu')] [2] = (coberturaphisup - coberturaphiinf) ./ iRep*100;

//medida de balanceamento

resultfinal[rows(coberturamu')] [3] = coberturaphiinf ./ iRep*100; //obs a esq do intervalo

resultfinal [rows(coberturamu')] [4] = coberturaphisup ./ iRep*100; //obs a dir do intervalo

resultfinal [rows (coberturamu')] [5] = meanc (compritotphi);

/* Cobertura total e porcentagem*/

cobertotal [] [0] = minc (muverd); //min das medias

cobertotal [] [1] = maxc(muverd); //max das medias

cobertotal []$[2]=$ meanc $(\mathrm{vEMV}[][\mathrm{p}]) ;$ //estimativa para phi

cobertotal [] [3] = meanc (comprimed); /*comprimento medio dos intervalos*/

cobertotal [] [4] = minc (coberturamu' ./ iRep*100); //min das coberturas

cobertotal []$[5]$ = meanc (coberturamu' ./ iRep*100); //media das coberturas

cobertotal [] [6] $=\operatorname{maxc}(($ coberturamusup' - coberturamuinf' $) . /$ iRep*100);

//maior desbalanceamento verificado a direita

cobertotal []$[7]=\operatorname{minc}((\operatorname{coberturamusup})-\operatorname{coberturamuinf} ') . /$ iRep*100);

//maior desbalanceamento verificado a esquerda

cobertotal [] [8] = maxc (coberturamuinf' ./ iRep*100);//maior valor observado para médias fora a esq

cobertotal [] [9] = maxc (coberturamusup' ./ iRep*100); //maior valor observado para médias fora a dir

/* ORGANIZAÇÃO DOS RESULTADOS - Estimação de Máxima Verossimilhança */

if (LIGajus $==5)$ \{resul1 $=\operatorname{zeros}(\mathrm{p}+2,9) ;\} \quad / *$ Inicialização da Matriz de Resultados $* /$

else $\{\operatorname{resul1}=\operatorname{zeros}(\mathrm{p}+1,9) ;\} \quad$ /* Inicialização da Matriz de Resultados */

/* Média das Estimativas */

resul1 []$[0]=(\text { meanc }(\text { vEMV }))^{\prime}$;

/* Desvio Padrão das Estimativas */

$\operatorname{resul1}[][1]=\operatorname{sqrt}((\operatorname{sumsqrc}(v E M V) . /$ iRep $) '-\operatorname{sqr}(\operatorname{resul1}[][0]))$;

/* Viés da Média das Estimativas */

if (LIGajus == 5) \{resul1[] [2] = (resul1[] [0] - (theta | lambdaorig)); $\}$

else $\{r \operatorname{sul1}[][2]=(\operatorname{resul1}[][0]-$ theta $) ;\}$

/* Raiz do Erro Quadrático Médio Estimado */

$\operatorname{resul1}[][3]=\operatorname{sqrt}\left((\operatorname{resul1}[][1]) \cdot{ }^{\wedge} 2+\operatorname{sqr}(\operatorname{resul1}[][2])\right)$;

/* Coeficiente de assimetria */ 


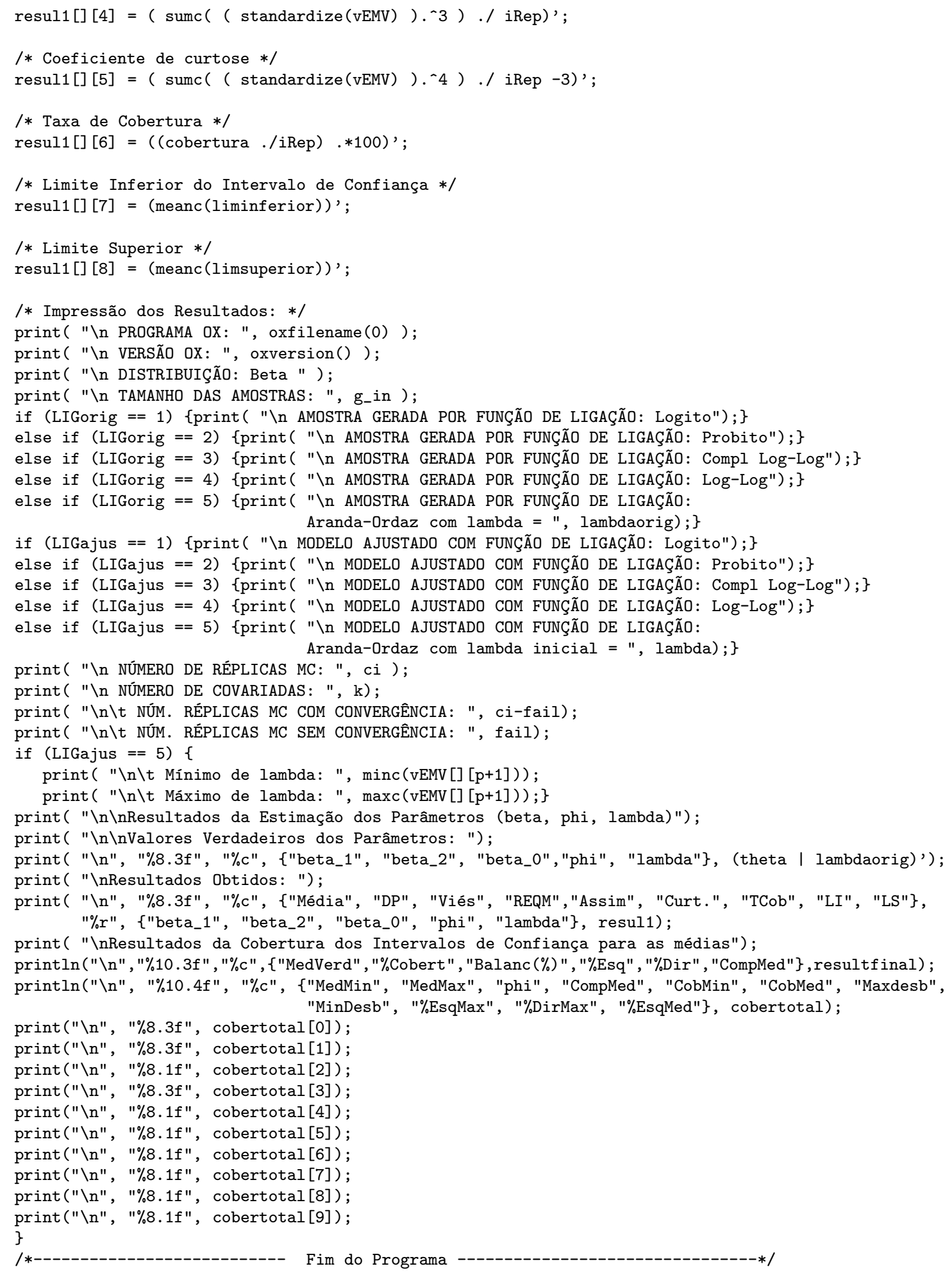


APÊNDICE B

\section{Resultados das simulações}

\section{B.1 Função de Ligação Correta Logito e Incorreta Probito}

Tabela B.1: Resultados dos intervalos de confiança para as respostas médias: taxa de cobertura e balanceamento; ligação correta logito, ligação incorreta probito, planejamento com réplicas, $\mu_{t} \in[0.021 ; 0.054], n=20$ e $\phi=20$.

\begin{tabular}{ccccc}
\hline \hline & \multicolumn{2}{c}{ Cobertura (\%) } & \multicolumn{2}{c}{ Balanceamento (\%) } \\
Médias & Correta & Incorreta & Correta & Incorreta \\
\hline 0.021 & 91.1 & 90.8 & 1.8 & 3.1 \\
0.023 & 90.8 & 90.7 & 1.9 & 3.0 \\
0.027 & 91.1 & 90.9 & 2.8 & 3.5 \\
0.031 & 90.5 & 90.5 & 3.3 & 3.9 \\
0.039 & 90.7 & 90.5 & 4.1 & 4.4 \\
0.040 & 91.1 & 91.1 & 0.2 & 1.4 \\
0.046 & 90.9 & 90.9 & 0.2 & 1.7 \\
0.053 & 90.9 & 90.6 & 1.6 & 2.9 \\
0.054 & 91.1 & 90.6 & 1.3 & 2.7 \\
0.054 & 91.2 & 90.6 & 1.8 & 3.2 \\
\hline$\phi=20$ & 96.3 & 96.3 & -0.7 & -0.7 \\
\hline \hline
\end{tabular}


Tabela B.2: Resultados dos intervalos de confiança para as respostas médias: taxa de cobertura e balanceamento; ligação correta logito, ligação incorreta probito, planejamento com réplicas, $\mu_{t} \in[0.021 ; 0.054], n=20$ e $\phi=120$.

\begin{tabular}{ccccc}
\hline \hline & \multicolumn{2}{c}{ Cobertura (\%) } & \multicolumn{2}{c}{ Balanceamento (\%) } \\
Médias & Correta & Incorreta & Correta & Incorreta \\
\hline 0.021 & 91.0 & 91.1 & 0.8 & 1.9 \\
0.023 & 91.0 & 91.1 & 0.5 & 1.1 \\
0.027 & 90.9 & 90.9 & 1.2 & 1.3 \\
0.031 & 91.0 & 91.1 & 1.3 & 0.9 \\
0.039 & 91.0 & 91.2 & 1.6 & 0.7 \\
0.040 & 90.8 & 90.7 & -0.3 & -0.2 \\
0.046 & 90.8 & 90.8 & -0.4 & 0.2 \\
0.053 & 91.0 & 90.9 & 0.5 & 1.4 \\
0.054 & 91.0 & 90.7 & 0.4 & 1.5 \\
0.054 & 91.0 & 90.9 & 0.7 & 1.9 \\
\hline$\phi=120$ & 95.8 & 95.8 & -1.4 & -1.3 \\
\hline \hline
\end{tabular}

Tabela B.3: Resultados dos intervalos de confiança para as respostas médias: taxa de cobertura e balanceamento; ligação correta logito, ligação incorreta probito, planejamento com réplicas, $\mu_{t} \in[0.021 ; 0.054], n=500$ e $\phi=20$.

\begin{tabular}{ccccc}
\hline \hline & \multicolumn{2}{c}{ Cobertura (\%) } & \multicolumn{2}{c}{ Balanceamento (\%) } \\
Médias & Correta & Incorreta & Correta & Incorreta \\
\hline 0.021 & 95.3 & 95.0 & 0.2 & 1.7 \\
0.023 & 95.2 & 95.1 & 0.6 & 1.0 \\
0.027 & 95.4 & 95.1 & 0.6 & 0.3 \\
0.031 & 95.1 & 95.1 & 0.9 & -0.6 \\
0.039 & 94.9 & 94.9 & 0.9 & -0.8 \\
0.040 & 94.9 & 94.8 & -0.2 & -0.8 \\
0.046 & 95.1 & 95.2 & -0.2 & -0.2 \\
0.053 & 95.0 & 94.9 & 0.4 & 1.2 \\
0.054 & 95.0 & 94.9 & 0.2 & 1.4 \\
0.054 & 94.8 & 94.7 & 0.2 & 1.6 \\
\hline$\phi=20$ & 95.2 & 95.1 & -0.3 & -0.2 \\
\hline \hline
\end{tabular}


Tabela B.4: Resultados dos intervalos de confiança para as respostas médias: taxa de cobertura e balanceamento; ligação correta logito, ligação incorreta probito, planejamento com réplicas, $\mu_{t} \in[0.021 ; 0.054], n=500$ e $\phi=120$.

\begin{tabular}{ccccc}
\hline \hline & \multicolumn{2}{c}{ Cobertura (\%) } & \multicolumn{2}{c}{ Balanceamento (\%) } \\
Médias & Correta & Incorreta & Correta & Incorreta \\
\hline 0.021 & 95.0 & 94.2 & -0.5 & 3.0 \\
0.023 & 94.9 & 94.9 & -0.2 & 0.5 \\
0.027 & 94.7 & 94.7 & -0.3 & -0.8 \\
0.031 & 94.9 & 93.9 & -0.1 & -3.4 \\
0.039 & 94.8 & 93.6 & 0.3 & -3.8 \\
0.040 & 95.0 & 94.7 & -0.1 & -1.4 \\
0.046 & 95.2 & 95.1 & -0.1 & -0.4 \\
0.053 & 95.1 & 95.0 & 0.1 & 1.2 \\
0.054 & 95.1 & 94.8 & 0.2 & 1.9 \\
0.054 & 95.2 & 94.6 & 0.1 & 2.3 \\
\hline$\phi=120$ & 95.3 & 95.3 & -0.4 & -0.4 \\
\hline \hline
\end{tabular}

Tabela B.5: Resultados dos intervalos de confiança para as respostas médias: taxa de cobertura e balanceamento; ligação correta logito, ligação incorreta probito, planejamento com réplicas, $\mu_{t} \in[0.385 ; 0.614], n=20$ e $\phi=20$.

\begin{tabular}{ccccc}
\hline \hline & \multicolumn{2}{c}{ Cobertura (\%) } & \multicolumn{2}{c}{ Balanceamento (\%) } \\
Médias & Correta & Incorreta & Correta & Incorreta \\
\hline 0.385 & 90.7 & 90.6 & 0.4 & 0.5 \\
0.388 & 91.2 & 91.2 & 0.6 & 0.8 \\
0.394 & 90.7 & 90.7 & 0.4 & 0.5 \\
0.434 & 91.7 & 91.5 & 0.3 & 0.3 \\
0.463 & 90.7 & 90.7 & 0.2 & 0.2 \\
0.466 & 91.4 & 91.3 & -0.4 & -0.3 \\
0.516 & 91.3 & 91.1 & 0.0 & -0.1 \\
0.559 & 91.5 & 91.4 & -0.3 & -0.3 \\
0.587 & 91.3 & 91.3 & -0.3 & -0.4 \\
0.614 & 91.2 & 91.2 & -0.3 & -0.4 \\
\hline$\phi=20$ & 95.8 & 95.8 & -1.3 & -1.3 \\
\hline \hline
\end{tabular}


Tabela B.6: Resultados dos intervalos de confiança para as respostas médias: taxa de cobertura e balanceamento; ligação correta logito, ligação incorreta probito, planejamento com réplicas, $\mu_{t} \in[0.385 ; 0.614], n=20$ e $\phi=120$.

\begin{tabular}{ccccc}
\hline \hline & \multicolumn{2}{c}{ Cobertura (\%) } & \multicolumn{2}{c}{ Balanceamento (\%) } \\
Médias & Correta & Incorreta & Correta & Incorreta \\
\hline 0.385 & 91.2 & 91.1 & -0.3 & -0.3 \\
0.388 & 91.2 & 91.3 & -0.3 & -0.2 \\
0.394 & 91.2 & 91.2 & -0.3 & -0.3 \\
0.434 & 91.4 & 91.4 & -0.2 & -0.3 \\
0.463 & 91.2 & 91.2 & -0.3 & -0.5 \\
0.466 & 91.4 & 91.4 & -0.2 & -0.2 \\
0.516 & 91.3 & 91.3 & 0.1 & 0.0 \\
0.559 & 90.9 & 90.9 & 0.1 & 0.2 \\
0.587 & 91.3 & 91.3 & -0.3 & -0.3 \\
0.614 & 91.1 & 91.1 & 0.1 & 0.0 \\
\hline$\phi=120$ & 96.0 & 96.0 & -1.4 & -1.4 \\
\hline \hline
\end{tabular}

Tabela B.7: Resultados dos intervalos de confiança para as respostas médias: taxa de cobertura e balanceamento; ligação correta logito, ligação incorreta probito, planejamento com réplicas, $\mu_{t} \in[0.385 ; 0.614], n=500$ e $\phi=20$.

\begin{tabular}{ccccc}
\hline \hline & \multicolumn{2}{c}{ Cobertura (\%) } & \multicolumn{2}{c}{ Balanceamento (\%) } \\
Médias & Correta & Incorreta & Correta & Incorreta \\
\hline 0.385 & 95.0 & 95.0 & -0.3 & -0.2 \\
0.388 & 95.2 & 95.2 & -0.1 & 0.0 \\
0.394 & 95.0 & 95.0 & -0.3 & -0.3 \\
0.434 & 94.7 & 94.7 & 0.1 & 0.0 \\
0.463 & 95.0 & 94.9 & -0.3 & -0.5 \\
0.466 & 94.9 & 94.9 & -0.2 & -0.2 \\
0.516 & 94.9 & 94.9 & -0.1 & -0.1 \\
0.559 & 94.8 & 94.7 & -0.3 & 0.0 \\
0.587 & 94.7 & 94.7 & 0.2 & 0.2 \\
0.614 & 94.9 & 94.8 & -0.3 & -0.4 \\
\hline$\phi=20$ & 95.5 & 95.5 & -0.1 & -0.1 \\
\hline \hline
\end{tabular}


Tabela B.8: Resultados dos intervalos de confiança para as respostas médias: taxa de cobertura e balanceamento; ligação correta logito, ligação incorreta probito, planejamento com réplicas, $\mu_{t} \in[0.385 ; 0.614], n=500$ e $\phi=120$.

\begin{tabular}{ccccc}
\hline \hline & \multicolumn{2}{c}{ Cobertura (\%) } & \multicolumn{2}{c}{ Balanceamento (\%) } \\
Médias & Correta & Incorreta & Correta & Incorreta \\
\hline 0.385 & 94.6 & 94.7 & 0.1 & 0.4 \\
0.388 & 94.7 & 94.8 & 0.1 & 0.3 \\
0.394 & 94.6 & 94.6 & 0.2 & 0.2 \\
0.434 & 95.0 & 95.0 & 0.5 & 0.3 \\
0.463 & 94.8 & 94.7 & 0.1 & -0.5 \\
0.466 & 94.9 & 94.9 & 0.4 & 0.3 \\
0.516 & 94.8 & 94.8 & 0.2 & 0.2 \\
0.559 & 94.3 & 94.4 & -0.5 & 0.1 \\
0.587 & 94.9 & 94.9 & 0.1 & 0.2 \\
0.614 & 94.6 & 94.5 & -0.2 & -0.3 \\
\hline$\phi=120$ & 95.3 & 95.3 & -0.7 & -0.7 \\
\hline \hline
\end{tabular}

\section{B.2 Função de Ligação Correta Probito e Incorreta Logito}

Tabela B.9: Resultados dos intervalos de confiança para as respostas médias: taxa de cobertura e balanceamento; ligação correta probito, ligação incorreta logito, planejamento com réplicas, $\mu_{t} \in[0.944 ; 0.977], n=20$ e $\phi=20$.

\begin{tabular}{ccccc}
\hline \hline & \multicolumn{2}{c}{ Cobertura (\%) } & \multicolumn{2}{c}{ Balanceamento (\%) } \\
Médias & Correta & Incorreta & Correta & Incorreta \\
\hline 0.944 & 90.8 & 91.1 & -2.8 & -1.4 \\
0.946 & 90.9 & 91.3 & -3.1 & -1.7 \\
0.948 & 91.3 & 91.4 & -3.4 & -2.2 \\
0.955 & 90.6 & 90.6 & -4.2 & -3.7 \\
0.962 & 90.2 & 90.4 & -4.2 & -3.5 \\
0.963 & 91.1 & 91.1 & -2.6 & -1.5 \\
0.968 & 91.0 & 91.0 & -2.3 & -1.4 \\
0.969 & 90.8 & 91.0 & -2.5 & -1.5 \\
0.973 & 90.3 & 90.7 & -3.9 & -2.8 \\
0.977 & 90.3 & 90.7 & -2.9 & -1.8 \\
\hline$\phi=20$ & 96.0 & 96.0 & -1.0 & -1.0 \\
\hline \hline
\end{tabular}


Tabela B.10: Resultados dos intervalos de confiança para as respostas médias: taxa de cobertura e balanceamento; ligação correta probito, ligação incorreta logito, planejamento com réplicas, $\mu_{t} \in[0.944 ; 0.977], n=20$ e $\phi=120$.

\begin{tabular}{ccccc}
\hline \hline & \multicolumn{2}{c}{ Cobertura (\%) } & \multicolumn{2}{c}{ Balanceamento (\%) } \\
Médias & Correta & Incorreta & Correta & Incorreta \\
\hline 0.944 & 90.7 & 90.8 & -0.7 & 0.3 \\
0.946 & 90.8 & 90.9 & -0.9 & 0.0 \\
0.948 & 90.8 & 90.8 & -0.9 & -0.2 \\
0.955 & 90.7 & 90.9 & -1.6 & -1.7 \\
0.962 & 91.2 & 91.0 & -1.2 & -1.4 \\
0.963 & 91.0 & 91.0 & 0.2 & 0.3 \\
0.968 & 91.2 & 91.1 & 0.1 & 0.5 \\
0.969 & 91.0 & 90.9 & -0.8 & -0.6 \\
0.973 & 90.9 & 91.1 & -1.3 & -0.6 \\
0.977 & 90.9 & 91.0 & -1.0 & 0.2 \\
\hline$\phi=120$ & 96.2 & 96.2 & -1.3 & -1.3 \\
\hline \hline
\end{tabular}

Tabela B.11: Resultados dos intervalos de confiança para as respostas médias: taxa de cobertura e balanceamento; ligação correta probito, ligação incorreta logito, planejamento com réplicas, $\mu_{t} \in[0.944 ; 0.977], n=500$ e $\phi=20$.

\begin{tabular}{ccccc}
\hline \hline & \multicolumn{2}{c}{ Cobertura (\%) } & \multicolumn{2}{c}{ Balanceamento (\%) } \\
Médias & Correta & Incorreta & Correta & Incorreta \\
\hline 0.944 & 94.5 & 94.4 & -0.6 & 0.7 \\
0.946 & 94.6 & 94.4 & -0.6 & 0.3 \\
0.948 & 94.7 & 94.7 & -0.6 & 0.1 \\
0.955 & 94.8 & 94.7 & -1.1 & -1.7 \\
0.962 & 94.9 & 94.9 & -0.6 & -1.7 \\
0.963 & 95.1 & 95.1 & -0.2 & -0.7 \\
0.968 & 95.1 & 95.1 & -0.2 & -0.5 \\
0.969 & 95.1 & 95.1 & -0.1 & -0.5 \\
0.973 & 94.8 & 94.9 & -0.5 & -0.2 \\
0.977 & 94.9 & 94.5 & -0.4 & 1.3 \\
\hline$\phi=20$ & 94.9 & 94.9 & -0.5 & -0.5 \\
\hline \hline
\end{tabular}


Tabela B.12: Resultados dos intervalos de confiança para as respostas médias: taxa de cobertura e balanceamento; ligação correta probito, ligação incorreta logito, planejamento com réplicas, $\mu_{t} \in[0.944 ; 0.977], n=500$ e $\phi=120$.

\begin{tabular}{ccccc}
\hline \hline & \multicolumn{2}{c}{ Cobertura (\%) } & \multicolumn{2}{c}{ Balanceamento (\%) } \\
Médias & Correta & Incorreta & Correta & Incorreta \\
\hline 0.944 & 94.5 & 94.4 & 0.0 & 2.0 \\
0.946 & 94.5 & 94.6 & 0.0 & 1.4 \\
0.948 & 94.7 & 94.6 & -0.1 & 0.5 \\
0.955 & 94.6 & 94.2 & 0.1 & -1.9 \\
0.962 & 94.5 & 94.3 & 0.2 & -2.3 \\
0.963 & 94.8 & 94.7 & 0.3 & -1.0 \\
0.968 & 94.9 & 94.9 & 0.3 & -0.6 \\
0.969 & 94.9 & 95.0 & 0.2 & -0.6 \\
0.973 & 94.9 & 95.0 & -0.4 & 0.4 \\
0.977 & 95.1 & 94.2 & -0.4 & 3.2 \\
\hline$\phi=120$ & 95.0 & 94.9 & -0.6 & -0.5 \\
\hline \hline
\end{tabular}

Tabela B.13: Resultados dos intervalos de confiança para as respostas médias: taxa de cobertura e balanceamento; ligação correta probito, ligação incorreta logito, planejamento com réplicas, $\mu_{t} \in[0.386 ; 0.611], n=20$ e $\phi=20$.

\begin{tabular}{ccccc}
\hline \hline & \multicolumn{2}{c}{ Cobertura (\%) } & \multicolumn{2}{c}{ Balanceamento (\%) } \\
Médias & Correta & Incorreta & Correta & Incorreta \\
\hline 0.386 & 91.1 & 91.2 & 0.1 & -0.1 \\
0.395 & 91.3 & 91.4 & -0.2 & -0.3 \\
0.455 & 91.1 & 91.2 & -0.1 & -0.2 \\
0.463 & 91.2 & 91.3 & 0.3 & 0.2 \\
0.516 & 91.2 & 91.3 & -0.2 & -0.2 \\
0.573 & 91.2 & 91.2 & 0.2 & 0.3 \\
0.596 & 91.8 & 91.8 & -0.2 & -0.1 \\
0.601 & 91.2 & 91.3 & 0.0 & 0.2 \\
0.603 & 91.7 & 91.8 & -0.2 & -0.1 \\
0.611 & 91.4 & 91.5 & -0.3 & -0.1 \\
\hline$\phi=20$ & 96.4 & 96.4 & -1.2 & -1.2 \\
\hline \hline
\end{tabular}


Tabela B.14: Resultados dos intervalos de confiança para as respostas médias: taxa de cobertura e balanceamento; ligação correta probito, ligação incorreta logito, planejamento com réplicas, $\mu_{t} \in[0.386 ; 0.611], n=20$ e $\phi=120$.

\begin{tabular}{ccccc}
\hline \hline & \multicolumn{2}{c}{ Cobertura (\%) } & \multicolumn{2}{c}{ Balanceamento (\%) } \\
Médias & Correta & Incorreta & Correta & Incorreta \\
\hline 0.386 & 90.7 & 90.7 & 0.4 & 0.3 \\
0.395 & 90.8 & 90.8 & 0.3 & 0.2 \\
0.455 & 91.0 & 91.1 & 0.2 & 0.3 \\
0.463 & 91.1 & 91.1 & 0.2 & 0.3 \\
0.516 & 91.2 & 91.3 & 0.2 & 0.2 \\
0.573 & 91.1 & 91.1 & 0.3 & 0.3 \\
0.596 & 91.0 & 91.0 & 0.4 & 0.4 \\
0.601 & 91.2 & 91.2 & 0.1 & 0.1 \\
0.603 & 91.0 & 91.0 & 0.3 & 0.3 \\
0.611 & 91.2 & 91.3 & 0.4 & 0.5 \\
\hline$\phi=120$ & 95.9 & 95.9 & -1.5 & -1.5 \\
\hline \hline
\end{tabular}

Tabela B.15: Resultados dos intervalos de confiança para as respostas médias: taxa de cobertura e balanceamento; ligação correta probito, ligação incorreta logito, planejamento com réplicas, $\mu_{t} \in[0.386 ; 0.611], n=500$ e $\phi=20$.

\begin{tabular}{ccccc}
\hline \hline & \multicolumn{2}{c}{ Cobertura (\%) } & \multicolumn{2}{c}{ Balanceamento (\%) } \\
Médias & Correta & Incorreta & Correta & Incorreta \\
\hline 0.386 & 94.9 & 94.9 & -0.2 & -0.3 \\
0.395 & 95.0 & 95.0 & 0.1 & 0.1 \\
0.455 & 94.8 & 94.8 & 0.0 & 0.2 \\
0.463 & 94.8 & 94.7 & -0.1 & 0.2 \\
0.516 & 94.8 & 94.8 & 0.2 & 0.1 \\
0.573 & 94.7 & 94.7 & 0.3 & 0.2 \\
0.596 & 94.9 & 94.9 & -0.1 & -0.1 \\
0.601 & 94.7 & 94.7 & 0.2 & 0.2 \\
0.603 & 94.8 & 94.8 & -0.3 & -0.2 \\
0.611 & 94.7 & 94.7 & -0.2 & -0.1 \\
\hline$\phi=20$ & 95.2 & 95.2 & -0.8 & -0.8 \\
\hline \hline
\end{tabular}


Tabela B.16: Resultados dos intervalos de confiança para as respostas médias: taxa de cobertura e balanceamento; ligação correta probito, ligação incorreta logito, planejamento com réplicas, $\mu_{t} \in[0.386 ; 0.611], n=500$ e $\phi=120$.

\begin{tabular}{ccccc}
\hline \hline & \multicolumn{2}{c}{ Cobertura (\%) } & \multicolumn{2}{c}{ Balanceamento (\%) } \\
Médias & Correta & Incorreta & Correta & Incorreta \\
\hline 0.386 & 94.9 & 94.9 & -0.1 & -0.3 \\
0.395 & 94.9 & 94.9 & 0.2 & 0.2 \\
0.455 & 94.8 & 94.8 & 0.2 & 0.7 \\
0.463 & 94.8 & 94.8 & 0.3 & 0.7 \\
0.516 & 94.9 & 95.0 & 0.4 & 0.2 \\
0.573 & 95.0 & 95.0 & 0.4 & 0.1 \\
0.596 & 95.0 & 95.0 & 0.2 & 0.1 \\
0.601 & 95.2 & 95.1 & 0.1 & 0.2 \\
0.603 & 95.0 & 95.0 & 0.2 & 0.3 \\
0.611 & 94.8 & 94.9 & 0.2 & 0.4 \\
\hline$\phi=120$ & 95.0 & 95.1 & -0.4 & -0.4 \\
\hline \hline
\end{tabular}

\section{B.3 Função de Ligação Correta Complemento Log- Log e Incorreta Logito}

Tabela B.17: Resultados dos intervalos de confiança para as respostas médias: taxa de cobertura e balanceamento; ligação correta complemento log-log, ligação incorreta logito, planejamento com réplicas, $\mu_{t} \in[0.022 ; 0.084], n=20$ e $\phi=20$.

\begin{tabular}{ccccc}
\hline \hline & \multicolumn{2}{c}{ Cobertura (\%) } & \multicolumn{2}{c}{ Balanceamento (\%) } \\
Médias & Correta & Incorreta & Correta & Incorreta \\
\hline 0.022 & 90.9 & 90.8 & 2.0 & 2.2 \\
0.023 & 91.2 & 91.2 & 2.1 & 2.3 \\
0.033 & 91.0 & 91.1 & 3.0 & 3.0 \\
0.034 & 90.4 & 90.5 & 3.1 & 3.1 \\
0.047 & 90.4 & 90.4 & 3.4 & 3.3 \\
0.066 & 90.8 & 90.9 & -0.6 & -0.5 \\
0.076 & 90.6 & 90.7 & 1.3 & 1.6 \\
0.079 & 90.6 & 90.7 & -1.2 & -0.8 \\
0.080 & 90.7 & 90.8 & 0.9 & 1.3 \\
0.084 & 90.6 & 90.8 & 1.1 & 1.6 \\
\hline$\phi=20$ & 96.2 & 96.2 & -1.0 & -1.0 \\
\hline \hline
\end{tabular}


Tabela B.18: Resultados dos intervalos de confiança para as respostas médias: taxa de cobertura e balanceamento; ligação correta complemento log-log, ligação incorreta logito, planejamento com réplicas, $\mu_{t} \in[0.022 ; 0.084], n=20$ e $\phi=120$.

\begin{tabular}{ccccc}
\hline \hline & \multicolumn{2}{c}{ Cobertura (\%) } & \multicolumn{2}{c}{ Balanceamento (\%) } \\
Médias & Correta & Incorreta & Correta & Incorreta \\
\hline 0.022 & 90.7 & 90.7 & 0.9 & 1.3 \\
0.023 & 91.1 & 91.1 & 0.4 & 0.6 \\
0.033 & 91.2 & 91.2 & 0.9 & 0.8 \\
0.034 & 90.8 & 90.8 & 1.5 & 1.3 \\
0.047 & 90.8 & 90.8 & 1.8 & 1.4 \\
0.066 & 91.5 & 91.5 & -0.8 & -0.9 \\
0.076 & 91.1 & 91.1 & 0.8 & 0.9 \\
0.079 & 91.4 & 91.4 & -1.1 & -0.8 \\
0.080 & 91.0 & 91.0 & 0.7 & 1.0 \\
0.084 & 91.1 & 91.1 & 0.4 & 0.7 \\
\hline$\phi=120$ & 96.1 & 96.0 & -1.4 & -1.4 \\
\hline \hline
\end{tabular}

Tabela B.19: Resultados dos intervalos de confiança para as respostas médias: taxa de cobertura e balanceamento; ligação correta complemento log-log, ligação incorreta logito, planejamento com réplicas, $\mu_{t} \in[0.022 ; 0.084], n=500$ e $\phi=20$.

\begin{tabular}{ccccc}
\hline \hline & \multicolumn{2}{c}{ Cobertura (\%) } & \multicolumn{2}{c}{ Balanceamento (\%) } \\
Médias & Correta & Incorreta & Correta & Incorreta \\
\hline 0.022 & 94.4 & 94.4 & 0.1 & 0.5 \\
0.023 & 94.8 & 94.8 & 0.0 & 0.4 \\
0.033 & 94.8 & 94.8 & 0.3 & 0.1 \\
0.034 & 94.6 & 94.7 & 0.4 & -0.1 \\
0.047 & 94.7 & 94.7 & 0.3 & -0.4 \\
0.066 & 94.8 & 94.7 & -0.2 & -0.4 \\
0.076 & 94.7 & 94.8 & -0.1 & 0.0 \\
0.079 & 94.7 & 94.7 & -0.3 & -0.1 \\
0.080 & 94.8 & 94.8 & 0.0 & 0.2 \\
0.084 & 94.5 & 94.4 & 0.0 & 0.6 \\
\hline$\phi=20$ & 94.9 & 94.9 & -0.5 & -0.5 \\
\hline \hline
\end{tabular}


Tabela B.20: Resultados dos intervalos de confiança para as respostas médias: taxa de cobertura e balanceamento; ligação correta complemento log-log, ligação incorreta logito, planejamento com réplicas, $\mu_{t} \in[0.022 ; 0.084], n=500$ e $\phi=120$.

\begin{tabular}{ccccc}
\hline \hline & \multicolumn{2}{c}{ Cobertura (\%) } & \multicolumn{2}{c}{ Balanceamento (\%) } \\
Médias & Correta & Incorreta & Correta & Incorreta \\
\hline 0.022 & 94.7 & 94.8 & 0.3 & 1.0 \\
0.023 & 94.9 & 95.0 & 0.0 & 0.8 \\
0.033 & 94.6 & 94.6 & -0.2 & -0.6 \\
0.034 & 94.8 & 94.7 & -0.1 & -0.7 \\
0.047 & 94.9 & 94.7 & 0.2 & -1.3 \\
0.066 & 94.8 & 94.8 & 0.1 & -0.5 \\
0.076 & 95.5 & 95.5 & 0.6 & 0.6 \\
0.079 & 94.8 & 94.7 & -0.3 & 0.0 \\
0.080 & 95.4 & 95.5 & 0.4 & 0.7 \\
0.084 & 95.4 & 95.4 & 0.3 & 1.0 \\
\hline$\phi=120$ & 95.0 & 95.0 & -0.5 & -0.5 \\
\hline \hline
\end{tabular}

Tabela B.21: Resultados dos intervalos de confiança para as respostas médias: taxa de cobertura e balanceamento; ligação correta complemento log-log, ligação incorreta logito, planejamento com réplicas, $\mu_{t} \in[0.343 ; 0.657], n=20$ e $\phi=20$.

\begin{tabular}{ccccc}
\hline \hline & \multicolumn{2}{c}{ Cobertura (\%) } & \multicolumn{2}{c}{ Balanceamento (\%) } \\
Médias & Correta & Incorreta & Correta & Incorreta \\
\hline 0.343 & 91.7 & 91.4 & 0.1 & 3.1 \\
0.377 & 91.4 & 91.6 & -0.3 & 0.5 \\
0.411 & 91.4 & 91.5 & 0.2 & 0.2 \\
0.466 & 91.3 & 90.9 & -0.2 & -2.6 \\
0.536 & 91.4 & 91.4 & -0.2 & -0.7 \\
0.540 & 91.1 & 90.6 & -0.4 & -3.0 \\
0.583 & 91.3 & 91.3 & -0.1 & 0.1 \\
0.644 & 91.6 & 91.6 & -1.1 & 0.7 \\
0.652 & 91.8 & 91.7 & -1.0 & 1.5 \\
0.657 & 91.6 & 91.5 & -1.3 & 1.4 \\
\hline$\phi=20$ & 96.4 & 96.3 & -0.9 & -0.9 \\
\hline \hline
\end{tabular}


Tabela B.22: Resultados dos intervalos de confiança para as respostas médias: taxa de cobertura e balanceamento; ligação correta complemento log-log, ligação incorreta logito, planejamento com réplicas, $\mu_{t} \in[0.343 ; 0.657], n=20$ e $\phi=120$.

\begin{tabular}{ccccc}
\hline \hline & \multicolumn{2}{c}{ Cobertura (\%) } & \multicolumn{2}{c}{ Balanceamento (\%) } \\
Médias & Correta & Incorreta & Correta & Incorreta \\
\hline 0.343 & 90.8 & 88.9 & -0.3 & 6.5 \\
0.377 & 91.5 & 91.7 & 0.1 & 1.4 \\
0.411 & 91.0 & 91.0 & -0.4 & -0.9 \\
0.466 & 91.6 & 89.6 & 0.3 & -6.8 \\
0.536 & 91.1 & 91.0 & -0.4 & -3.0 \\
0.540 & 91.1 & 88.6 & 0.2 & -7.9 \\
0.583 & 91.2 & 91.4 & -0.5 & -1.7 \\
0.644 & 90.4 & 90.5 & -0.5 & 2.8 \\
0.652 & 90.5 & 90.1 & -0.2 & 4.8 \\
0.657 & 90.5 & 90.0 & -0.5 & 4.7 \\
\hline$\phi=120$ & 96.0 & 95.9 & -1.4 & -1.2 \\
\hline \hline
\end{tabular}

Tabela B.23: Resultados dos intervalos de confiança para as respostas médias: taxa de cobertura e balanceamento; ligação correta complemento log-log, ligação incorreta logito, planejamento com réplicas, $\mu_{t} \in[0.343 ; 0.657], n=500$ e $\phi=20$.

\begin{tabular}{ccccc}
\hline \hline & \multicolumn{2}{c}{ Cobertura (\%) } & \multicolumn{2}{c}{ Balanceamento (\%) } \\
Médias & Correta & Incorreta & Correta & Incorreta \\
\hline 0.343 & 94.7 & 88.7 & -0.2 & 10.6 \\
0.377 & 94.9 & 95.0 & -0.1 & 1.0 \\
0.411 & 94.4 & 94.2 & -0.3 & -1.5 \\
0.466 & 94.9 & 86.6 & -0.2 & -12.8 \\
0.536 & 94.9 & 93.3 & -0.1 & -4.5 \\
0.540 & 95.0 & 84.9 & -0.5 & -14.7 \\
0.583 & 94.8 & 94.4 & -0.1 & -2.0 \\
0.644 & 95.1 & 94.2 & -0.6 & 3.4 \\
0.652 & 94.9 & 91.7 & -0.3 & 6.9 \\
0.657 & 95.1 & 91.9 & -0.4 & 6.6 \\
\hline$\phi=20$ & 95.4 & 95.4 & -0.2 & -0.1 \\
\hline \hline
\end{tabular}


Tabela B.24: Resultados dos intervalos de confiança para as respostas médias: taxa de cobertura e balanceamento; ligação correta complemento log-log, ligação incorreta logito, planejamento com réplicas, $\mu_{t} \in[0.343 ; 0.657], n=500$ e $\phi=120$.

\begin{tabular}{ccccc}
\hline \hline & \multicolumn{2}{c}{ Cobertura (\%) } & \multicolumn{2}{c}{ Balanceamento (\%) } \\
Médias & Correta & Incorreta & Correta & Incorreta \\
\hline 0.343 & 95.1 & 58.8 & 0.2 & 41.2 \\
0.377 & 94.9 & 94.5 & 0.2 & 2.7 \\
0.411 & 94.8 & 94.1 & -0.1 & -3.0 \\
0.466 & 94.8 & 50.9 & 0.2 & -49.1 \\
0.536 & 94.3 & 85.6 & 0.0 & -13.9 \\
0.540 & 95.0 & 42.6 & 0.4 & -57.4 \\
0.583 & 94.3 & 92.8 & -0.1 & -5.1 \\
0.644 & 94.6 & 87.6 & 0.4 & 11.9 \\
0.652 & 94.5 & 73.3 & 0.3 & 26.6 \\
0.657 & 94.7 & 75.8 & 0.4 & 24.1 \\
\hline$\phi=120$ & 95.2 & 95.0 & -0.4 & 1.0 \\
\hline \hline
\end{tabular}

Tabela B.25: Resultados dos intervalos de confiança para as respostas médias: taxa de cobertura e balanceamento; ligação correta complemento log-log, ligação incorreta logito, planejamento com réplicas, $\mu_{t} \in[0.913 ; 0.974], n=20$ e $\phi=20$.

\begin{tabular}{ccccc}
\hline \hline & \multicolumn{2}{c}{ Cobertura (\%) } & \multicolumn{2}{c}{ Balanceamento (\%) } \\
Médias & Correta & Incorreta & Correta & Incorreta \\
\hline 0.913 & 91.1 & 91.2 & -2.9 & 0.3 \\
0.917 & 90.9 & 91.2 & -3.3 & -0.5 \\
0.920 & 90.8 & 91.1 & -3.4 & -1.2 \\
0.933 & 90.8 & 90.7 & -4.4 & -4.2 \\
0.946 & 90.4 & 90.1 & -4.7 & -4.6 \\
0.949 & 91.0 & 90.9 & -2.3 & -1.1 \\
0.957 & 91.0 & 90.9 & -2.1 & -0.8 \\
0.959 & 90.3 & 90.4 & -3.1 & -1.6 \\
0.966 & 91.1 & 91.5 & -3.7 & -1.9 \\
0.974 & 91.0 & 91.2 & -3.3 & 0.2 \\
\hline$\phi=20$ & 95.9 & 96.1 & -1.0 & -1.1 \\
\hline \hline
\end{tabular}


Tabela B.26: Resultados dos intervalos de confiança para as respostas médias: taxa de cobertura e balanceamento; ligação correta complemento log-log, ligação incorreta logito, planejamento com réplicas, $\mu_{t} \in[0.913 ; 0.974], n=20$ e $\phi=120$.

\begin{tabular}{ccccc}
\hline \hline & \multicolumn{2}{c}{ Cobertura (\%) } & \multicolumn{2}{c}{ Balanceamento (\%) } \\
Médias & Correta & Incorreta & Correta & Incorreta \\
\hline 0.913 & 91.0 & 90.9 & -0.5 & 2.5 \\
0.917 & 90.9 & 91.1 & -0.5 & 1.6 \\
0.920 & 90.7 & 90.8 & -0.9 & 0.4 \\
0.933 & 91.1 & 90.8 & -1.3 & -3.2 \\
0.946 & 91.5 & 90.9 & -1.5 & -3.6 \\
0.949 & 91.3 & 91.1 & -1.2 & -2.3 \\
0.957 & 91.4 & 91.3 & -1.3 & -1.3 \\
0.959 & 91.4 & 91.5 & -0.9 & -1.1 \\
0.966 & 91.0 & 91.4 & -2.1 & -0.5 \\
0.974 & 91.0 & 90.6 & -1.5 & 3.5 \\
\hline$\phi=120$ & 96.1 & 96.1 & -1.1 & -1.1 \\
\hline \hline
\end{tabular}

Tabela B.27: Resultados dos intervalos de confiança para as respostas médias: taxa de cobertura e balanceamento; ligação correta complemento log-log, ligação incorreta logito, planejamento com réplicas, $\mu_{t} \in[0.913 ; 0.974], n=500$ e $\phi=20$.

\begin{tabular}{ccccc}
\hline \hline & \multicolumn{2}{c}{ Cobertura (\%) } & \multicolumn{2}{c}{ Balanceamento (\%) } \\
Médias & Correta & Incorreta & Correta & Incorreta \\
\hline 0.913 & 95.0 & 93.5 & 0.1 & 4.0 \\
0.917 & 95.0 & 94.2 & 0.1 & 2.6 \\
0.920 & 95.0 & 94.7 & -0.1 & 1.6 \\
0.933 & 95.2 & 93.8 & -0.7 & -3.9 \\
0.946 & 95.2 & 93.0 & -0.7 & -5.5 \\
0.949 & 95.1 & 94.5 & -0.1 & -2.7 \\
0.957 & 95.2 & 95.0 & 0.2 & -1.6 \\
0.959 & 95.0 & 94.5 & -0.5 & -2.5 \\
0.966 & 95.3 & 95.4 & -0.4 & 0.9 \\
0.974 & 95.1 & 92.2 & -0.5 & 6.6 \\
\hline$\phi=20$ & 95.1 & 95.2 & -0.2 & -0.1 \\
\hline \hline
\end{tabular}


Tabela B.28: Resultados dos intervalos de confiança para as respostas médias: taxa de cobertura e balanceamento; ligação correta complemento log-log, ligação incorreta logito, planejamento com réplicas, $\mu_{t} \in[0.913 ; 0.974], n=500$ e $\phi=120$.

\begin{tabular}{ccccc}
\hline \hline & \multicolumn{2}{c}{ Cobertura (\%) } & \multicolumn{2}{c}{ Balanceamento (\%) } \\
Médias & Correta & Incorreta & Correta & Incorreta \\
\hline 0.913 & 95.1 & 91.1 & 0.1 & 8.2 \\
0.917 & 95.1 & 93.6 & 0.1 & 4.8 \\
0.920 & 95.1 & 94.8 & 0.0 & 2.0 \\
0.933 & 95.1 & 89.9 & -0.2 & -9.2 \\
0.946 & 95.0 & 86.6 & 0.0 & -12.7 \\
0.949 & 95.2 & 91.2 & -0.4 & -7.4 \\
0.957 & 95.1 & 93.8 & -0.4 & -4.0 \\
0.959 & 94.8 & 93.6 & 0.2 & -3.4 \\
0.966 & 94.8 & 93.9 & -0.3 & 3.7 \\
0.974 & 95.1 & 76.0 & -0.2 & 23.8 \\
\hline$\phi=120$ & 94.9 & 95.0 & -0.5 & 0.2 \\
\hline \hline
\end{tabular}

\section{B.4 Função de Ligação Correta Log-log e Incorreta Logito}

Tabela B.29: Resultados dos intervalos de confiança para as respostas médias: taxa de cobertura e balanceamento; ligação correta log-log, ligação incorreta logito, planejamento com réplicas, $\mu_{t} \in[0.026 ; 0.087], n=20$ e $\phi=20$.

\begin{tabular}{ccccc}
\hline \hline & \multicolumn{2}{c}{ Cobertura (\%) } & \multicolumn{2}{c}{ Balanceamento (\%) } \\
Médias & Correta & Incorreta & Correta & Incorreta \\
\hline 0.026 & 90.7 & 90.9 & 3.3 & -0.1 \\
0.034 & 90.6 & 91.2 & 4.0 & 2.1 \\
0.041 & 90.4 & 90.3 & 3.3 & 2.0 \\
0.043 & 91.1 & 90.9 & 2.5 & 1.2 \\
0.051 & 91.1 & 90.8 & 2.4 & 1.1 \\
0.054 & 90.4 & 90.1 & 4.4 & 4.2 \\
0.067 & 90.4 & 90.3 & 4.1 & 3.8 \\
0.080 & 90.5 & 90.8 & 3.1 & 0.9 \\
0.083 & 90.4 & 90.7 & 3.1 & 0.4 \\
0.087 & 90.5 & 90.8 & 2.7 & -0.6 \\
\hline$\phi=20$ & 96.1 & 96.1 & -1.2 & -1.2 \\
\hline \hline
\end{tabular}


Tabela B.30: Resultados dos intervalos de confiança para as respostas médias: taxa de cobertura e balanceamento; ligação correta log-log, ligação incorreta logito, planejamento com réplicas, $\mu_{t} \in[0.026 ; 0.087], n=20$ e $\phi=120$.

\begin{tabular}{ccccc}
\hline \hline & \multicolumn{2}{c}{ Cobertura (\%) } & \multicolumn{2}{c}{ Balanceamento (\%) } \\
Médias & Correta & Incorreta & Correta & Incorreta \\
\hline 0.026 & 90.7 & 90.6 & 0.9 & -4.1 \\
0.034 & 90.7 & 91.2 & 1.7 & -0.2 \\
0.041 & 91.3 & 91.3 & 1.2 & 1.3 \\
0.043 & 90.7 & 90.5 & 0.9 & 0.9 \\
0.051 & 90.6 & 90.5 & 0.9 & 1.8 \\
0.054 & 91.4 & 90.8 & 2.1 & 4.1 \\
0.067 & 90.8 & 90.4 & 1.4 & 3.5 \\
0.080 & 90.6 & 90.6 & 1.0 & -0.3 \\
0.083 & 90.7 & 90.9 & 0.4 & -1.6 \\
0.087 & 90.7 & 90.6 & 0.3 & -2.6 \\
\hline$\phi=120$ & 96.3 & 96.2 & -1.4 & -1.3 \\
\hline \hline
\end{tabular}

Tabela B.31: Resultados dos intervalos de confiança para as respostas médias: taxa de cobertura e balanceamento; ligação correta log-log, ligação incorreta logito, planejamento com réplicas, $\mu_{t} \in[0.026 ; 0.087], n=500$ e $\phi=20$.

\begin{tabular}{ccccc}
\hline \hline & \multicolumn{2}{c}{ Cobertura (\%) } & \multicolumn{2}{c}{ Balanceamento (\%) } \\
Médias & Correta & Incorreta & Correta & Incorreta \\
\hline 0.026 & 95.1 & 91.9 & 0.4 & -6.9 \\
0.034 & 94.9 & 95.0 & 0.5 & -0.9 \\
0.041 & 94.8 & 94.4 & 0.6 & 2.5 \\
0.043 & 94.9 & 94.6 & 0.1 & 1.7 \\
0.051 & 94.8 & 94.1 & 0.3 & 2.9 \\
0.054 & 94.7 & 92.7 & 0.8 & 5.8 \\
0.067 & 94.9 & 93.8 & 0.7 & 3.8 \\
0.080 & 94.9 & 94.8 & 0.4 & -1.2 \\
0.083 & 95.0 & 94.5 & 0.5 & -2.5 \\
0.087 & 95.0 & 93.8 & 0.5 & -3.8 \\
\hline$\phi=20$ & 95.2 & 95.3 & 0.0 & 0.2 \\
\hline \hline
\end{tabular}


Tabela B.32: Resultados dos intervalos de confiança para as respostas médias: taxa de cobertura e balanceamento; ligação correta log-log, ligação incorreta logito, planejamento com réplicas, $\mu_{t} \in[0.026 ; 0.087], n=500$ e $\phi=120$.

\begin{tabular}{ccccc}
\hline \hline & \multicolumn{2}{c}{ Cobertura (\%) } & \multicolumn{2}{c}{ Balanceamento (\%) } \\
Médias & Correta & Incorreta & Correta & Incorreta \\
\hline 0.026 & 94.7 & 76.2 & 0.3 & -23.7 \\
0.034 & 94.7 & 93.7 & 0.5 & -3.9 \\
0.041 & 94.7 & 93.8 & 0.2 & 3.7 \\
0.043 & 95.2 & 93.9 & 0.4 & 3.9 \\
0.051 & 95.1 & 91.2 & 0.3 & 7.4 \\
0.054 & 94.9 & 86.3 & 0.5 & 13.2 \\
0.067 & 94.9 & 90.0 & 0.3 & 9.3 \\
0.080 & 95.0 & 94.7 & 0.2 & -2.1 \\
0.083 & 95.2 & 93.3 & 0.1 & -5.2 \\
0.087 & 95.2 & 90.5 & 0.1 & -8.8 \\
\hline$\phi=120$ & 95.1 & 95.0 & -0.8 & 0.1 \\
\hline \hline
\end{tabular}

Tabela B.33: Resultados dos intervalos de confiança para as respostas médias: taxa de cobertura e balanceamento; ligação correta log-log, ligação incorreta logito, planejamento com réplicas, $\mu_{t} \in[0.430 ; 0.592], n=20$ e $\phi=20$.

\begin{tabular}{ccccc}
\hline \hline & \multicolumn{2}{c}{ Cobertura (\%) } & \multicolumn{2}{c}{ Balanceamento (\%) } \\
Médias & Correta & Incorreta & Correta & Incorreta \\
\hline 0.430 & 91.2 & 91.3 & 0.4 & -1.0 \\
0.469 & 91.2 & 91.3 & 0.5 & -0.2 \\
0.488 & 91.3 & 91.3 & 0.9 & 0.6 \\
0.488 & 91.5 & 91.4 & 0.2 & -0.1 \\
0.515 & 91.5 & 91.4 & 1.1 & 1.1 \\
0.529 & 91.2 & 91.3 & 0.0 & -0.4 \\
0.530 & 91.4 & 91.5 & 0.1 & -0.5 \\
0.548 & 91.0 & 91.2 & 0.4 & -0.1 \\
0.588 & 91.3 & 91.4 & 0.8 & 0.2 \\
0.592 & 91.4 & 91.6 & 0.8 & -0.1 \\
\hline$\phi=20$ & 96.2 & 96.2 & -0.8 & -0.8 \\
\hline \hline
\end{tabular}


Tabela B.34: Resultados dos intervalos de confiança para as respostas médias: taxa de cobertura e balanceamento; ligação correta log-log, ligação incorreta logito, planejamento com réplicas, $\mu_{t} \in[0.430 ; 0.592], n=20$ e $\phi=120$.

\begin{tabular}{ccccc}
\hline \hline & \multicolumn{2}{c}{ Cobertura (\%) } & \multicolumn{2}{c}{ Balanceamento (\%) } \\
Médias & Correta & Incorreta & Correta & Incorreta \\
\hline 0.430 & 90.9 & 90.7 & 0.7 & -1.4 \\
0.469 & 91.1 & 91.0 & 0.9 & 0.6 \\
0.488 & 90.8 & 90.8 & 0.4 & 1.4 \\
0.488 & 91.2 & 91.1 & 0.7 & 1.0 \\
0.515 & 91.0 & 90.8 & 0.4 & 1.9 \\
0.529 & 91.5 & 91.5 & 0.3 & 0.6 \\
0.530 & 91.4 & 91.5 & 0.4 & 0.6 \\
0.548 & 91.5 & 91.5 & 0.0 & 0.1 \\
0.588 & 91.0 & 90.9 & 0.0 & -1.0 \\
0.592 & 91.0 & 91.0 & 0.0 & -1.3 \\
\hline$\phi=120$ & 95.9 & 95.9 & -1.3 & -1.3 \\
\hline \hline
\end{tabular}

Tabela B.35: Resultados dos intervalos de confiança para as respostas médias: taxa de cobertura e balanceamento; ligação correta log-log, ligação incorreta logito, planejamento com réplicas, $\mu_{t} \in[0.430 ; 0.592], n=500$ e $\phi=20$.

\begin{tabular}{ccccc}
\hline \hline & \multicolumn{2}{c}{ Cobertura (\%) } & \multicolumn{2}{c}{ Balanceamento (\%) } \\
Médias & Correta & Incorreta & Correta & Incorreta \\
\hline 0.430 & 94.9 & 94.5 & 0.1 & -2.7 \\
0.469 & 94.9 & 95.1 & 0.1 & -0.1 \\
0.488 & 94.9 & 94.8 & 0.6 & 1.8 \\
0.488 & 95.3 & 95.2 & 0.0 & 0.6 \\
0.515 & 94.8 & 94.2 & 0.3 & 2.7 \\
0.529 & 94.9 & 94.9 & -0.2 & 0.6 \\
0.530 & 95.0 & 95.0 & -0.2 & 0.5 \\
0.548 & 95.1 & 95.0 & 0.2 & 0.4 \\
0.588 & 95.1 & 94.8 & -0.1 & -1.3 \\
0.592 & 95.0 & 94.6 & -0.1 & -1.8 \\
\hline$\phi=20$ & 95.2 & 95.3 & -0.6 & -0.5 \\
\hline \hline
\end{tabular}


Tabela B.36: Resultados dos intervalos de confiança para as respostas médias: taxa de cobertura e balanceamento; ligação correta log-log, ligação incorreta logito, planejamento com réplicas, $\mu_{t} \in[0.430 ; 0.592], n=500$ e $\phi=120$.

\begin{tabular}{ccccc}
\hline \hline & \multicolumn{2}{c}{ Cobertura (\%) } & \multicolumn{2}{c}{ Balanceamento (\%) } \\
Médias & Correta & Incorreta & Correta & Incorreta \\
\hline 0.430 & 94.8 & 91.3 & 0.1 & -7.3 \\
0.469 & 95.1 & 95.2 & 0.0 & -0.2 \\
0.488 & 94.9 & 93.8 & 0.2 & 3.9 \\
0.488 & 95.1 & 94.8 & 0.1 & 1.7 \\
0.515 & 95.1 & 92.4 & 0.0 & 6.1 \\
0.529 & 94.7 & 94.4 & 0.1 & 2.1 \\
0.530 & 94.7 & 94.4 & 0.1 & 1.8 \\
0.548 & 94.8 & 94.7 & 0.1 & 0.9 \\
0.588 & 95.1 & 94.5 & 0.2 & -2.2 \\
0.592 & 94.8 & 94.0 & 0.3 & -3.8 \\
\hline$\phi=120$ & 94.9 & 95.0 & -0.3 & -0.1 \\
\hline \hline
\end{tabular}

Tabela B.37: Resultados dos intervalos de confiança para as respostas médias: taxa de cobertura e balanceamento; ligação correta log-log, ligação incorreta logito, planejamento com réplicas, $\mu_{t} \in[0.932 ; 0.974], n=20$ e $\phi=20$.

\begin{tabular}{ccccc}
\hline \hline & \multicolumn{2}{c}{ Cobertura (\%) } & \multicolumn{2}{c}{ Balanceamento (\%) } \\
Médias & Correta & Incorreta & Correta & Incorreta \\
\hline 0.932 & 90.8 & 90.8 & -1.1 & -1.4 \\
0.932 & 91.2 & 91.2 & -1.5 & -1.8 \\
0.934 & 90.7 & 90.8 & -1.6 & -2.0 \\
0.943 & 90.8 & 90.8 & 0.3 & 0.0 \\
0.950 & 90.7 & 90.8 & 0.3 & 0.2 \\
0.952 & 90.5 & 90.5 & -3.6 & -3.6 \\
0.961 & 90.6 & 90.7 & -3.4 & -3.5 \\
0.967 & 90.8 & 90.8 & -2.6 & -2.7 \\
0.972 & 91.0 & 91.0 & -1.9 & -2.0 \\
0.974 & 90.6 & 90.5 & -1.9 & -2.1 \\
\hline$\phi=20$ & 95.8 & 95.8 & -1.4 & -1.4 \\
\hline \hline
\end{tabular}


Tabela B.38: Resultados dos intervalos de confiança para as respostas médias: taxa de cobertura e balanceamento; ligação correta log-log, ligação incorreta logito, planejamento com réplicas, $\mu_{t} \in[0.932 ; 0.974], n=20$ e $\phi=120$.

\begin{tabular}{ccccc}
\hline \hline & \multicolumn{2}{c}{ Cobertura (\%) } & \multicolumn{2}{c}{ Balanceamento (\%) } \\
Médias & Correta & Incorreta & Correta & Incorreta \\
\hline 0.932 & 90.7 & 90.7 & 0.4 & 0.2 \\
0.932 & 90.5 & 90.5 & 0.2 & 0.1 \\
0.934 & 90.7 & 90.7 & 0.3 & 0.1 \\
0.943 & 90.7 & 90.7 & 0.6 & 0.6 \\
0.950 & 90.8 & 90.8 & 0.4 & 0.4 \\
0.952 & 90.6 & 90.7 & -1.2 & -1.0 \\
0.961 & 91.0 & 91.0 & -1.3 & -1.2 \\
0.967 & 90.7 & 90.7 & -1.0 & -1.0 \\
0.972 & 91.2 & 91.1 & -0.9 & -0.9 \\
0.974 & 90.9 & 90.9 & -0.9 & -1.0 \\
\hline$\phi=120$ & 95.6 & 95.6 & -1.5 & -1.5 \\
\hline \hline
\end{tabular}

Tabela B.39: Resultados dos intervalos de confiança para as respostas médias: taxa de cobertura e balanceamento; ligação correta log-log, ligação incorreta logito, planejamento com réplicas, $\mu_{t} \in[0.932 ; 0.974], n=500$ e $\phi=20$.

\begin{tabular}{ccccc}
\hline \hline & \multicolumn{2}{c}{ Cobertura (\%) } & \multicolumn{2}{c}{ Balanceamento (\%) } \\
Médias & Correta & Incorreta & Correta & Incorreta \\
\hline 0.932 & 94.6 & 94.6 & -0.2 & -0.5 \\
0.932 & 94.9 & 94.9 & -0.4 & -0.5 \\
0.934 & 94.6 & 94.6 & -0.5 & -0.6 \\
0.943 & 95.1 & 95.1 & -0.5 & -0.4 \\
0.950 & 95.2 & 95.2 & -0.4 & -0.3 \\
0.952 & 94.8 & 94.8 & -0.6 & -0.2 \\
0.961 & 94.7 & 94.6 & -0.4 & -0.1 \\
0.967 & 94.7 & 94.8 & -0.4 & -0.4 \\
0.972 & 94.8 & 94.8 & 0.0 & -0.1 \\
0.974 & 94.8 & 94.6 & -0.5 & -0.8 \\
\hline$\phi=20$ & 94.7 & 94.7 & -0.7 & -0.7 \\
\hline \hline
\end{tabular}


Tabela B.40: Resultados dos intervalos de confiança para as respostas médias: taxa de cobertura e balanceamento; ligação correta log-log, ligação incorreta logito, planejamento com réplicas, $\mu_{t} \in[0.932 ; 0.974], n=500$ e $\phi=120$.

\begin{tabular}{ccccc}
\hline \hline & \multicolumn{2}{c}{ Cobertura (\%) } & \multicolumn{2}{c}{ Balanceamento (\%) } \\
Médias & Correta & Incorreta & Correta & Incorreta \\
\hline 0.932 & 94.8 & 94.8 & 0.1 & -0.2 \\
0.932 & 94.9 & 95.0 & 0.0 & -0.4 \\
0.934 & 94.9 & 94.9 & 0.0 & -0.1 \\
0.943 & 94.6 & 94.6 & 0.5 & 0.6 \\
0.950 & 94.7 & 94.8 & 0.5 & 0.7 \\
0.952 & 95.0 & 94.8 & -0.2 & 0.6 \\
0.961 & 94.8 & 94.7 & -0.1 & 0.6 \\
0.967 & 94.9 & 94.9 & 0.5 & 0.5 \\
0.972 & 94.6 & 94.6 & -0.1 & -0.3 \\
0.974 & 94.8 & 94.7 & 0.3 & -0.3 \\
\hline$\phi=120$ & 95.1 & 95.2 & -0.5 & -0.5 \\
\hline \hline
\end{tabular}




\section{Referências Bibliográficas}

[1] Aranda-Ordaz, F.J. (1981). On two families of transformations to additivity for binary response data. Biometrika, 68, 357-363.

[2] Atkinson, A.C. (1985). Plots, Transformations and Regression: An Introduction to Graphical Methods of Diagnostic Regression Analysis. New York: Oxford University Press.

[3] Bury, K. (1999). Statistical Distributions in Engineering. New York: Cambridge University Press.

[4] Demétrio, C.G.B. (2001). Modelos Lineares Generalizados em Experimentação Agronômica. $46^{\circ}$ Reunião Anual da RBRAS e $9^{\circ}$ SEAGRO.

[5] Doornik, J.A. (2001). Ox: An Object-Oriented Matrix Programming Language, $4^{\circ}$ edição. London: Timberlake Consultants \& Oxford: http://www.doornik.com/index.html.

[6] Espinheira, P.L., Ferrari, S.L.P. \& Cribari-Neto, F. (2007). On beta regression residuals. A aparecer no Journal of Applied Statistics.

[7] Espinheira Ospina, P.L. (2007). Regressão beta. Tese de Doutorado, Universidade de São Paulo - USP, Brasil.

[8] Ferrari, S.L.P. \& Cribari-Neto, F. (2004). Beta regression for modelling rates and proportions. Journal of Applied Statistics, 31, 799-815.

[9] Johnson, N.L., Kotz, S. \& Balakrishnan, N. (1995). Continuous Univariate Distributions, $2^{\circ}$ edição. New York: John Wiley \& Sons. 
[10] Kieschnick, R. \& McCullough, B.D. (2003). Regression analysis of variates observed on $(0,1)$ : percentages, proportions and fractions. Statistical Modelling, 3, 193-213.

[11] Lima, L.B. (2007). Um teste de especificação correta em modelos de regressão beta. Dissertação de Mestrado, Universidade Federal de Pernambuco - UFPE, Brasil.

[12] McCullagh, P. \& Nelder, J.A. (1989). Generalized Linear Models, 2 edição. London: Chapman \& Hall.

[13] Myers, R.H. Montgomery, D.C. \& Vining, G.G. (2002). Generalized Linear Models With Applications in Engineering and the Sciences. New York: Wiley.

[14] Nocedal, J. \& Wright, S.J. (1999). Numerical Optimization. New York: Springer-Verlag.

[15] Oliveira, M.S. (2004). Um modelo de regressão beta: teoria e aplicações. Dissertação de Mestrado, Universidade de São Paulo - USP, Brasil.

[16] Ospina, R., Cribari-Neto, F. \& Vasconcellos, K.L.P. (2006). Improved point and interval estimation for a beta regression model. Computational Statistics \& Data Analysis, 51, $960-981$.

[17] Paula, G.A. (2004). Modelos de Regressão com Apoio Computacional. Disponível em http://www.ime.usp.br/ giapaula/livro.html

[18] Papke, L. \& Wooldridge, J. (1996). Econometric methods for fractional response variables with an application to 401(K) plan participation rates. Journal of Applied Econometrics, 11, 619-632.

[19] Prater, N.H. (1956). Estimate gasoline yields from crude. Petroleum Refiner, 35, 236-238.

[20] Rao, C.R. (1973). Linear Statistical Inference and Its Applications, $2^{\circ}$ edição. New York: Wiley.

[21] Sen, P.K. \& Singer, J.M. (1993). Large Sample Methods in Statistics: An Introduction With Applications. New York: Chapman \& Hall.

[22] Simas, A.B. (2006). Beta regression for modeling rates and proportions, version 1.2 (http://cran.r-project.org). 
[23] Smithson, M. \& Verkuilen, J. (2005). Beta regression: practical issues in estimation. Disponível em http://www.anu.edu.au/psychology/people/smithson/details/ betareg/betareg.html.

[24] Smithson, M. \& Verkuilen, J. (2006). A better lemon squeezer? Maximum-likelihood regression with beta-distributed dependent variables. Psychological Methods, 11, 54-71. 